Universidade de São Paulo

Faculdade de Medicina de Ribeirão Preto

\title{
2016
}

Adaptação Transcultural para o Português Brasileiro da

Tampa Scale for Kinesiophobia for Temporomandibular

Disorders (TSK/TMD)
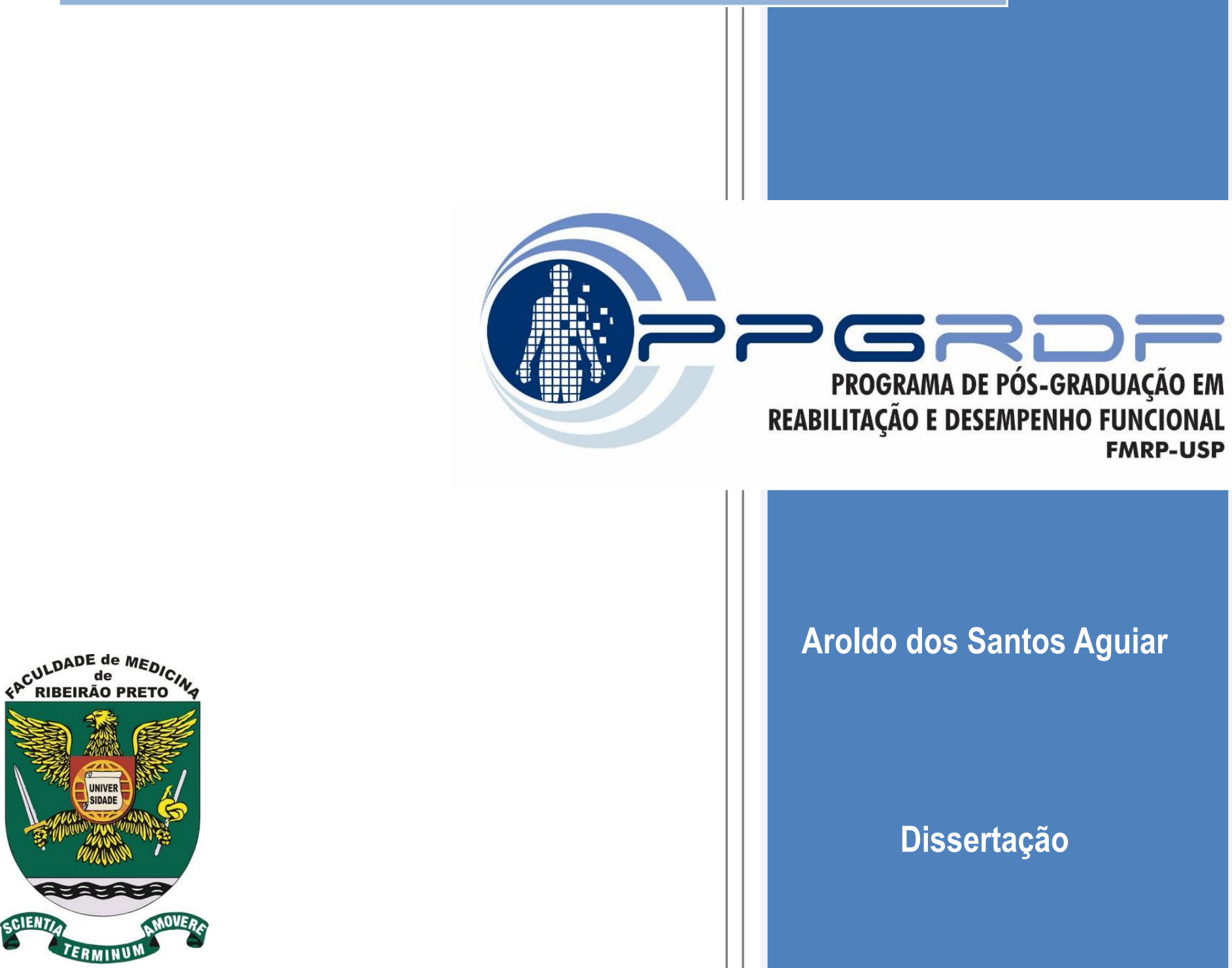

Aroldo dos Santos Aguiar 
UNIVERSIDADE DE SÃO PAULO

FACULDADE DE MEDICINA DE RIBEIRÃO PRETO

AROLDO DOS SANTOS AGUIAR

\section{Adaptação Transcultural para o Português Brasileiro da Tampa Scale for Kinesiophobia for Temporomandibular Disorders (TSK/TMD)}

Dissertação apresentada à Faculdade de Medicina de Ribeirão Preto da Universidade de São Paulo para obtenção do título de mestre pelo Programa de PósGraduação em Reabilitação e Desempenho Funcional

Área de concentração: Fisioterapia Orientadora: Profa. Dra. Thaís Cristina Chaves

Ribeirão Preto 
Autorizo a reprodução e divulgação total ou parcial deste trabalho, por qualquer meio convencional ou eletrônico, para fins de estudo e pesquisa, desde que citada a fonte.

\section{Catalogação da Publicação}

Faculdade de Medicina de Ribeirão Preto da Universidade de São Paulo

Aguiar, Aroldo dos Santos

Adaptação Transcultural para o Português Brasileiro da Tampa Scale for

Temporomandibular Disorders (TSK/TMD). Ribeirão Preto, 2016.

$$
\text { p.155: il. } 2 ; 30 \mathrm{~cm}
$$

Dissertação de Mestrado, apresentada à Faculdade de Medicina de Ribeirão Preto/USP - Programa de Pós Graduação Reabilitação e Desempenho Funcional. Área de concentração: Fisioterapia.

Orientador: Chaves, Thaís Cristina.

1.Adaptação Transcultural. 2.Cinesiofobia. 3.Disfunção Temporomandibular. 4.Desordens Musculoesqueléticas. 5.Tampa Scale for Kinesiophobia for Temporomandibular Disorders. 6.Questionário. 
UNIVERSIDADE DE SÃO PAULO

FACULDADE DE MEDICINA DE RIBEIRÃO PRETO

AROLDO DOS SANTOS AGUIAR

Adaptação Transcultural para o Português Brasileiro da Tampa Scale for Kinesiophobia for Temporomandibular Disorders (TSK/TMD) 


\section{FOLHA DE APROVACC̃̃O}

Aroldo dos Santos Aguiar

Adaptação Transcultural para o Português Brasileiro da Tampa Scale for Kinesiophobia For Temporomandibular Disorders (TSK/TMD).

Dissertação apresentada à Faculdade de Medicina de Ribeirão Preto da Universidade de São Paulo para obtenção do título de mestre em Ciências do Programa de Pós Graduação Reabilitação e Desempenho Funcional

Área de concentração: Fisioterapia

Aprovado em:

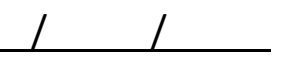

Banca Examinadora

Profa Dra Thaís Cristina Chaves

Instituição: Curso de Terapia Ocupacional - Faculdade de Medicina de Ribeirão Preto - USP Assinatura:

Prof Dra

Instituição:

Assinatura:

Profa Dra

Instituição:

Assinatura:

Profa Dra

Instituição:

Assinatura: 
Dedico,

“ A Deus, por me fazer encantado pelas coisas simples da vida; a família pelo incondicional amor e apoio. 


\section{Agradecimentos}

Muitas pessoas me auxiliaram em cada uma das etapas deste trabalho. A todos gostaria de expressar meu profundo agradecimento.

À minha família: aos meus pais Loide e Lázaro, pelo amor, compreensão, esforços para que eu sempre tivesse a oportunidade de buscar a realização dos meus sonhos; aos meus irmãos André e Adeildo, por apoiar minhas escolhas e orgulhar-se delas.

À minha amada esposa Paula, por ser presente e motivadora, sempre por perto me incentivando e à disposição para o que fosse necessário, não poupando apoio incondicional, pelos sacrifícios compartilhados, por sua paciência e companheirismo. Muito obrigado por me compreender e dedicar-se tanto a mim e à construção de meu sonho. A você deixo uma frase: "Amo como ama o amor. Não conheço nenhuma outra razão para amar senão amar. Que queres que te diga, além de que te amo, se o que quero dizer-te é que te amo?" Fernando Pessoa.

Agradeço a todos os meus familiares, amigos e pacientes queridos pela compreensão, apoio, carinho e por torcerem pelo meu sucesso.

Agradeço a todos os membros do Lapidom (Laboratório de Pesquisa Interdisciplinar em Dor Musculoesquelética: Aline, Camila, Cheila, Fernando, Fabricio, Mariana, Mariana Romano, Marina, Mirela, Roberta, Stella e Tiago) pela amizade e apoio em todos os momentos que se fizeram necessários, por compartilhar ideias e pela ajuda na execução deste trabalho.

Agradeço a todos os professores e alunos do programa de Pós-graduação em reabilitação e desempenho funcional pela disponibilidade, atenção e aprendizado. Agradeço também a todos os funcionários da USP - Ribeirão Preto, em especial a secretária do curso de Terapia Ocupacional Sônia, por toda atenção e ajuda prestada. 
Ao Prof. Dr. Cesar Bataglion, pela receptividade com que me acolheu na Clinica de Pacientes especiais da FORP/USP e a grande disponibilidade que sempre demonstrou, muito obrigado por confiar em nosso trabalho.

Às minhas queridas alunas de Iniciação Cientifica (Mariana Lira e Roberta Silva) por terem me acompanhado, auxiliado e me ajudado em todas as etapas deste estudo. 


\section{Meus sinceros agradecimentos}

Á professora Thais Cristina Chaves, pela paciência na orientação e incentivo que tornaram possível a conclusão deste estudo. Agradeço imensamente por partilhar seus conhecimentos, por sua paciência e aceitar minhas limitações, pelo convívio, pelo apoio, pela compreensão e pela amizade, não polpou esforços para que déssemos vida á este trabalho. Eu posso dizer que a minha formação, inclusive pessoal, não teria sido a mesma sem a sua pessoa, parece que foi ontem quando tivemos nosso primeiro contato numa aula de pós graduação em Uberlândia-MG em 2011, despertando em mim o desejo pela ciência, quando fui procura-la trazia comigo inúmeras dúvidas e incertezas, e mesmo assim, abriu as portas do seu laboratório, e no mesmo instante me senti em casa e hoje estou aqui, orgulhoso em fazer parte desta equipe. Por isto e muito mais professora, agradeço. Obrigado por me proporcionar o conhecimento não apenas racional, mas a manifestação do caráter e afetividade da educação no processo de formação profissional, por tanto que se dedicou a mim, não somente por ter me ensinado, mas por ter me feito aprender.

O sentido da palavra mestre, nunca fará justiça à dedicação e terão os meus eternos agradecimentos. 
“Tempo é viver, é celebrar, é conhecer. Tempo é poder amar ao nosso tempo. $O$ tempo só pode ser a mágica de fazer tudo acontecer e possibilitar que os sonhos possam florescer, leve o tempo que precisar." 


\section{RESUMO}

INTRODUÇÃO: O medo do movimento (cinesiofobia) parece desempenhar um papel importante no desenvolvimento da dor crónica. No entanto, em Disfunção Temporomandibular (DTM), há uma escassez de estudos sobre este tema. A Escala de Tampa para Kinesiophobia para DTM (TSK / TMD) é o instrumento mais utilizado para medir o medo de movimento e não está disponível em Português do Brasil. OBJETIVO: O objetivo deste estudo foi adaptar transculturalmente o TSK/TMD para o Português Brasileiro e avaliar suas propriedades psicométricas em termos de consistência interna, confiabilidade, validade de construto e estrutural. MÉTODOS: Um total de 100 pacientes do sexo feminino com DTM crônica participaram do processo de validação da TSK/TMD-Br. O coeficiente de correlação intraclasse (CCI) foi utilizado para a análise estatística de confiabilidade (teste-reteste), $\alpha$ de Cronbach para consistência interna, correlação de Pearson para classificar a validade de construto e análise fatorial confirmatória (AFC) para a validade estrutural. RESULTADOS: AFC aprovou o modelo pré-especificado com dois domínios e 12 itens (Evitando Movimento-EM/Foco Somático-SF) e todos os itens apresentaram carga fatorial superior a 0,4. Foram encontrados níveis aceitáveis de confiabilidade (CCI> 0,75) para todas as questões e domínios da TSK/TMD-Br. Para consistência interna, $\alpha$ de Cronbach de 0,78 para ambos os domínios. Foram observadas correlações moderadas $(0,40<\mathrm{r}<0,70)$ para a maioria dos domínios e para o escore total entre TSK/TMD-Br vs. catastrofização, depressão e limitação funcional da mandíbula. CONCLUSÃO: TSK / TMD-Br 12 itens demonstrou propriedades de medida satisfatórias (validade transcultural, confiabilidade, consistência interna e análise estrutural), e pode ser utilizado em ambientes clínicos e para fins de pesquisa.

Palavras-Chave: Disfunção Temporomandibular, Cinesiofobia, Escalas e questionários, Validação, Confiabilidade. 


\section{ABSTRACT}

BACKGROUND: Fear of movement (kinesiophobia) seems to play an important role in the development of chronic pain. However, in Temporomandibular Disorders (TMD) there is a scarcity of studies about this topic. The Tampa Scale for Kinesiophobia for TMD (TSK/TMD) is the most widely used instrument to measure fear of movement and it is not available in Brazilian Portuguese. OBJECTIVE: The purpose of this study was to culturally adapt the TSK/TMD to Brazilian Portuguese and to assess its psychometric properties in terms of internal consistency, reliability, and construct and structural validity. METHODS: A total of 100 female patients with chronic TMD participated in the validation process of the TSK/TMD-Br. The intraclass correlation coefficient (ICC) was used for statistical analysis of reliability (testretest), Cronbach's alpha for internal consistency, Pearson's rank correlation for construct validity, and confirmatory factor analysis (CFA) for structural validity. RESULTS: CFA endorsed the pre-specified model with two domains and 12-items (Activity Avoidance - AA/ Somatic Focus - SF) and all items obtained a loading factor greater than 0.4. Acceptable levels of reliability were found (ICC>0.75) for all questions and domains of the TSK/TMD-Br. For internal consistency, Cronbach's $\alpha$ of 0.78 for both domains were found. Moderate $(0.40<\mathrm{r}<0.70)$ correlations were observed for the majority of domains and for the total score between TSK/TMD-Br vs. catastrophizing, depression and jaw functional limitation.CONCLUSION: TSK/TMD-Br 12 items demonstrated sound psychometric properties (transcultural validity, reliability, internal consistency and structural validity) and can be used in clinical settings and for research purposes.

Key-words: Temporomandibular Disorders, Kinesiophobia, Surveys and Questionnaires, Validation, Reliability. 


\section{LISTA DE TABELAS}

Tabela 1- Caracterização da amostra para cada etapa de validação da TSK/TMD-Br.

Tabela 2- Descrição (media e Desvio padrão: DP) dos dados antropométricos, nível de escolaridade e dados clínicos da amostra total $(n=100)$

Tabela 3 - Classificação do diagnóstico de Disfunção Temporomandibular (DTM) de acordo com o Research Diagnostic Criteria for Temporomandibular Disorders (RDC/TMD). .48

Tabela 4 - Itens do COSMIN que foram considerados no estudo de adaptação transcultural e validação da TSK/TMD versão português Brasil

Tabela 5 - Valores médios de reprodutibilidade teste-reteste (CCI) e IC $95 \%$ das pontuações dos domínios da TSK-TMD-Br (n=30)....

Tabela 6 - Descrição dos valores de $\alpha$ de Cronbach e da Correlação Total do Item (CTI) e dos domínios e das questões da TSK/TMD-Br.

Tabela 7 - Análise fatorial confirmatória dos modelos de estrutura fatorial das versões da TSKTMD-Br.

Tabela 8 - Valores de Correlação entre as pontuações totais e domínios da TSK/TMD-Br e os instrumentos Escala de Pensamento Catastrófico sobre a Dor (B-PCS), Questionário sobre a saúde do paciente (PHQ-8), Índice de Limitação Funcional Mandibular (MFIQ) e Pontuação do domínio intensidade, pontuação do domínio incapacidade e pontuação total da Escala Graduada de Dor Crônica (EGDC-Br) para n=100.

Tabela 9 - Valores de correlação entre as pontuações totais e os domínios da TSK/TMD-Br e os domínios da ferramenta B-PCS para $\mathrm{n}=100$

Tabela 10 - Valores das diferenças nas pontuações das escalas entre os subgrupos DTM.....67 


\section{LISTA DE FIGURAS}

Figura 1 - Etapas adotadas no processo de tradução e retrotradução da Tampa Scale for Kinesiophobia for Temporomandibular Disorders (TSK/TMD) 54

Figura 2 - Localização da Dor Orofacial.. .55

Figura 3 - Análise Fatorial da TSK/TMD-Br .63 
LISTA DE SIGLAS

\begin{tabular}{|c|c|}
\hline ATM & Articulação Temporomandibular \\
\hline DTM & Disfunção Temporomandibular \\
\hline RDC/TMD & Research Diagnostic Criteria for Temporomandibular Disorders \\
\hline DC/TMD & Diagnostic Criteria for Temporomandibular Disorders \\
\hline COSMIN & $\begin{array}{l}\text { COnsensus-based Standards for the selection of Health Measurement } \\
\text { INstruments }\end{array}$ \\
\hline IADR & International Association for Dental Research \\
\hline TSK & Tampa Scale for Kinesiophobia \\
\hline TSK/TMD & Tampa Scale for Kinesiophobia for Temporomandibular Disorders \\
\hline FMRP & Faculdade de Medicina de Ribeirão Preto \\
\hline FORP & Faculdade de Odontologia de Ribeirão Preto \\
\hline HC-FMRP & Hospital das Clínicas da Faculdade de Medicina de Ribeirão Preto \\
\hline USP & Universidade de São Paulo \\
\hline IC & Intervalo de Confiança \\
\hline CCI & Coeficiente de Correlação Intraclasse \\
\hline CTI & Correlação Total do Item \\
\hline SPSS & Statistical Package for Social Science \\
\hline EPM & Erro Padrão da Medida \\
\hline MDD & Mínima Diferença Detectável \\
\hline T1 & $\begin{array}{l}\text { Tradução inglês/português realizada pelo tradutor leigo quanto ao } \\
\text { construto }\end{array}$ \\
\hline
\end{tabular}


T2

T3

T123

RT

RT1

RT2

RT3

B-PCS

PHQ-8

EGDC

MFIQ

AFC

CAIC

CFI

GFI

ECVI

RMSEA

EM

FS

ETC

DLC
Tradução inglês/português realizada pelo tradutor com conhecimento do construto

Tradução dutch/português realizada pelo tradutor leigo quanto ao construto

Síntese das Traduções

Retrotradução

Retrotradução-versão do tradutor 1

Retrotradução- versão do tradutor 2

Retrotradução- versão do tradutor 3 (Dutch)

Escala de Pensamentos Catastróficos sobre Dor

Questionário sobre a saúde do paciente

Escala Graduada de Dor Crônica

Índice de Limitação Funcional Mandibular

Análise Fatorial Confirmatória

Critério de Consistencia de Informação de Akaike

Índice de ajuste comparativo

Índice Goodness of it

Índice de validação cruzada esperada

Erro médio quadrático de aproximação

Evitando Movimento

Foco Somático

Escala Tampa de Cinesiofobia

Dor Lombar Crônica 


\section{SUMÁRIO}

1. INTRODUÇÃO

1.1. Disfunção Temporomandibular (DTM).... Erro! Indicador não definido.

1.2. Cinesiofobia Erro! Indicador não definido. 1

1.3. Disfunção Temporomandibular e Cinesiofobia

2. OBJETIVOS 30

2.1. Objetivo geral 30

2.2. Objetivos secundários 30

3. MÉTODOS 32

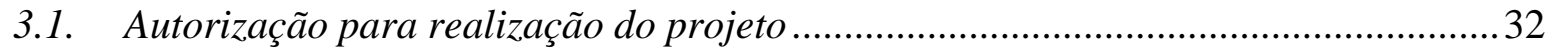

3.2. População do estudo e coleta dos dados ..................................................................... 32

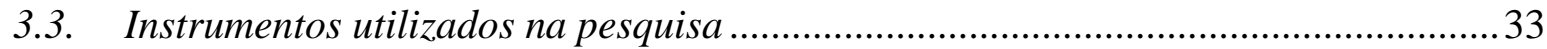

3.3.1. Research Diagnostic Criteria for Temporomandibular Disorders RDC/TMD......... 33

3.3.2. Tampa Scale for Kinesiophobia for Temporomandibular Disorders(TSK/TMD) ......33

3.3.3. A Escala de Pensamento Catastrófico sobre Dor (B-PCS).........................................34

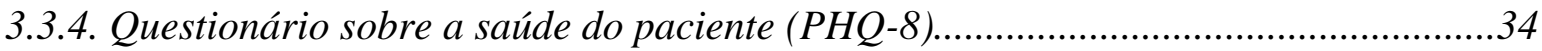

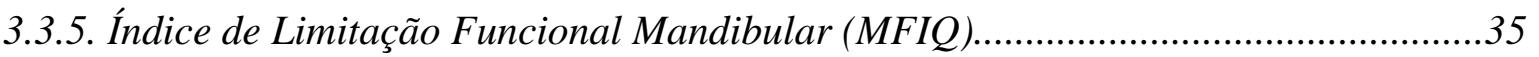

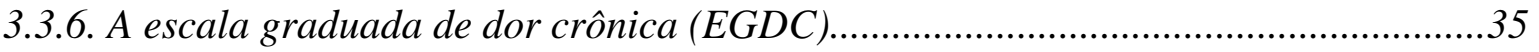

3.4. Adaptação transcultural da TSK/TMD para o português-Brasil .............................. 36

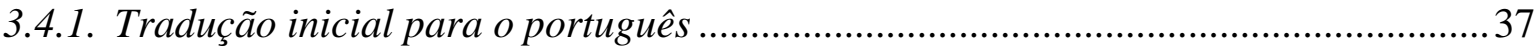

3.4.2. Síntese das traduções e Consenso entre os tradutores .............................................. 38

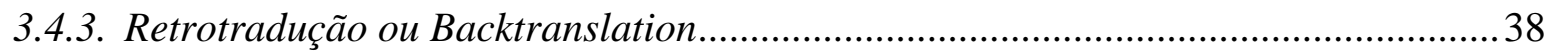

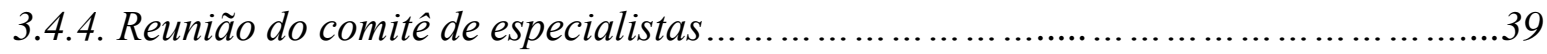

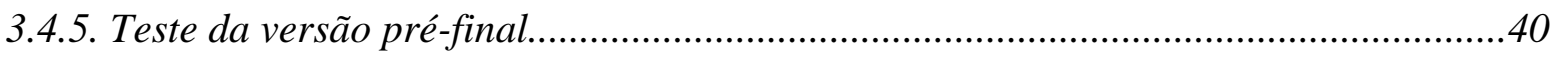

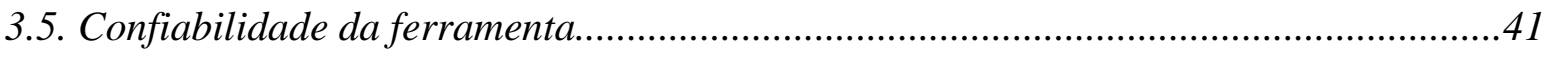

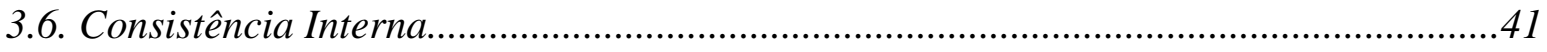

3.7. Validade de Construto-teste de hipóteses e validade estrutural......................................41

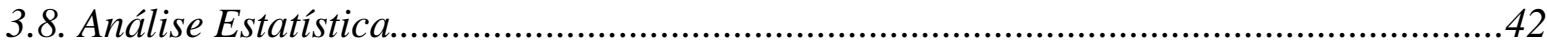

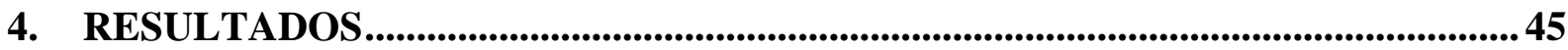

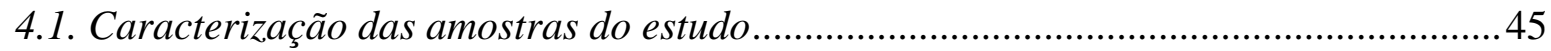

4.2. Adaptação transcultural da TSK/TMD-Br e Teste da versão pré-final.....................49 


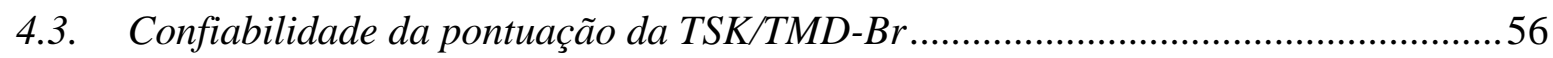

4.4. Consistência Interna dos itens e domínios da TSK/TMD-Br .....................................56

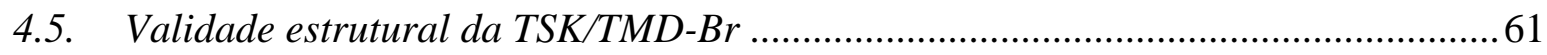

4.6. Validade de Construto e Teste de Hipótese......................................................63

4.7. Erro padrão da medida e Mínima Diferença Detectável.............................................66

4.8 Disfunção Temporomandibular e os subtipos de DTM ................................66

5. DISCUSSÃ̃

5.1. Amostras do estudo e Diferenças entre os subgrupos de DTM..................................69

5.2. Adaptação transcultural da TSK/TMD versão português-Brasil .............................. 71

5.3. Confiabilidade da TSK/TMD versão português-Brasil...............................................72

5.4. Consistência Interna,Validade estrutural e Erro padrão da medida da TSK/TMD-Br..73

5.5. Validade de Construto- teste de hipóteses da TSK/TMD-Br.......................................76

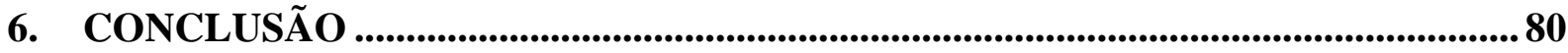

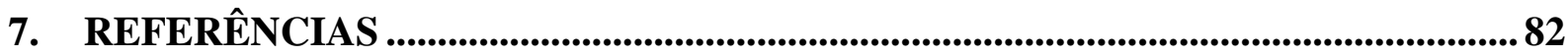

ANEXO A-Autorização para a adaptação transcultural da Tampa Scale for Kinesiophobia for Temporomandibular Disorders (TSK/TMD) 93

ANEXO B - Carta de aceite do Comitê de Ética. 94

ANEXO C - Versão em inglês da Tampa Scale for Kinesiophobia for Temporomandibular Disorders (TSK/TMD)

ANEXO D - Versão em holandês (original) da Tampa Scale for Kinesiophobiafor

Temporomandibular Disorders (TSK/TMD) 97

APÊEDICE 1 - Termo de Consentimento Formal e Esclarecido 98

APÊNDICE 2 - VersãoTradutor leigo (T1) da TSK/TMD-Br.

APÊNDICE 3 - Versão Tradutor expert (T2) da TSK/TMD-Br. 
APÊNDICE 5 - Versão Sintetizada (T123) da TSK/TMD-Br

APÊNDICE 6 - Versão Pré-final

APÊNDICE 7 - Formulário de sugestões para aprimorar o questionário

APÊNDICE 8 - Versão final da TSK/TMD-Br

APÊNDICE 9 - Relatório $1^{a}$ Reunião

APÊNDICE 10 - Versão retrotraduzida para o inglês $(R T 1)$

APÊNDICE 11 - Versão retrotraduzida para o inglês (RT2)

APÊNDICE 12 - Versão retrotraduzida para o holandês (RT3)

APÊNDICE 13 - Relatório da $2^{a}$ Reunião. 


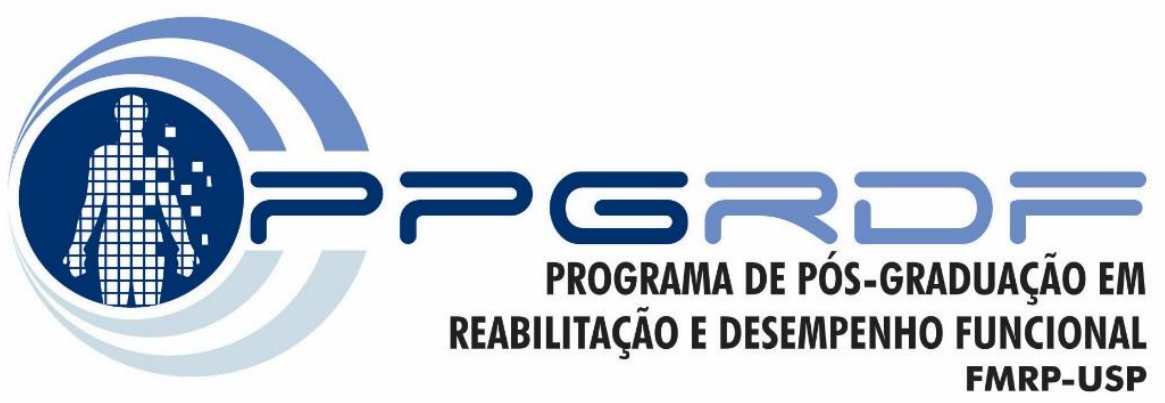

INTRODUÇÃO

“Bom mesmo é ir à luta com determinação,

abraçar a vida com paixão,

perder com classe e vencer com ousadia,

pois o triunfo pertence a quem se atreve.

A vida é muita para ser insignificante.

Charles Chaplin 


\section{INTRODUÇÃO}

\subsection{Disfunção Temporomandibular (DTM)}

A Articulação Temporomandibular (ATM), em conjunto com outras estruturas faciais faz parte do sistema estomatognático que é a unidade funcional do corpo responsável pelas funções de mastigação, fala e deglutição. A ATM conecta a mandíbula ao crânio e regula o movimento mandibular, é uma articulação bi-condilar em que os côndilos, localizados nas duas extremidades da mandíbula, funcionam simultaneamente (INGAWALE et al., 2009), assim a movimentação da ATM direita está diretamente relacionada à movimentação da ATM esquerda, o que deve ser considerado na avaliação e tratamento dos pacientes. Suas superfícies articulares são cobertas por fibrocartilagem avascular e não inervada, composta de tecido conjuntivo denso fibroso, menos susceptível ao envelhecimento, ao impacto articular e ao desgaste natural, com uma elevada capacidade de regeneração (OKESON, 2003).

A Disfunção temporomandibular (DTM) é um conjunto de disfunções que acomete as estruturas articulares e periarticulares da ATM, como os músculos mastigatórios, tecidos moles e ósseos adjacentes, podendo ocorrer de forma exclusiva em um desses tecidos ou pela combinação desses componentes (WADHW, KAPILA, 2008). Pode ser caracterizada por sinais (ruídos articulares e limitações na amplitude de movimento ou desvios durante a função mandibular) e sintomas (dor pré-articular, dor na ATM ou nos músculos mastigatórios) (DWORKIN e LERESCHE, 1992). É, ainda, considerada uma condição multifatorial cujos fatores etiológicos podem ser divididos em fatores predisponentes, precipitantes ou perpetuantes (BEVILAQUAGROSSI et al., 2007).

A DTM atinge preferencialmente mulheres, sendo o pico de prevalência dessa doença na população entre os 20 e 40 anos (MANFREDINI et al., 2011), alguns autores nomeiam esta faixa 
etária como produtiva da sociedade, sendo que múltiplos fatores podem influenciar o desenvolvimento e a evolução da DTM (MACFARLANE, 2001; HILGENBERG et al., 2012).

A DTM é a mais prevalente de todos os tipos de dor orofacial (DWORKIN, 2011; FILLINGIM et al., 2011). Estudos epidemiológicos demonstram que 40-75\% da população adulta apresentam ao menos um sinal, sendo que 33-39,2\% apresentam ao menos um sintoma álgico na face ou na ATM (DE LEEUW, 2010; GONÇALVES et al., 2009), no entanto se todos os sintomas que envolvem a DTM forem incluídos a prevalência é de 50\% na população adulta (MANFREDINI et al., 2011). No Brasil, a prevalência de pelo menos um sinal/sintoma é de 37,5\% (GONÇALVES et al., 2009).

O quadro álgico relacionado à DTM é crônico, flutuante e para a maioria das pessoas, de intensidade leve (EGERMARK et al., 2001), porém gera implicações negativas no contexto social e afetivo, uma vez que interfere nas habilidades de comunicação como falar, sorrir, gargalhar, beijar e pode gerar desconforto nos hábitos do cotidiano como a mastigação, a higienização oral e o bocejo (STUDART, ACIOLI, 2011).

Para Swinkels-Meewisse et al. (2003) a identificação precoce de indivíduos com DTM, com risco de tornarem-se pacientes crônicos, é necessária para a realização de intervenções adequadas. Com a finalidade de evitar a cronicidade e assim reduzir suas consequências econômicas, psicossociais associados à esta disfunção. Além disso, pacientes com DTM crônica frequentemente relatam sintomas de depressão, má qualidade do sono e baixa disposição (McNEELY et al., 2006).

A fisiopatologia da DTM ainda não é bem estabelecida, porém evidências de hiperexcitabilidade do sistema nervoso central, ausência de correlação direta da dor com uma lesão tecidual, o grande impacto funcional e o envolvimento psicológico, semelhante a outras dores crônicas, sugerem que mecanismos de sensibilização central e alterações nas vias moduladoras de dor podem ser os mecanismos envolvidos nessa condição (FERNANDEZ-De-LAS-PEÑAS et al., 2009; FERNANDEZ-De-LAS-PEÑAS et al., 2010). 
No entanto, embora a prevalência e o impacto negativo da DTM sejam altos (FILLINGIM et al., 2011; MANFREDINI et al., 2011), a procura por tratamento especializado não é muito frequente e os principais motivos apontados para essa não procura é a dificuldade de diagnóstico preciso, falta de informação tanto do profissional quanto do paciente quanto à condição e o caráter flutuante dos sinais e sintomas (DURHAM et al., 2010).

Portanto, um bom diagnóstico clínico e cinético-funcional é de extrema importância para estabelecer o prognóstico de pacientes com DTM. Existem diferentes ferramentas disponíveis atualmente na literatura científica a fim de avaliar a DTM (CHAVES et al., 2008), sendo divididas entres critérios diagnósticos, questionários e índices clínicos e anamnésicos.

Segundo FRICTON (2003), em pacientes com DTM é difícil se estabelecer um diagnóstico específico devido interposição de possíveis outros diagnósticos relacionados, as complexas interrelações psicossociais e somáticas que existem, as múltiplas semelhanças entre os sinais e sintomas para diferentes diagnósticos, e a alta frequência de múltiplos diagnósticos (FRICTON, 2003). A investigação dos aspectos psicológicos e psicossociais nos indivíduos com DTM tem sido amplamente recomendada (YAP et al., 2004), sendo a não inclusão deste aspecto na abordagem do paciente frequentemente associada a altas taxas de insucesso nos tratamentos e progressão da cronificação da condição e da dor.

YAP et al. (2004) relataram que os piores quadros de alterações psicológicas e psicossociais são encontrados nos indivíduos com dor miofascial, subtipo de disfunção caracterizada por acometimento muscular. Além disso, ressalta que a severidade destas condições, com perpetuação da dor e limitação da mobilidade do sistema mastigatório reflete-se em limitações no dia-a-dia, além de restrições da função mandibular como dificuldade mastigatória e na ingestão de alimentos (YAP et al., 2004).

Dentre os critérios diagnósticos destaca-se o Research Diagnostic Criteria for Temporomandibular Disorders (RDC/TMD), que se trata de critério cuja abordagem é biaxial, 
considerando tanto os aspectos físicos (Eixo I) quanto o status psicossocial (Eixo 2). Esse critério promove, portanto, uma abordagem global adequada para o tratamento da DTM uma vez que permite identificar tanto os aspectos físicos quanto os aspectos psicossociais que constituem o quadro clínico do paciente e facilita o tratamento multi ou interdisciplinar indicado para cada caso (SCHIFFMAN et al., 2014). O RDC/TMD recebe inúmeras criticas e por isso passa por constantes modificações, em 2014 ocorreu a transição para Diagnostic Criteria (DC/TMD), embora seu uso seja recomendado não é aconselhável sem que haja um estudo de tradução e validação oficial para o português brasileiro.

\subsection{Cinesiofobia}

O termo Cinesiofobia é definido como medo excessivo, irracional e debilitante do movimento e da atividade física, que resulta em sentimentos de vulnerabilidade à dor ou em medo de reincidência da lesão (CLARK et al., 1996).

Segundo Vlaeyen et al. (1999), indivíduos com dor musculoesquelética podem desenvolver dor crônica em associação com o medo da dor ao movimento. De acordo com o fear-avoidance modelo foram descritos dois tipos de comportamento nos pacientes com dor crônica, o confrontador e o evitador (VLAEYEN et al., 1999).

Os indivíduos que apresentam o perfil confrontador acreditam que a presença da dor não representa e/ou justifica limitação em suas atividades de vida, e enfrentam a dor de forma ativa, ou seja, sem interromper ou modificar suas atividades funcionais na busca de melhora. Entretanto, os indivíduos evitadores apresentam medo do movimento e acreditam que o movimento e a atividade física estejam diretamente relacionados à presença da dor, comportam-se de forma a evitar as atividades, o que pode contribuir para cronificação da dor. (VLAEYEN et al., 1995; CLARK et al., 1996; PICAVET et al., 2002). 
Um dos instrumentos mais utilizados atualmente para avaliar a cinesiofobia é a Tampa Scale for Kinesiophobia (TSK), que consiste em uma escala auto-administrável, composta por um conjunto de 17 itens que representam de forma subjetiva a percepção individual de cada sujeito sobre segurança e confiança em realizar movimento, abordando a dor e a intensidade dos sintomas (CROMBEZ et al., 1999; VISSCHER et al., 2010).

A TSK original está validada em diferentes línguas e culturas tais como: a Norueguesa (HAUGEN, 2008), a Holandesa (VLAEYEN et al., 1995) e a Sueca (LUNDBERG, 2004). A versão traduzida e adaptada para o Português Brasileiro seguiu a metodologia recomendada (GUILLEMIN et al., 1993), e foi denominada de Escala Tampa para Cinesiofobia (ETC), sendo aplicada em 50 indivíduos com dor lombar crônica (DLC) não especifica. A análise de Rasch demonstrou valores aceitáveis de validade de construto para a ETC no Português Brasileiro (SIQUEIRA et al., 2007).

A TSK demosntrou ser um instrumento válido e confiável, com adequada consistência interna ( $\alpha=0,68-0,80)$ em indivíduos com dor lombar crônica (VLAEYEN et al., 1995; CROMBEZ et al., 1999). Além disso, em um trabalho com dor lombar aguda a TSK demonstrou boa confiabilidade teste-reteste $(\alpha=0,76)$ e boa consistência interna $(\alpha=0,70)$ (SWINKELS-MEEWISSE et al., 2003).

Em um estudo coorte, a TSK foi utilizada em programas preventivos e demonstrou que indivíduos com altos níveis de cinesiofobia apresentaram maior predisposição à cronificação e incapacidade relacionadas à dor (PICAVET et al., 1999).

VLAEYEN et al. (1995), relataram que a inatividade pode levar à deteriorização musculoesquelética, diminuição da força muscular, diminuição da mobilidade e distúrbios psicológicos, tais como somatização e sintomas depressivos (VLAEYEN et al., 1995). 


\subsection{Disfunção Temporomandibular e Cinesiofobia}

Em pacientes com dores crônicas musculoesqueléticas, os fatores psicossociais, cognitivos e comportamentais são moduladores importantes da dor e incapacidade, estes fatores parecem ter papel importante na progressão da dor aguda para crônica (PINCUS et al., 2002). Alguns autores demonstraram que a medida de cinesiofobia é um forte preditor de incapacidade em pacientes com dor lombar aguda e crônica (CROMBEZ et al., 1999; SWINKELS-MEEWISSE et al., 2003; ROELOFS et al., 2004), fibromialgia (ROELOFS et al., 2004) e osteoartrite (HEUTS et al., 2004).

VLAEYEN et al. (1999) demonstram existir pouca correlação entre a intensidade da dor e o grau de incapacidade, desta forma, chamam à atenção para a importância de uma abordagem biopsicossocial para melhor entender os aspcetos relacionados à cronificação da dor. Tais abordagens biopsicossociais consideram não somente a influência dos aspectos físicos e funcionais relacionados à disfunção, mas também os psicológicos e sociais, tais como depressão, ansiedade e o medo de que o movimento possa causar dor (VLAYEN et al., 1999).

Dentro desse contexto, o acometimento provocado pela DTM está relacionado a alterações físicas e psicológicas como a depressão e a somatização, além de alterações psicossociais, incluindo interferências no trabalho, em casa, nas relações interpessoais e uso excessivo de serviços de saúde (JOHN et al., 2007; VISSCHER et al., 2010). Alguns autores sugerem que dentre os aspectos biopsicossociais relatados na literatura que podem estar relacionados a um pior prognóstico da DTM estão incluídos a catastrofização e a cinesiofobia (VISSCHER et al., 2010).

Entretanto, são escassos os trabalhos na literatura verificando a influência da cinesiofobia para o prognóstico e cronificação da DTM. Nesse sentido, VISSCHER et al. (2010), propuseram a adaptação e validação da TSK para pacientes com DTM, uma vez que segundo os autores a TSK não apresentava itens com validade de conteúdo suficientes para ser utilizada em pacientes com DTM. A TSK é basicamente direcionada para a dor, que nem sempre é o sintoma mais debilitante nos pacientes com DTM. Assim, muitos pacientes se queixam de ruídos articulares e limitação de 
movimentos mandibulares (VISSCHER et al., 2010) que podem estar associados ao medo de movimentação.

$\mathrm{Na}$ modificação da TSK para TSK-TMD (Tampa Scale for Kinesiophobia for Temporomandibular Disorders), inicialmente os termos gerais utilizados na TSK original foram adaptados para atender melhor as queixas frequentemente relatadas pelos pacientes com DTM. Assim, as palavras, "exercício", "corpo" e "fisicamente ativo" foram substituídas por "exercício mandibular", "mandíbula", e "usando a minha boca", respectivamente. Além disso, devido à DTM ser multifatorial e não só relacionada à dor, este termo foi removido de alguns itens e substituído por "sintomas". Além disso, foi criado um novo item que aborda o travamento mandibular e, dessa forma, a TSK/TMD contém 18 itens e não apenas 17 como o original (VISSCHER et al., 2010).

A TSK/TMD já foi devidamente testada quanto as suas propriedades psicométricas. VISSCHER et al. (2010), investigaram em seu estudo a consistência interna, baseada no cálculo $\alpha$ Cronbach's e foi observado um $\alpha$ excelente para o domínio de EM a 0,82 e para FS a 0,66, bem como, níveis aceitáveis de confiabilidade, sendo de 0,67 para o domínio EM e 0,71 para o domínio FS. Entretanto, esta escala ainda não está disponível na versão em português-brasileiro, o que impossibilita sua aplicação no Brasil. Dessa forma se fez necessária a realização do processo de adaptação transcultural da ferramenta para aplicação no Brasil, além da avaliação de suas propriedades psicométricas para o Português brasileiro (BEATON et al., 2000).

\subsection{Tradução, adaptação transcultural e propriedades de medida}

O termo adaptação transcultural refere-se a um processo que concerne tanto à tradução quanto a adaptação linguística necessária para que um instrumento possa ser utilizado em uma população com cultura e idiomas distintos daquela para qual foi desenvolvida, com objetivo de manter a equivalência entre o instrumento original e a versão adaptada, bem como assegurar a melhor compreensão possível para população-alvo (BEATON et al., 2000). 
Quando no processo de tradução e adaptação transcultural de uma ferramenta, observa-se boas propriedades psicométricas, existe a possibilidade da sua utilização na comparação entre estudos internacionais e/ou multicêntricos, viabilizando a padronização e comparação dos resultados (BEATON et al., 2002). Segundo Beaton et al. (2000), é necessário após a adaptação cultural, verificar empiricamente se a nova versão apresenta propriedades psicométricas semelhantes às da escala original. Desta forma assegura-se que o instrumento de pesquisa adequado para aplicação clinica, apresente critérios seguidos na elaboração e validação deste, garantido a confiabilidade dos dados. Portanto o instrumento deve ser avaliado segundo suas propriedades psicométricas quanto à fidedignidade e validade (BEATON et al., 2000; SWINKELS-MEEWISSE et al., 2003; ALEXANDRE, COLUCI et al., 2011).

De acordo com os argumentos descritos por Guillemin (1993), a utilização de instrumentos equivalentes em populações e culturas distintas, permite a comparação de doenças ou serviços entre diversos sistemas saúde evitando discrepâncias transculturais em seus métodos de medição. Isso permite preservar a validade interna em comparações entre pesquisas realizadas em países e culturas distintas e a validade externa que permite aceitabilidade para realização de pesquisas em âmbito internacional (GUILLEMIN, 1993).

Alguns autores descreveram diretrizes para orientar e padronizar os processos de tradução de uma ferramenta (GUILLEMIN et al., 1993; WARE et al., 1995; BULLINGER et al., 1998; BEATON et al., 2000; EREMENCO et al., 2005; REICHENHEIM e MORAES, 2007), dentre eles destacam-se os guias propostos por Guillemin et al. (1993) e por Beaton et al (2000).

O COnsensus-based Standards for the selection of health Measurement INstruments (COSMIN) (MOKKINK et al., 2012) contribuiu para padronizar aspectos na área de psicometria, disponibilizando uma recomendação detalhada das etapas necessárias para validação e adaptação transcultural e avaliação crítica de estudos que empregaram tais processos. O COSMIN é um consenso baseado em parâmetros para a seleção de instrumentos de medida da área da saúde, 
consenso este proveniente de um estudo Delphi, com a participação de 43 integrantes em que foi concebida uma lista contendo tais normas (MOKKINK et al., 2010).

O processo de tradução e retrotradução podem acontecer em etapas: tradução inicial para o português, síntese das traduções, reunião para consenso dos tradutores, retrotradução, comitê de especialistas e teste da versão pré-final do questionário (GUILLEMIN et al., 1993; BEATON et al., 2000; BEATON et al., 2002; MOKKINK et al., 2012).

O processo de tradução e adaptação transcultural de acordo com o COSMIN recomenda ao menos dois tradutores a cada passo, e devem executar as traduções individualmente, sendo um leigo e o outro especialista sobre o assunto. As duas versões traduzidas são comparadas e uma versão a partir destas é sintetizada (GUILLEMIN et al., 1993; BEATON et al., 2000; MOKKINK et al., 2010). O processo de retrotradução garante que a versão traduzida reflete o conteúdo da versão original (GUILLEMIN et al., 1993; BEATON et al., 2000; MOKKINK et al., 2010).

Durante as reuniões os membros do comitê formado por uma equipe multidisciplinar são instruídos a buscar equivalência entre a versão original e a versão pré-final em 4 áreas, garantindo a criação de uma versão ao mesmo tempo compreensível para a população-alvo e que mantenha equivalência com o instrumento original (GUILLEMIN et al., 1993).

A equivalência semântica verifica se as palavras apresentam o mesmo significado da versão original, se é possível que existam múltiplos sentidos para um determinado item ou se há problemas gramaticais na tradução (GUILLEMIN et al., 1993).

Já a equivalência idiomática busca a existência de coloquialismos e expressões idiomáticas que são difíceis de traduzir (GUILLEMIN et al., 1993). Caso isso ocorra, recomenda-se que o comitê formule uma expressão equivalente na versão pré-final (GUILLEMIN et al., 1993). Já a equivalência conceitual faz menção a certas palavras que possuem diferentes significados conceituais entre culturas (GUILLEMIN et al., 1993). 
A equivalência cultural ou de experiências explora se os itens contemplam as experiências de vida diária, pois é possível que em diferentes culturas ou países algumas tarefas não sejam realizadas, mesmo quando as palavras utilizadas para exemplificá-las são traduzíveis (GUILLEMIN et al., 1993). Recomenda-se que o item seja substituído por um similar que de fato represente experiências reais na cultura alvo, um exemplo seria a dificuldade para comer com garfo, se na cultura-alvo não se usa esse tipo de talher para alimentação (GUILLEMIN et al., 1993).

Na ausência de consenso é possível que a etapa de tradução e retrotradução fossem realizadas novamente para verificar se outra expressão resolveria o problema. Voluntários são convidados a completar o questionário da versão pré-final e responder um formulário sobre sua impressão de cada item, opções de resposta, cabeçalhos dos itens, instruções e layout da ferramenta. Destaca-se que na fase versão pré-final quando aplicada for identificada a necessidade de reformulações, os questionários previamente aplicados devem ser excluídos e novos voluntários selecionados para compor a amostra final e responder à última versão do questionário. Isso poderia ocorrer quantas vezes fossem necessárias, até que se completasse um grupo de indivíduos que não referisse mais que $20 \%$ de dificuldade ao responder o questionário (ORFALE et al., 2005). Na versão final, o questionário deverá ser facilmente entendido por uma criança de 12 anos (TERWEE et al., 2007).

Reconhece-se ainda, a necessidade de seguir protocolos aceitos internacionalmente para viabilizar a padronização dos processos de tradução e adaptação cultural, pois estudos sobre avaliação das propriedades de medida de um instrumento devem apresentar alta qualidade metodológica para garantir que o construto pretendido está sendo avaliado, devendo ainda preencher os requisitos referentes às análises estatísticas (DE VET et al., 2011; MOKKINK et al., 2012).

De acordo com o protocolo COSMIN (MOKKINK et al., 2012), dentro do domínio de reprodutibilidade da ferramenta (o grau no qual a medida é livre de erro aleatório e sistemático) se encaixam as propriedades de medida "Reprodutibilidade" e "Consistência Interna". A medida de 
reprodutibilidade é definida como a proporção de variância total da medida em relação às verdadeiras medidas provindas das respostas dos voluntários (MOKKINK et al., 2012). Já a consistência interna é definida como o grau de inter-relações entre os itens (MOKKINK et al., 2012).

A validade de construto é outra propriedade de medida, definida como o grau em que as pontuações de um instrumento são consistentes com as hipóteses (MOKKINK et al., 2012). Esta é subdivida em teste de hipóteses, validade estrutural e validade transcultural. O teste de hipóteses é definido como o grau em que as pontuações de uma ferramenta de avaliação são consistentes com as hipóteses que geraram o construto em questão (por exemplo, a correlação entre pontuações de questionários que mensuram construtos similares), isso baseando-se na hipótese de que o construto mensura de maneira valida o construto a ser medido. A validade estrutural é o grau com o qual um instrumento mostra-se como um reflexo das dimensões do construto a ser mensurado. Já a validade transcultural é o grau com o qual a performance dos itens de um instrumento adataptado transculturalmente demonstra uma reflexão adequada dos itens da versão original do instrumento (MOKKINK et al., 2012).

Assim, a justificativa para realização da tradução e adptação transcultural da TSK/TMD está relacionada ao fato de não existir no Brasil nenhum instrumento desenvolvido e/ou adaptado para nosso idioma que se proponha a avaliar Cinesiofobia em individuos com DTM, bem como as vantagens associadas ao processo de tradução e a adaptação transcultural de instrumentos desenvolvidos e validados em outros países, como simplicidade, economia e universalização das medidas (GUILLEMIN et al., 1993). Assim, a adaptação e validação da TSK/MD para o português brasileiro a tornará disponível para utilização por pesquisadores e clínicos no Brasil de um instrumento que auxiliará na avaliação e acompanhamento de indivíduos com DTM. 


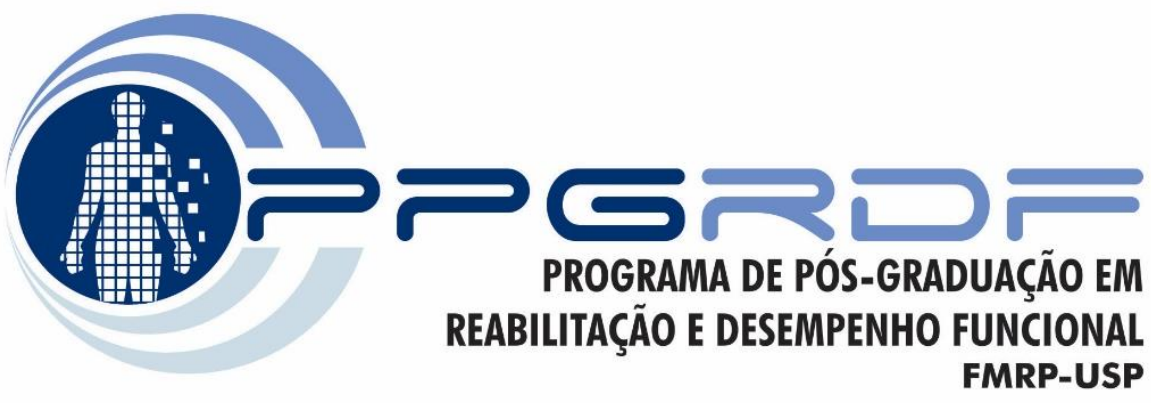

\section{OBJETIVOS}

"Conheça todas as teorias, domine

todas as técnicas, mas ao tocar uma alma humana, seja apenas outra alma humana."

Carl Jung 


\section{OBJETIVOS}

\subsection{Objetivo geral}

Realizar a tradução e adaptação transcultural para o português brasileiro da Tampa Scale for Kinesiophobia for Temporomandibular Disorders (TSK-TMD).

\subsection{Objetivos secundários}

Avaliar as seguintes propriedades de medida da versão em português-Brasil da TSK/TMD: consistência interna dos itens, confiabilidade, validade de construto (teste de hipóteses e validade estrutural) da TSK/TMD-Br.

Verificar diferenças nos níveis de cinesiofobia, catastrofização, depressão e incapacidade mandibular e relacionada ä dor crônica entre os subgrupos de pacientes com DTM artrogênica, miogênica e mista. 


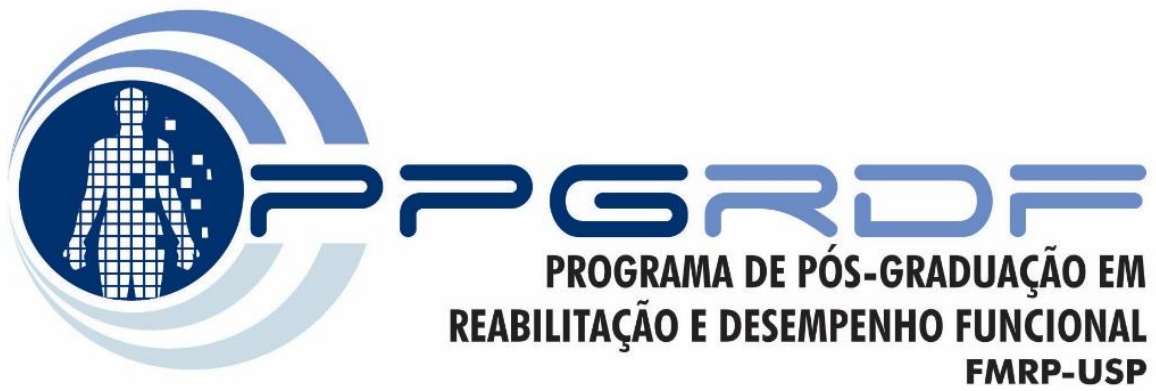

MÉTODOS

"Os que se encantam com a prática sem a ciência são como os timoneiros que entram no navio sem timão nem bússola, nunca tendo certeza do seu destino”.

Leonardo da Vinci 


\section{MÉTODOS}

\subsection{Autorização para realização do projeto}

Permissão para a realização da tradução e adaptação transcultural da TSK-TMD para o português brasileiro foi solicitada e obtida através de correspondência eletrônica com o autor da escala Corine Visscher (ANEXO A), a autora informou que a ferramenta é de domínio publico e que estaria disponível em http://www.rdc-tmdinternational.org/OtherInstruments/TSKTMD.asp.

Este projeto foi submetido a apreciação e aprovação (Processo HCFMRP No 2721/2014 ANEXO B) do comitê de ética em pesquisa envolvendo seres humanos do Hospital das Clínicas da Faculdade de Medicina de Ribeirão Preto da Universidade de São Paulo (FMRP/USP).

As voluntárias concordantes com a participação assinaram um termo de consentimento livre e esclarecido, contendo informações sobre o estudo, quanto à liberdade de adesão e desistência, ausência de danos à vida e direito de preservação da identidade, de acordo com a resolução $\mathrm{n}^{\circ} 466$ de Abril de 2012 do Conselho Nacional de Saúde (Apêndice 1).

\subsection{População do estudo e coleta dos dados}

Este estudo foi realizado de Setembro de 2014 a Abril de 2015, contando com a participação de 100 indivíduos do sexo feminino com idade de 18 a 50 anos, com diagnóstico de DTM crônica, pacientes da Clinica de Odontologia da Faculdade de Odontologia de Ribeirão Preto da Universidade de São Paulo (FORP/USP).

Para inclusão neste estudo as voluntárias apresentaram queixa de dor na região orofacial relacionada à DTM confirmada pela aplicação do RDC/TMD (DWORKIN e LERESCHE, 1992), e foram excluídas deste estudo as voluntárias que não apresentaram sinais e sintomas de DTM e as 
que apresentaram histórico de tumores, traumas, infecções e desordens inflamatórias com comprometimento de raízes nervosas.

\subsection{Instrumentos utilizados na pesquisa}

\subsubsection{Research Diagnostic Criteria for Temporomandibular Disorders (RDC/TMD)}

O Research Diagnostic Criteria for Temporomandibular Disorders (RDC/TMD) é uma avaliação clínica, não invasiva, utilizada para diagnosticar a DTM, internacionalmente reconhecida, criado em 1992 (DWORKIN e LERESCHE, 1992) baseado em recomendações de especialistas internacionais e nas informações disponíveis na época, constituído por dois eixos de abordagem, o Eixo I (Aspectos Físicos) e Eixo II (Aspectos Psicossociais). O RDC/TMD representa um avanço significativo nos últimos 20 anos, por permitir a realização de estudos padronizados sejam estudos experimentais, clínicos ou populacionais, ressalta-se que todas as especificações são cuidadosamente documentadas e padronizadas, conduzindo a um exame clínico sistemático, outra vantagem seria as definições operacionais baseadas em termos não ambíguos, ou seja, ao invés de relatar que o paciente apresenta limitação de abertura na avaliação do RDC/TMD essa abertura é quantificada e classificada.

\subsubsection{Tampa Scale for Kinesiophobia for Temporomandibular Disorders (TSK/TMD)}

A Tampa Scale for Kinesiophobia for Temporomandibular Disorders (ANEXO C), consiste em um questionário auto-aplicável composto por 18 questões que abordam a dor e a intensidade dos sintomas da DTM e por 2 domínios. O domínio Evitando Moviemnto (EM) reflete a crença de que a atividade ou movimento pode resultar em reincidiva da lesão ou em dor as questões 1, 2, 10,13,15, 17 e 18 se enquadraram neste domínio, já o domínio Foco Somático (FS) reflete a crença de que há problemas de saúde graves subjacentes e é composto pelas questões 3, 5, 6, 7 e 11, no entanto, todas as questões abordam a dor e a intensidade dos sintomas da DTM. A escala relaciona o medo que a atividade 
física ou os movimentos mandibulares possa causar dor e/ou reincidência da lesão, com a cronicidade da DTM. Os escores variam de um a quatro pontos, sendo que a resposta "discordo totalmente" equivale a um ponto, "discordo parcialmente" a dois pontos, "concordo parcialmente" a três pontos e "concordo totalmente" a quatro pontos, e para obtenção do escore total final é necessário a inversão dos escores das questões quatro, oito, doze e dezesseis, o escore final pode ser de no mínimo 18 e no máximo 72 pontos, sendo que, quanto maior a pontuação maior o grau de cinesiofobia. A TSK/TMD apresenta boa confiabilidade $(\mathrm{CCI}=0,66-0,83)$ e valores de validade aceitáveis (VISSCHER et al., 2010).

\subsubsection{A Escala de Pensamento Catastrófico sobre Dor (B-PCS)}

A B-PCS (SEHN et al., 2012) é um instrumento único, validado e confiável (SULLIVAN; BISHOP, 1995), desenvolvido para avaliar o grau de catastrofização sobre a dor, trata-se de um questionário auto-aplicavel composto por 13 itens, no qual o paciente deve relatar o grau com que apresenta qualquer pensamento ou sentimento descrito no questionário quando acometidos por dor, respeitandoa graduação de 5 pontos que varia de Mínima a Muito Intensa. O instrumento é composto por três subescalas: Desesperança, Magnificação e Ruminação, a pontuação para as subescalas são dadas pela soma dos itens correspondentes e a pontuação total é calculada pela soma de todos os itens, varia de 0 a 52 pontos. Os valores de validade da versão em português brasileiro são aceitáveis(goodness-of-fit índices > 0,90, RMSEA =0,09), e os valores de consistência interna $(\alpha$ Cronbach $=0,86-0,93$ ) e confiabilidade(CCI =,91-,94) (SEHN et al., 2012).

\subsubsection{Questionário sobre a saúde do paciente (PHQ-8)}

O PHQ-8 (LIMA et al., 2009) constitui-se de oito perguntas que avaliam a presença de cada um dos sintomas para o episódio de depressão, os oitos itens abordam os sintomas como humor deprimido, anedonia (perda de interesse ou prazer em fazer as coisas), problemas com o sono, 
cansaço ou falta de energia, mudança no apetite ou peso, sentimento de culpa ou inutilidade, problemas de concentra- ção, sentir-se lento ou inquieto e pensamentos suicidas. A frequência de cada sintoma nas últimas duas semanas é avaliada em uma escala Likert de 0 a 3 correspondendo às respostas "nenhuma vez", "vários dias", "mais da metade dos dias" e "quase todos os dias", respectivamente. O questionário apresenta valores de validade aceitáveis (LIMA et al., 2009).

\subsection{5. Índice de Limitação Funcional Mandibular (MFIQ)}

O MFIQ (CAMPOS et al., 2012) tem um sistema de pontuação que o caracteriza como índice, possibilitando classificar os voluntários em categorias de severidade de limitação funcional relacionada à DTM, o questionário apresenta 17 questões para as quais são possíveis cinco respostas, com valores variando de 0 a 4 e a pontuação total é obtida somando-se os valores das respostas a cada questão, mas a graduação não é linear. Os autores propuseram uma ponderação em que a pontuação é dividida pelo número de itens respondidos multiplicado por quatro (que é o valor máximo da resposta a cada questão); e o coeficiente assim obtido ainda deve ser cotejado a determinadas condições do conjunto de respostas, para se obter o grau de acometimento e a categoria de severidade. Os valores de validade aceitáveis (goodness-of-fit índices > 0,87, RMSEA = 0,09), consistência interna ( $\alpha$ Cronbach $=0,87-0,92$ ) e confiabilidade $(\mathrm{CCI}=0,82-0,89$ ) foram descritos para MFIQ brasileira (CAMPOS et al., 2012).

\subsubsection{A escala graduada de dor crônica (EGDC)}

A EGDC (VON KORFF et al., 2001) é composta por 8 questões, avalia a persistência, intensidade e incapacidade associadas à dor crônica, as respostas são baseadas nas recordações dos últimos seis meses, a frequência da dor é avaliada através dos números de dias em que o paciente refere ter sentido dor, o escore persistência da dor é calculado com esta questão, sendo considerado dor persistente aquela presente em $50 \%$ ou mais dos dias e não persistente a dor presente em menos 
de $50 \%$ dos dias. As questões 2,3 e 4 solicitam informações sobre a dor atual, graduadas em escala Likert com valores entre zero e dez. A questão 5 refere-se ao número de dias em que a dor impediu a realizações de atividades e resulta no escore dias de incapacidade que varia de 0 a 180 . As questões 6, 7 e 8 solicitam informações sobre a interferência da dor para realização de atividades diárias, de lazer e trabalho, graduadas em escala likert com valores entre zero e dez, a média dos valores destas questões resulta no escore de incapacidade com valores entre 0 e 100 . Os escores dia de incapacidade e incapacidade são convertidos em um valor entre zero e três pontos e a soma destes pontos é denominada pontos de incapacidade. Os cincos graus de dor são definidos a partir do escore intensidade característica da dor e pontos de incapacidade, todas as pessoas com menos de três pontos são classificadas com dor de baixa interferência (grau I e II), aquelas que apresentam três ou mais pontos de incapacidade são classificados com dor de alta interferência (grau III e IV) (VON KORFF et al, 2001).

\subsection{Adaptação transcultural da TSK/TMD para o Português-Brasil}

Realizar somente a tradução literal de um instrumento pode torná-lo incompreensível em outras línguas, devido à existência de nuances culturais (frases coloquiais, gírias, jargões e expressões idiomáticas) que, ao serem traduzidas para um contexto diferente perdem o significado original (BEATON et al., 2000; ALEXANDRE; COLUCI., 2011). Portanto, instrumentos desenvolvidos em outras línguas e culturas devem ser adaptados ou modificados até ficarem linguística e semanticamente compreensíveis, para um novo idioma, cultura e estilo de vida.

Neste estudo, os processos de tradução e retrotradução seguiu o protocolo COSMIN (MOKKINK et al., 2012) e ocorreram em cinco etapas: tradução inicial para o português, síntese das traduções, a retrotradução ou back-translation, o Comitê de Especialistas e teste da versão préfinal do questionário (BEATON et al., 2002; BEATON et al., 2000; GUILLEMIN; BOMBARDIER, BEATON, 1993). 


\subsubsection{Tradução inicial para o português}

A versão original em Holandês (dutch), foi traduzida para o português por 1 tradutor expert brasileiro dominante da língua dutch, e a versão em inglês, por 1 tradutor leigo e 1 tradutor expert fluentes em ambas as línguas, cuja língua mãe era o português. Beaton et al. (2000) recomendam que a tradução seja realizada a partir da versão original do questionário. Por outro lado, Guillemin, Bombardier e Beaton (1993) prevêm que em situações em que a língua original da ferramenta pode dificultar a operacionalização da participação de tradutores fluentes, é possível a realização da tradução a partir de uma versão inicial em inglês literal. Assim, realizamos o processo de tradução a partir de uma versão em inglês disponibilizada pelos autores da ferramenta original (2 tradutores e 2 retrotradutores) e a partir de uma versão em dutch (1 tradutor e 1 retrotradutor).

Ao final do processo os tradutores foram convidados a preencher o item de "comentários adicionais" do formulário de tradução para que pudessem destacar frases ou incertezas originadas do processo de tradução, bem como, a razão para as escolhas feitas.

Os tradutores também foram convidados a traduzir os tópicos de conteúdo dos itens, opções de resposta e instruções, e tiveram que atender a dois diferentes perfis:

- Tradutores inglês/português: o tradutor 1-inglês (T1) não estava ciente dos conceitos do questionário que estava sendo traduzido e não era profissional da saúde. O objetivo de incluir esse tradutor está relacionado ao fato de que este era menos influenciado pelas metas acadêmicas e possivelmente conseguiu de uma maneira mais adequada refletir a língua utilizada pela população. Este tradutor tinha o português como língua mãe. O tradutor 2inglês (T2), pelo contrário, estava ciente dos conceitos do questionário (Disfunção Temporomandibular e Cinesiofobia). Presume-se que este tradutor tenha fornecido uma tradução mais adequada na perspectiva clínica e mais confiável na perspectiva de propriedades de medida. Este tradutor também tinha o português como língua mãe. 
- Tradutor dutch/português: o tradutor 3-dutch (T3) estava ciente dos conceitos do questionário que está sendo traduzido (DTM e Cinesiofobia) e tinha domínio do dutch, além de ter o português como língua mãe.

\subsubsection{Síntese das traduções e Consenso entre tradutores}

Ambas as traduções foram sintetizadas e as discrepâncias corrigidas a fim de se criar um documento único. Assim, os tradutores e um pesquisador relator/observador reuniram-se para sintetizar as versões obtidas como sugerido por Beaton et al. (2000). Esse processo foi realizado tendo em mãos as versões T1, T2 e T3 para o português da TSK/TMD. Essa versão sintética foi chamada T123 (APÊNDICE 5) e foi acompanhada de um documento resultante do processo de síntese escrito pelo pesquisador relator considerando todos os aspectos discutidos e o modo como foram resolvidos. O consenso foi favorecido em detrimento da percepção de um profissional envolvido.

\subsubsection{Retrotradução ou Backtranslation}

Nessa fase 2 tradutores, cuja língua mãe deveria ser o inglês, foram convidados a traduzir a versão T123 do questionário, em português, para o inglês. Esses tradutores eram totalmente "cegos" para a versão do questionário original, ou seja, era importante que nenhum desses tradutores tivessem tido acesso prévio ao conteúdo do TSK/TMD. Esse processo foi realizado para garantir que a versão traduzida estivesse contemplando e refletindo os mesmos conteúdos da versão original. Para que a versão pré-final ficasse ainda mais fidedigna a versão original, o autor da ferramenta foi convidado a participar do processo de backtranslation verificando se as questões, bem como o layout da ferramenta estavam de acordo com o objetivo inicial do desenvolvimento do questionário. Esse processo auxilia na amplificação de traduções incorretas, inconsistências grosseiras e erros conceituais e garante uma tradução consistente. As três versões originárias desse processo foram 
definidas RT1, RT2, RT3 (RT - retrotradução). A vesrão RT3 foi através da tradução da versão T123 para o dutch (APÊNDICE 5).

\subsubsection{Reunião do Comitê de Especialistas}

É uma etapa crucial para se alcançar a equivalência transcultural, sendo que a composição dos membros desse comitê deve contemplar profissionais da saúde, da área de reabilitação, os tradutores e tradutores de inglês e dutch. Os autores da TSK/TMD original foram informados sobre todas as etapas das reuniões via relatório de atividades e sobre as principais dificuldades durante esse processo, bem como por contato via e-mail.

O papel desse comitê é consolidar todas as versões do questionário e conceber a versão préfinal a ser aplicada nos testes de campo. O comitê foi incumbido de revisar todas as traduções (T1, T2, T3, T123, RT1, RT2, RT3) e chegar a um consenso sobre possíveis discrepâncias. Os comentários adicionais feitos nos processos de tradução e retro tradução foram trazidos, bem como os relatórios escritos pelo pesquisador relator/observador. O pesquisador relator/observador novamente agrupou em um relatório os principais aspectos discutidos e as razões para a tomada de decisões específicas.

Os membros do comitê foram instruídos a buscar equivalência entre a versão original em dutch, inglês e a versão pré-final em 4 áreas:

- Equivalência semântica: o significado associado a cada item. As palavras apresentam o mesmo significado da versão original? É possível que existam múltiplos sentidos para um determinado item? Existem problemas gramaticais na tradução?

- Equivalência idiomática: coloquialismos e expressões idiomáticas são difíceis de traduzir, caso isso ocorra recomenda-se que o comitê formule uma expressão equivalente na versão pré-final.

- Equivalência de experiências/cultural: os itens devem contemplar as experiências de vida diária, considerando-se que em diferentes culturas ou países a carga emocional, e as 
características de dor são interpretadas de formas distintas, bem como as características quando traduzíveis. Recomenda-se, quando há discrepância, que o item seja substituído por um similar que de fato represente experiências reais na cultura alvo.

- Equivalência conceitual: Algumas vezes certas palavras possuem diferentes significados conceituais entre culturas. Um exemplo é o significado do termo família.

$\mathrm{O}$ comitê avaliou as versões originais e retrotraduzidas para todas as equivalências. Na ausência de consenso era possível que as etapas de tradução e retrotradução tivessem que ser realizada novamente para verificar se outra expressão resolveria o problema, o que não ocorreu. Todos os tradutores estavam presentes na reunião de comitê para o caso da necessidade de uma nova tradução e retrotradução. A partir desta reunião do comitê foi obtida a versão pré-final (APÊNDICE 6) que foi enviada para o autor da ferramenta original para revisão e após as considerações do autor da ferramenta original, foi testada em campo.

\subsubsection{Teste da Versão Pré- Final}

O Teste da Versão Pré-Final da ferramenta pode ser considerado como a análise da Validação de Face do questionário, uma vez que esta mede o grau no qual os voluntários ou examinadores (quando a ferramenta é aplicada por examinador) consideram os itens da ferramenta em questão apropriados para o construto e para os propósitos de mensuração (NEVO, 1985), compreendida pela aplicação da ferramenta em uma amostra de voluntários. Essa é uma medida relacionada à aceitabilidade da ferramenta pelo público alvo (HAYNES et al., 1985).

Nesta etapa o questionário na sua versão Pré-final foi aplicado na população-alvo (no caso mulheres com diagnóstico de DTM crônica), em uma amostra de 30 sujeitos, segundo recomendações de Beaton et al. (2000). Em caso de surgir um número maior que 20\% de dúvidas sobre cada questão separadamente em relação ao total da amostra ou se houvesse necessidade de reformulações do questionário (ORFALE et al., 2005) um novo grupo de voluntários seria recrutado, 
entretanto, enquanto houvesse necessidade de reformulações da ferramenta, novos voluntários seriam incluídos para compor a amostragem, sendo que as voluntárias não poderiam participar novamente do preenchimento da ferramenta (TERWEE et al., 2012) (Apêndice 7).

\subsection{Confiabilidade da ferramenta}

Os voluntários que responderam a versão final da TSK/TMD-Br (Apêndice 8), foram convidados a preencher novamente o questionário após uma semana para a verificação da confiabilidade das respostas ao instrumento. Vale ressaltar que esta trata-se de uma ferramenta autoadministrável. O tamanho amostral nesta etapa contou com 30 voluntárias, segundo recomendações feitas pelo COSMIN (TERWEE et al., 2012).

\subsection{Consistência Interna}

A consistência interna é o grau em que os itens de uma ferramenta se correlacionam e é importante para homogeneizar os resultados de um questionário utilizando-se para tal a avaliação do grau de consistência entre os itens que compõem a ferramenta (TERWEE et al., 2007; TERWEE et al., 2012). Desta maneira, de acordo com o protocolo de COSMIN (TERWEE et al., 2012) e como sugere Terwee et al. (2007) deve ser considerada uma amostra de no mínimo 100 indivíduos ou de 5 a 7 vezes o número de itens da ferramenta para assegurar a estabilidade da matriz de covariância. Sendo assim, utilizamos uma amostra de 100 mulheres com diagnóstico de DTM crônica, para verificar a consistência da TSK/TMD-Br.

\subsection{Validade de Construto - teste de hipóteses e validade estrutural}

A validade de construto pode ser definida como o grau em que as pontuações de um instrumento são consistentes com a hipótese, e é obtido através da avaliação das inter-relações internas do instrumento, comparação com outros instrumentos ou entre grupos relevantes, 
considerando a hipótese de que o instrumento de comparação apresenta confiabilidade no que pretende medir (TERWEE et al., 2007). Além da validade de construto (teste de hipóteses), foi verificada a validade estrutural da ferramenta através da análise fatorial confirmatória (AFC). Para AFC foi observado valor de CAIC uma medida de adequação do ajuste do modelo, já o CFI e GFI mensuram o quanto o modelo adapta-se em comparação com um modelo de linha base, e estes índices são relativamente independentes do tamanho da amostra, para CFI e GFI valores acima de 0,90 indicam uma adaptação adequada e valores acima de 0,95 indicam um bom ajuste (SCHERMELLEH-ENGEL et al., 2003). Já o ECVI é uma medida relativa para comparar modelos concorrentes, e modelos com valores mais baixos indicam melhor ajuste (SCHERMELLEHENGEL et al., 2003). O RMSEA quantifica as divergências entre od dados e o modelo proposto por grau de liberdade, valores abaixo de 0,08 indicam uma adaptação adequada (SCHERMELLEHENGEL et al., 2003). As magnitudes das cargas fatoriais para cada variável foram consideradas quando analisado as contribuições dos itens no modelo, sendo que as variáveis apresentaram carga fatorial superior à 0,4 considerado representativa para construção de medida de cada domínio.

Para verificação da validade de construto da TSK/TMD-Br, foi realizada comparação do instrumento com a Escala de pensamento catastrófico sobre a dor (B-PCS) que avalia o construto catastrofização, com o Questionário sobre saúde do paciente (PHQ-8) que avalia o construto depressão, com o Índice de Limitação Funcional Mandibular (MFIQ) que avalia a limitação funcional e com a Escala Graduada de Dor Crônica (EGDC) que mensura incapacidade relacionada a dor. Foi estipulada uma hipótese de correlação positiva e moderada entre as pontuações das ferramentas. Considerando uma amostra de 100 indivíduos.

\subsection{Análise Estatística}

Para a caracterização amostral foi utilizada a estatística descritiva, com as medidas de média, porcentagem e intervalo de confiança (IC) a 95\%. Para análise estatística da confiabilidade foi 
utilizado o Coeficiente de Correlação Interclasse (CCI), com os níveis de classificação como descrito por Fleiss et al. (2003), sendo CCI $<0,40$ considerado pobre, 0,40<CCI $<0$, 7, moderado e CCI> 0.75, excelente.

O coeficiente de correlação de Pearson foi utilizado para verificação da validade de construto, comparando-se as pontuações da TSK/TMD-Br com as demais ferramentas, a força da correlação foi graduada da seguinte maneira: $\mathrm{R}<0,29$ : pobre; $0,3<\mathrm{R}<0,69$ : moderada; $\mathrm{R}>0,7$ : forte (DANCEY; REIDY, 2004).

Para a análise da consistência interna foi utilizado o coeficiente de $\alpha$ de Cronbach, com resultados esperados entre 0,7 e 0,95 (TERWEE et al., 2007). O Item Total Correlation (ITC) mensura a correlação entre um item de uma escala e a pontuação total desta excluindo-se aquele item. Valores entre 0,2 e 0,8 foram considerados aceitáveis, pois a correlação entre os itens maior que 0,2 indica que os itens se correlacionam mais fortemente com o domínio a que pertencem, e valores não muito maiores que 0,5 são desejáveis (CLARK e WATSON, 1998). Omitem-se valores inferiores a 0,2 como indicação de uma correlação inexistente com o construto (CLARK e WATSON, 1998). O ITC foi calculado utilizando o Coeficiente de Correlação de Pearson, utilizado para distribuições assimétricas (PICON et al., 2006). O alpha de Cronbach se o item for excluído, representa o coeficiente de confiabilidade alpha (GLIEM e GLIEM, 2003). Entretanto, quando o item é removido da escala, verifica-se se os mesmos aumentariam significativamente o valor do coeficiente alpha (PICON et al., 2006).

Para análise do Erro Padrão da Medida (SEM - Standard Error of Measurement) foi utilizada a fórmula descrita por Weir (2005): EPM = DP $\sqrt{ }$ CCIx $(1-C C I)(20)$ na qual DP = desvio padrão. Já a Mínima Diferença Detectável foi calculada considerando-se: MDD =1,96 x $\sqrt{2} \times$ EPM. Todas as análises foram realizadas através do software estatístico Statistical Package for Social Science for Windows (SPSS) versão 17 (SPSS Inc, Chicago,USA). 


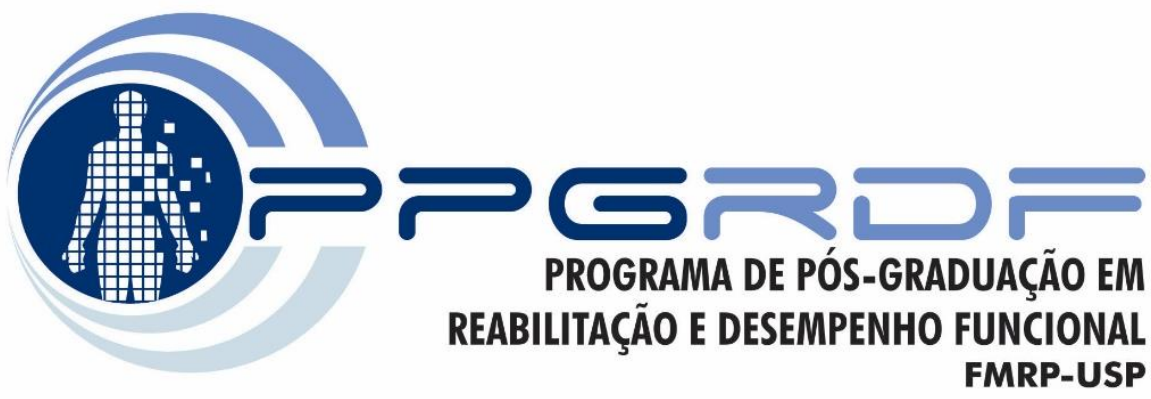

"Um passo a frente e você não está mais no mesmo lugar." 


\section{RESULTADOS}

\subsection{Caracterização das amostras do estudo}

Este estudo foi coletado de Setembro de 2014 a Abril de 2015, contando com a participação de 100 pacientes com diagnóstico de DTM crônica da Clinica de pacientes especiais da FORP/USP, inicialmente para o processo de adaptação transcultural do questionário foram recrutadas 30 voluntárias com média de idade 37,17£9,73 anos, para responder a versão pré-final do questionário, ao longo deste processo foi realizado alterações e reaplicado em um número igual de participantes até obtenção da versão final da Escala Tampa de Cinesiofobia para Disfunções Temporomandibulares (TSK/TMDBr). Em uma segunda fase do projeto, a versão final transculturalmente adaptada para o português brasileiro foi aplicado em 70 voluntárias, totalizando uma amostra de 100 voluntários com idade média 36,88 $\pm 9,80$, para confiabilidade, consistência interna dos itens da ferramenta, validação de construto, análise fatorial, correlação da TSK/TMD-Br com as demais ferramentas e para a reprodutibilidade da versão transculturalmente traduzida e adaptada a média de idade foi de 35,63 $\pm 10,17$ anos (Tabela 1 ).

Tabela 1. Caracterização da amostra para cada etapa de validação da TSK/TMD-Br

\begin{tabular}{ccc}
\hline Etapas do Estudo & Tamanho Amostral & Média e DP de idade \\
\hline Teste Pré-Final & 30 & $37,17 \pm 9,73$ \\
$\begin{array}{c}\text { Confiabilidade, Validação, } \\
\text { Consitência Interna e } \\
\text { Análise Fatorial }\end{array}$ & 100 & $36,88 \pm 99,80$ \\
Confiabilidade & 30 & $35,63 \pm 10,17$
\end{tabular}

TSK/TMD-Br- Escala Tampa de Cinesiofobia para Disfunção Temporomandibular versão Brasileira; DP- Desvio Padrão. 
Houve uma maior quantidade de voluntárias com nível de escolaridade de ensino médio incompleto/completo ( $\mathrm{n}=42$ ), seguido do nível ensino básico incompleto/completo $(n=40)$ e do ensino superior $(n=22)($ Tabela 2$)$.

Table 2. Descrição (media e Desvio padrão: DP) dos dados antropométricos, nível de escolaridade e dados clínicos da amostra total $(n=100)$.

\begin{tabular}{lcccc}
\hline \multicolumn{1}{c}{ Nível de escolaridade } & $\begin{array}{c}\text { Tamanho } \\
\text { amostral }\end{array}$ & $\begin{array}{c}\text { Idade } \\
\text { (Média e DP) } \\
\text { Anos }\end{array}$ & $\begin{array}{c}\text { Peso } \\
\text { (Média e DP) }\end{array}$ & $\begin{array}{c}\text { Altura } \\
\text { kg }\end{array}$ \\
\hline Amostra completa & $\mathrm{n}=100$ & $36.88(9.80)$ & $66.10(13.97)$ & $1.62(0.07)$ \\
\hline $\begin{array}{l}\text { Ensino básico } \\
\text { Incompleto/completo }\end{array}$ & 40 & $42.14(8.95)$ & $66.64(15.82)$ & $1.61(0.08)$ \\
$\begin{array}{l}\text { Ensino médio } \\
\text { Incompleto/completo }\end{array}$ & 42 & $34.21(9.15)$ & $67.83(13.93)$ & $1.63(0.06)$ \\
Ensino superior & & & & \\
Incompleto/completo & 22 & $31.11(6.86)$ & $64.50(10.32)$ & $1.65(0.05)$ \\
\hline
\end{tabular}

\section{Dados Clínicos}

Intensidade da dor $4.35(2.88)$

Relato da intensidade da dor (maioria dos

dias)*

B-PCS (0 a 65)

$30.88(12.40)$

PHQ (0 a 24)

MFIQ (0 a 52)

$15.33(12.00)$

n: tamanho amostral; DP: desvio padrão

* Média da dor nos ultimos seis meses

B-PCS: Escala de pensamentos catastrófico sobre dor

PHQ: Questionário sobre saúde do paciente

MFIQ: Índice de limitação functional mandibular

Com relação aos subtipos de DTM, houve uma prevalência significativamente menor de diagnósticos para DTM do tipo Artrogênico (n=12), quando comparado com os outros subgrupos de DTM miogênico e misto. Também verificamos uma frequência Dor 
Miofascial + Deslocamento do disco sem redução e com limitação na abertura + Artralgia no subgrupo de DTM mista relação aos demais diagnósticos (Tabela 3). No subgrupo do tipo DTM Miogênica (n=44), não se observou diagnóstico de Dor Miofascial com abertura limitada, enquanto o diagnóstico de Dor Miofascial foi excluivo (100\%) (Tabela $3)$.

Na primeira etapa foram recrutados 30 sujeitos $(37,17, \mathrm{DP}=9,73)$ para o teste da versão pré-final, 30 voluntárias para a etapa de reprodutibilidade $(35,63, \mathrm{DP}=10,37)$ e $100(36,88, \mathrm{DP}=9,80)$ para etapa de validação da ferramenta. Não foi observada diferença na média de idade entre os grupos nas diferentes etapas do estudo $\left(F_{(2,127)}=0,03, p=0,96\right)$. 
Tabela 3. Classificação do diagnóstico de Disfunção Temporomandibular (DTM) de acordo com o Research Diagnostic Criteria for Temporomandibular Disorders (RDC/TMD).

\section{Diagnóstico de DTM}

Porcentagem de diagnósticos

(n)

Miogênico

$100 \%(\mathrm{n}=44)^{*}$

$(\mathrm{n}=0)$

44

$X^{2}=29,33, p<0.05$

Artrogênico

$16 \%(\mathrm{n}=2)$

$42 \%(n=5)$

$25 \%(\mathrm{n}=3)$

$17 \%(\mathrm{n}=2)$

12

\begin{tabular}{lc}
\hline Qui-quadrado & $\mathrm{X}^{2}=0,9, \mathrm{p}=0,82$ \\
\hline & $\mathbf{M i s t o}$ \\
$\begin{array}{l}\text { Dor Miofascial + Deslocamento do disco com redução } \\
\text { Dor Miofascial + Deslocamneto do disco com redução }+\end{array}$ & $2 \%(\mathrm{n}=1)$ \\
$\begin{array}{l}\text { Artralgia } \\
\text { Dor Miofascial + Deslocamento do disco sem redução e com }\end{array}$ & $7 \%(\mathrm{n}=3)$ \\
$\begin{array}{l}\text { limitação na abertura } \\
\text { Dor Miofascial + Artralgia }\end{array}$ & $25 \%(\mathrm{n}=11)$ \\
$\begin{array}{l}\text { Dor Miofascial + Deslocamento do disco sem redução e com } \\
\text { limitação na abertura + Artralgia } \\
\text { Total de DTM Misto }\end{array}$ & $48 \%(\mathrm{n}=21)^{*}$ \\
\hline Qui-quadrado & $\mathbf{4 4}$ \\
\hline $\begin{array}{l}\text { Total de DTM } \\
\text { Qui-quadrado comparação subgrupos (miogenico, } \\
\text { artrogenico e misto) }\end{array}$ & $\mathrm{X}^{2}=13,85, \mathrm{p}=0,007$ \\
\hline
\end{tabular}

DTM- Disfunção Temporomandibular; RDC/TMD- Research Diagnostic Criteria for Temporomandibular Disorders.

* Diferença significativa, teste de qui-quadrado $(\mathrm{p}<0,05)$ 


\subsection{Adaptação trasncultural da TSK-TMD-Br e Teste da versão pré-final}

O processo de tradução e adaptação transcultural do questionário seguiu o protocolo COSMIN (MOKKINK et al., 2012). Segundo recomendações do COSMIN, três grandes esferas na avaliação de psicometria de instrumentos de avaliação em saúde devem ser considerados: confiabilidade, validade e responsividade. A confiabilidade engloba consistência interna, confiabilidade e medida de erro, a validade considera as validades de construto, critério e conteúdo e a responsividade que constitui sozinha uma das esferas (MOKKINK et al, 2010). Em estudos de adaptações transculturais, recomenda-se que alguns itens sejam considerados como demonstrado na tabela 4 . Ao decorrer desta discussão vamos demonstrar quais recursos foram empregados e que resultados foram obtidos para alcançar cada um dos itens recomendados pelo COSMIM no processo de validação transcultural. Na tabela 4 os itens que foram contemplados neste estudo estão marcados com X e nos itens não abordados estão marcados com asterisco. 
Tabela 4. Itens do COSMIN que foram considerados no estudo de adaptação transcultural e validação da TSK/TMD versão português Brasil.

1. A porcentagem de itens "perdidos" foi mencionada?

2. Houve uma descrição de como os itens perdidos foram manipulados?

3. O tamanho da amostra incluído foi adequado?

4. Estavam descritas ambas as línguas: a original em que o instrumento foi desenvolvido e a que o instrumento foi traduzido?

5. Foi descrito adequadamente a experiência das pessoas envolvidas no processo de tradução? Por exemplo: experiência na(s) doença(s) envolvida(s), experiência no construto a ser medido e experiência em ambas as línguas.

6. Os tradutores trabalharam de forma independente um do outro?

7. Os itens foram traduzidos e retrotraduzidos?

8. Foi descrito de forma adequada como as diferenças entre as versões original e traduzida foram resolvidas?

9. A tradução foi revista por um comitê? (Por exemplo: Desenvolvedores originais)

10. O instrumento foi pré-testado (Por exemplo: entrevistas cognitivas) para verificar a interpretação, a relevância cultural da tradução, e facilidade de compreensão?

11. A amostra utilizada no pré-teste foi descrita adequadamente?

12. As amostras foram semelhantes para todas as características, exceto Língua e / ou aspectos culturais?

13. Houve falhas importantes no projeto ou nos métodos de estudo?

$\mathrm{X}$

$\mathrm{X}$

$\mathrm{X}$

$\mathrm{X}$

$\mathrm{X}$

$\mathrm{X}$

$\mathrm{X}$

Não

\section{Métodos estatísticos}

14. Para TCT: Foi realizada análise fatorial confirmatória?

$\mathrm{X}$

Ou

15. Para TRI: A função diferencial do item (FDI) entre grupos linguísticos foi avaliada?

$\mathrm{X}$ - itens contemplados; $*$ Nenhum item foi perdido.

O processo constou em algumas etapas: tradução inicial para o português por dois tradutores, sendo um expert sobre o construto a ser medido e outro leigo na temática, síntese das traduções com consenso de tradutores, retrotradução por dois novos tradutores cegos para a versão original, novo comitê de especialistas e teste da versão pré-final do questionário (Figura 1). Além disso, houve a submissão da versão final da ferramenta e do desenho do processo de tradução para aprovação. 
Inicialmente a versão em Inglês (Anexo C) disponibilizada pela autora (VISSCHER et al., 2010) foi submetida à tradução inicial para o Português-Brasil por dois tradutores, fluentes em ambas as línguas, cuja primeira língua era o português, sendo um deles leigo sobre a temática (Tradutor 1 - T1) não estava ciente dos conceitos do questionário que está foi traduzido, e tratava-se de profissional que não atua na área da saúde, o objetivo de incluir esse tradutor está relacionado ao fato de que este é menos influenciado pelas metas acadêmicas e possivelmente consiga de uma maneira mais adequada refletir a língua utilizada pela população. E o outro tradutor ao contrario é expert sobre o assunto (Tradutor 2 - T2), este tradutor estava ciente dos conceitos do questionário que foi traduzido (DTM e Cinesiofobia), presume-se que este tradutor forneceu uma tradução mais adequada na perspectiva clínica e mais confiável na perspectiva de propriedades de medida, como recomendado pelo COSMIN (MOKKINK et al., 2012). O Tradutor dutch/português (Tradutor 3-T3), também estava ciente dos conceitos do questionário que está sendo traduzido (DTM e Cinesiofobia) e com domínio do dutch.

Os tradutores também traduziram os tópicos de conteúdo dos itens, opções de resposta e instruções contidas ao longo da escala (Figura 1).

As três traduções em Português-Brasil, T1 (Apêndice 2), T2 (Apendice 3) e T3 (Apêndice 4), foram confrontadas e sintetizadas (Figura 1), além disso, as discrepâncias foram corrigidas na $1^{\mathrm{a}}$ reunião do comitê de especialistas, fizeram parte desta reunião os tradutores, experts e indivíduos nativos do Brasil, com domínio do Português-Brasil, a fim de se criar um documento único (versão T123 - Apêndice 5), seguindo o protocolo COSMIN (MOKKINK et al., 2012). Assim, os tradutores, um pesquisador relator/observador, dez pesquisadores experts em disfunções musculoesqueléticas e 
membros da sociedade se reuniram para sintetizar as versões obtidas (BEATON et al., 2000).

Esse processo foi realizado tendo em mãos as versões T1, T2 e T3, a versão original da TSK/TMD em Holandês (dutch) (ANEXO D) e a versão em inglês. Um documento resultante do processo de síntese escrito pelo pesquisador relator considerando todos os aspectos discutidos e como eles foram resolvidos (Apêndice 9) (Figura 2).

Após esta etapa, dois tradutores, não profissionais da área de saúde, sendo um nativo americano e outro brasileiro com domínio do inglês foram convidados a traduzir para o inglês a versão T123 da escala, etapa denominada de Retrotradução - RT (Figura 2). Esses tradutores eram "cegos" para todas as versões prévias do questionário, ou seja, nenhum dos tradutores teve acesso antes de sua tradução ao conteúdo do TSK/TMD, nem à versão original da ferramenta, seguindo as recomendações do COSMIN (MOKKINK et al., 2012).

As duas versões resultantes desse processo foram definidas como RT1 e RT2 (Apêndice 10 e 11) e comparadas pelo pesquisador relator/observador com a versão em Inglês fornecida pela autora em um relatório para compor os documentos discutidos na etapa seguinte. Uma tradução da versão original da TSK/TMD em dutch (TSK/TMD-T3) (Apêndice 4) foi realizada por uma tradutora leiga cuja língua nativa é o português e que residiu 16 anos na Holanda (Figura 1), a versão resultante foi retrotraduzida por um tradutor cuja a língua nativa é Dutch e foi definida como RT3 (Apêndice 12).

A etapa subsequente consistiu na segunda reunião com especialistas, esta foi uma etapa crucial para alcançar a equivalência transcultural e a composição dos membros desse comitê contemplou profissionais da saúde, da área de reabilitação, da área de disfunção temporomandibular, estudiosos da área da fisioterapia além dos tradutores, 
professores de línguas e membros da sociedade (Figura 1). O relatório da segunda reunião de experts pode ser consultado no Apêndice 13.

O comitê foi incumbido de revisar todas as traduções (T1, T2, T3, T123, RT1, RT2, RT3) e chegar a um consenso sobre possíveis discrepâncias. O papel desse comitê foi consolidar todas as versões do questionário e conceber a versão Pré-Final (TSK/TMDv.1 - Apêndice 6) para ser aplicada nos testes de campo, tendo em mãos, a versão original em Dutch (Holandês) e a versão em Inglês, bem como, todos os comentários adicionais feitos durante todos os processos de tradução e retrotradução e os relatórios escritos pelo pesquisador relator/observador. O pesquisador relator/observador novamente agrupou em um relatório os principais aspectos discutidos e as razões para a tomada de decisões específicas.

Os membros do comitê foram instruídos a encontrar palavras e expressões que fossem facilmente entendidas por uma criança de 12 anos, considerando as equivalências (semântica, idiomática, cultural e conceitual) entre as versões original, em inglês e préfinal da TSK/TMD (TERWEE et al., 2007).

O comitê avaliou as versões original, em inglês, traduzidas e retrotraduzidas para todas as equivalências. Os tradutores estavam presentes na reunião de comitê para que caso fosse necessária uma nova tradução e retrotradução, em decorrência de ausência de consenso esta pudesse ser realizada imediatamente. A partir desta etapa foi gerada a versão Pré-final do questionário.

A versão Pré-final do questionário foi aplicada na população-alvo numa amostra de 30 pessoas (BEATON et al., 2000). Um total de 8 voluntárias responderam à esta versão do questionário juntamente com um questionário de sugestões, em que houve a necessidade de reformulação do layout para melhor entendimento, acrescentando-se uma figura (figura 2), demarcando a localização da dor orofacial. 
Em última instância foi realizado o envio do TSK/TMD-Br (Apêndice 8) para a aprovação do autor da ferramenta original e dos membros do comitê. Este processo tem como objetivo informar o autor quanto às etapas que foram seguidas (BEATON et al., 2000).

\section{Processo de Adaptação Transcultural}

Tampa Scale for Kinesiophobia for Temporomandibular Disorders (TSK/TMD)

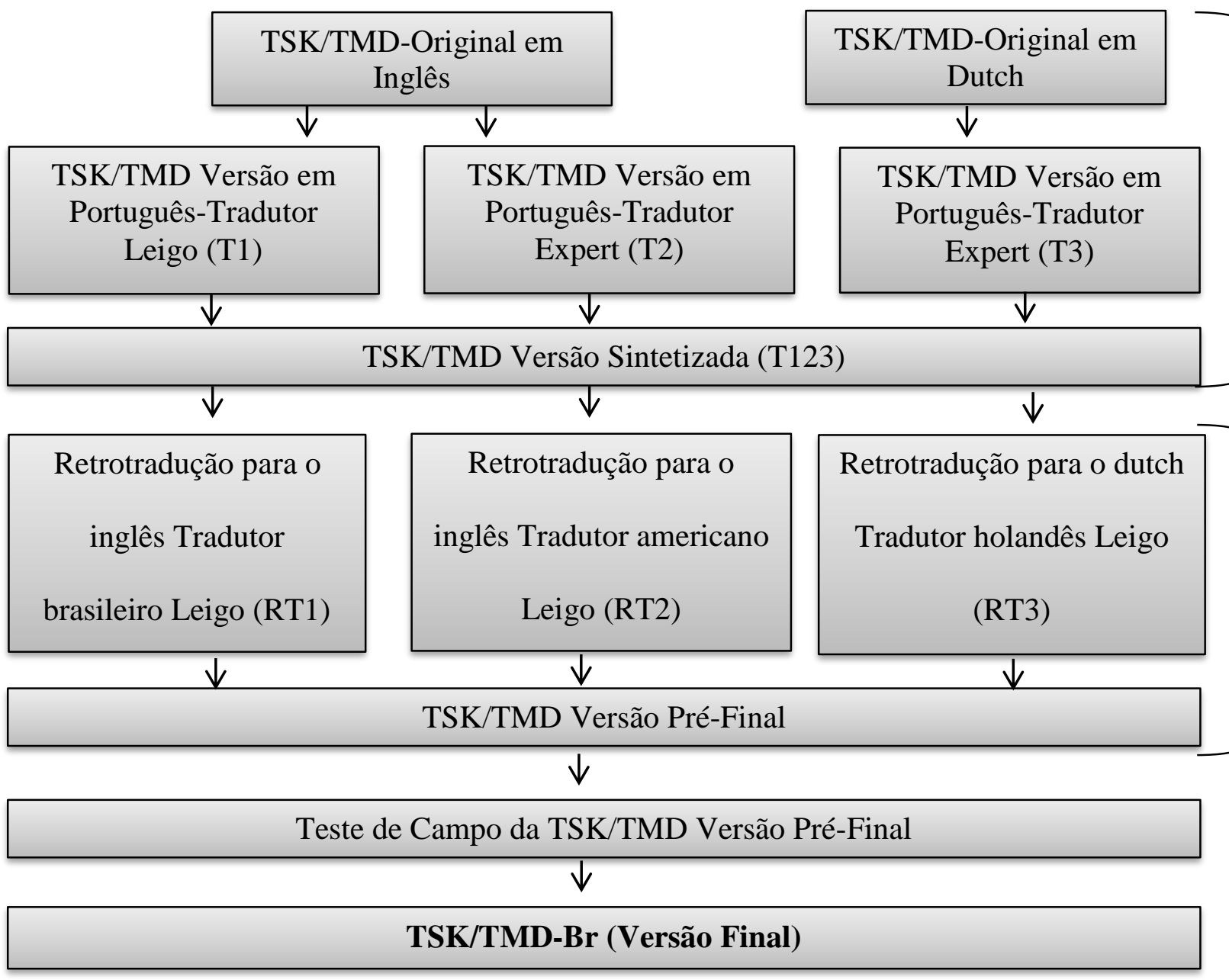

Figura 1- Etapas adotadas no processo de tradução e retrotradução da Tampa Scale for Kinesiophobia for Temporomandibular Disorders (TSK/TMD). 


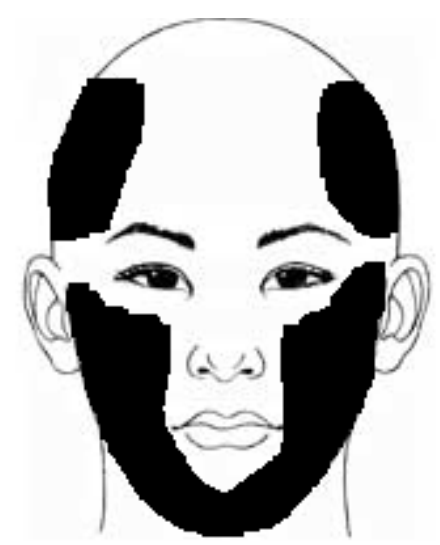

Figura 2. Localização da dor orofacial

Nas fases de adaptação da escala foram realizadas algumas alterações, estas mudanças estão descritas detalhadamente no apêndice 9 e 13. Na introdução da escala sugeri-se que no trecho inicial acrescentasse a palavra, por favor, e o restante do trecho foi substituído por o que lhe incomoda, no final optou-se por substituir a resposta "sim, são possíveis em todas as questões", por marque sim ou não no quadro abaixo, a frase ficou da seguinte forma: Por favor, indique na lista abaixo, o que lhe incomoda (marque sim ou não nos quadrados abaixo). Nos itens de opção da introdução da escala foram feitas as seguintes substituições: eu movimento minha boca para eu mexo minha boca, estalidos por estalos, crepitações por outros ruídos e a substituição de outros problemas mandibulares para outros incômodos da região mandibular. O comitê sugeriu que na frase "a mandíbula trava ou bloqueia que eu não posso abri-la”, fosse substituída por" Minha mandíbula fica travada ou presa de maneira que minha boca não abre ou fecha direito". Os itens de respostas da escala foram substituídos de concordo/discordo totalmente para eu concordo/discordo fortemente.

Não foi obtido consenso sobre a tradução mais adequada para a questão 17. Dessa forma, através de um consenso durante a fase de reunião do comitê de especialistas optouse por dividi-lá em 17a “Alguém que tenha problemas mandibulares, como o meu, não 
deveria ter que mexer a sua mandíbula" e 17b "Você não deveria mexer sua mandíbula se você tem problemas mandibulares como o meu”. Durante a fase de teste da versão préfinal a opção 17a foi escolhida pelo público alvo (100\%) como a afirmação mais clara. Para todas as demais questões não foram relatadas dúvidas durante a fase de teste da versão pré-final, desta forma, não foi necessária uma nova reformulação da escala na etapa de teste da versão pré-final da TSK/TMD-Br.

\subsection{Confiabilidade da pontuação da TSK/TMD-Br}

A confiabilidade do questionário foi testada e foi verificado nível de reprodutibilidade excelente (ICC $>0,75)$ para todos os domínios e pontuação final do questionário (Tabela 5).

\subsection{Consistência Interna dos itens e domínios da TSK/TMD-Br}

De acordo com checklist COSMIN (MOKKINK et al., 2010) a consitência interna garante homogeneizar os resultados do questionário, para esta avaliação verificou-se o grau de consistência entre os itens que compõem a ferramenta, estabelecida por meio do alpha de Cronbach que foi superior a 0,70 e o Item Total Correlation de cada domínio entre 0,51 e 0,75 (Tabela 6). Os valores de alpha de Cronbach se o item for deletado variaram entre 0,74 e 0,76 (Tabela 6). 
Tabela 5. Valores médios de reprodutibilidade teste-reteste (CCI) e IC 95\% das pontuações dos domínios da TSK-TMD-Br (n=30).

\begin{tabular}{|c|c|c|}
\hline Domínio Evitando o Movimento & $\begin{array}{l}\text { Coeficiente de Correlação } \\
\text { Intraclasse }\end{array}$ & EPM/MDD \\
\hline Questões & CCI (IC95\%) & \\
\hline 1. Eu tenho medo de me machucar, se eu movimentar minha mandíbula. & $0,88(0,76-0,94)$ & $0,28 / 0,79$ \\
\hline 2. Se eu ignorasse meus sintomas na região mandibular, eles poderiam piorar. & $0,84(0,66-0,92)$ & $0,30 / 0,84$ \\
\hline $\begin{array}{l}\text { 10. A maneira mais segura de evitar que os meus sintomas piorem é } \\
\text { simplesmente ter cuidado e não mexer minha mandíbula mais do que o } \\
\text { necessário. }\end{array}$ & $0,79(0,57-0,90)$ & $0,31 / 0,86$ \\
\hline $\begin{array}{l}\text { 13. Meus sintomas mandibulares me avisam quando devo parar de mexer } \\
\text { minha mandíbula para evitar que eu me machuque. }\end{array}$ & $0,78(0,55-0,90)$ & $0,27 / 0,74$ \\
\hline $\begin{array}{l}\text { 15. Eu não consigo fazer tudo o que outras pessoas fazem, porque eu machuco } \\
\text { minha mandíbula muito facilmente. }\end{array}$ & $0,75(0,47-0,88)$ & $0,30 / 0,84$ \\
\hline $\begin{array}{l}\text { 17. Ninguém que tenha problemas mandibulares, como o meu, deveria mexer } \\
\text { sua mandíbula. }\end{array}$ & $0,86(0,70-0,93)$ & $0,20 / 0,54$ \\
\hline $\begin{array}{l}\text { 18. Tenho medo de abrir muito minha boca, porque é possível que eu não } \\
\text { consiga fechá-la novamente. }\end{array}$ & $0,92(0,84-0,96)$ & $0,20 / 0,56$ \\
\hline Pontuação Total do Domínio Evitando Movimento & $0,93(0,87-0,97)$ & $0,94 / 2,60$ \\
\hline
\end{tabular}

Domínio Foco Somático 


\begin{tabular}{|c|c|c|}
\hline $\begin{array}{l}\text { 3. Parece que há alguma coisa errada na minha região mandibular que pode } \\
\text { ficar séria. }\end{array}$ & $0,77(0,52-0,89)$ & $0,29 / 0,81$ \\
\hline 5. As pessoas não levam minhas queixas na mandíbula a sério. & $0,86(0,71-0,93)$ & $0,24 / 0,65$ \\
\hline $\begin{array}{l}\text { 6. Por causa dos meus sintomas mandibulares minha saúde está em risco pelo } \\
\text { resto da minha vida. }\end{array}$ & $0,87(0,73-0,93)$ & $0,24 / 0,67$ \\
\hline $\begin{array}{l}\text { 7. Meus sintomas mandibulares significam que eu machuquei minha } \\
\text { mandíbula. }\end{array}$ & $0,87(0,72-0,93)$ & $0,23 / 0,63$ \\
\hline $\begin{array}{l}\text { 1. Eu não teria tantos sintomas mandibulares se alguma coisa potencialmente } \\
\text { prejudicial não estivesse acontecendo. }\end{array}$ & $0,89(0,78-0,95)$ & $0,19 / 0,52$ \\
\hline Pontuação Total do Domínio Foco Somático & $0,95(0,90-0,97)$ & $0,46 / 1,28$ \\
\hline Pontuação Total da TSK/TMD-Br & $0,95(0,89-0,97)$ & $1,17 / 3,24$ \\
\hline
\end{tabular}

n- número de indivíduos da amostra; CCI- Coeficiente de Correlação Intraclasse; IC95\%- Intervalo de Confiança; EPM- Erro Padrão de Medida; MDD- Mudança Diferença detectável 
Tabela 6. Descrição dos valores de $\alpha$ de Cronbach e da Correlação Total do Item (CTI) e dos domínios e das questões da TSK/TMD-Br.

\begin{tabular}{|c|c|c|}
\hline \multicolumn{3}{|l|}{ Domínio Evitando Movimento } \\
\hline Questões & $\begin{array}{l}\text { Correlação Total do Item } \\
\text { Corrigido }\end{array}$ & $\begin{array}{l}\text { Alpha de Cronbach se o } \\
\text { item for excluído }\end{array}$ \\
\hline $\begin{array}{l}\text { 1. Eu tenho medo de me machucar, se eu movimentar minha } \\
\text { mandíbula. }\end{array}$ & 0,73 & 0,74 \\
\hline $\begin{array}{l}\text { 2. Se eu ignorasse meus sintomas na região mandibular, eles } \\
\text { poderiam piorar. }\end{array}$ & 0,54 & 0,76 \\
\hline $\begin{array}{l}\text { 10. A maneira mais segura de evitar que os meus sintomas piorem é } \\
\text { simplesmente ter cuidado e não mexer minha mandíbula mais do que } \\
\text { o necessário. }\end{array}$ & 0,67 & 0,75 \\
\hline $\begin{array}{l}\text { 13. Meus sintomas mandibulares me avisam quando devo parar de } \\
\text { mexer minha mandíbula para evitar que eu me machuque. }\end{array}$ & 0,72 & 0,75 \\
\hline $\begin{array}{l}\text { 15. Eu não consigo fazer tudo o que outras pessoas fazem, porque eu } \\
\text { machuco minha mandíbula muito facilmente. }\end{array}$ & 0,75 & 0,74 \\
\hline $\begin{array}{l}\text { 17. Ninguém que tenha problemas mandibulares, como o meu, } \\
\text { deveria mexer sua mandíbula. }\end{array}$ & 0,72 & 0,75 \\
\hline $\begin{array}{l}\text { 18. Tenho medo de abrir muito minha boca, porque é possível que eu } \\
\text { não consiga fechá-la novamente. }\end{array}$ & 0,70 & 0,74 \\
\hline
\end{tabular}

\section{Escore total do domínio Evitando Movimento}


Alpha de Cronbach médio= $\mathbf{0 , 7 8}$

\begin{tabular}{lcc}
\hline \multicolumn{1}{c}{ Domínio Foco Somático } & \\
\hline 3. Parece que há alguma coisa errada na minha região mandibular que & 0,65 & 0,74 \\
pode ficar séria. & 0,51 & 0,76 \\
$\begin{array}{l}\text { 5. As pessoas não levam minhas queixas na mandíbula a sério. } \\
\text { 6. Por causa dos meus sintomas mandibulares minha saúde está em }\end{array}$ & 0,67 & 0,74 \\
risco pelo resto da minha vida. & 0,64 & 0,75 \\
7. Meus sintomas mandibulares significam que eu machuquei minha & \\
mandíbula. & 0,69 \\
$\begin{array}{l}\text { 11. Eu não teria tantos sintomas mandibulares se alguma coisa } \\
\text { potencialmente prejudicial não estivesse acontecendo. }\end{array}$ & 0,74 \\
\hline
\end{tabular}

\section{Escore total do Domínio Foco Somático}

Alpha de Cronbach Médio= $\mathbf{0 , 7 8}$ 


\subsection{Validade estrutural da TSK/TMD-Br}

A análise fatorial confirmatória foi utilizada para testar a estrutura fatorial da TSK/TMD-Br. Três modelos diferentes foram testados, a escolha dos modelos foram baseados nos modelos proposto por Visscher et al. (2010), sendo que o modelo 1) é um modelo com dois domínios e 18 itens, considerando que o item 18 da TSK/TMD original apresenta uma boa adequação por abranger conteúdo especifico para pacientes com DTM (MILLER et al., 1991), já o modelo 2) é um modelo com 12 itens e com um domínio, este modelo abrange os itens $1,2,3,5,6,7,10,11,13,15,17$ e 18 , este modelo é conhecido como Short-Form (WOBY et al., 2005), o modelo 3) apresenta o melhor ajuste, também contém 12 itens, no entanto apresenta dois domínios: EM-1, 2, 10, 13, 15, 17 e 18; FS-3, 5, 6, 7 e 11 (VISSCHER et al., 2010).

Foram testados três modelos acima citados. Considerando os melhores índices de ajuste para estrutura de fatores avaliou-se os seguintes critérios: 1) Qui-quadrado (df); Critério de consistência de informação de de Akaike -CAIC; Índice de ajuste comparativo-CFI; Índice goodness of it -GFI; Índice de validação cruzada esperadaECVI; Erro médio quadrático de aproximação-RMSEA.O modelo com melhores índices foi o modelo 3. Foram observados maiores valores de CFI e GFI $(>0,90)$ e menores valores de qui-quadrado, CAIC e ECVI. Já o RMSEA para os três modelos demonstrou níveis aceitáveis inferiores a 0,08 (Tabela 7). 
Tabela 7. Análise fatorial confirmatória dos modelos de estrutura fatorial das versões da TSK-TMD-Br.

\begin{tabular}{|c|c|c|c|c|c|c|}
\hline & $X^{2}(\mathbf{d f})$ & CAIC & CFI & GFI & ECVI (IC90\%) & RMSEA (IC90\%) \\
\hline Modelo 1 & 1,61 & 4,28 & 0,88 & 0,80 & $2,94(2,57-3,38)$ & $0,07(0,59-0,98)^{*}$ \\
\hline Modelo 2 & 1,64 & 3,30 & $0,96 *$ & $0,93 *$ & $1,47(1,33-1,70)$ & $0,08(0,03-0,12)^{*}$ \\
\hline Modelo 3 & 1,57 & 3,46 & $0,97 *$ & $0,94 *$ & $1,49(1,36-1,70)$ & $0,07(0,02-0,12)^{*}$ \\
\hline \multicolumn{7}{|c|}{$\begin{array}{l}\text { Modelo1- Apresentou } 1 \text { domínio dos } 18 \text { itens da TSK/TMD; Modelo 2- Apresentou } 1 \text { domínio baseado e } \\
12 \text { itens da TSK/TMD; Modelo 3- Apresentou } 2 \text { domínios em } 12 \text { itens da TSK/TMD) }\end{array}$} \\
\hline
\end{tabular}

$\mathrm{Na}$ análise das cargas fatoriais da TSK/TMD-Br foi observado que as questões 1 , 2, 10,13,15, 17 e 18 se enquadraram em um domínio específico denominado Domínio Evitando Movimento (EM) (VISSCHER et al., 2010) subescala que reflete a crença de que a atividade ou movimento pode resultar em reicidiva da lesão ou em dor. Já as questões 3, 5, 6, 7 e 11 se enquadaram no domínio Foco Somático (FS), que reflete a crença de que há problemas de saúde graves subjacentes. Todos os itens apresentaram carga fatorial superior a 0,4 considerada adequada (MANLY, 1994). 
\begin{tabular}{l|l} 
Resultados & 63
\end{tabular}

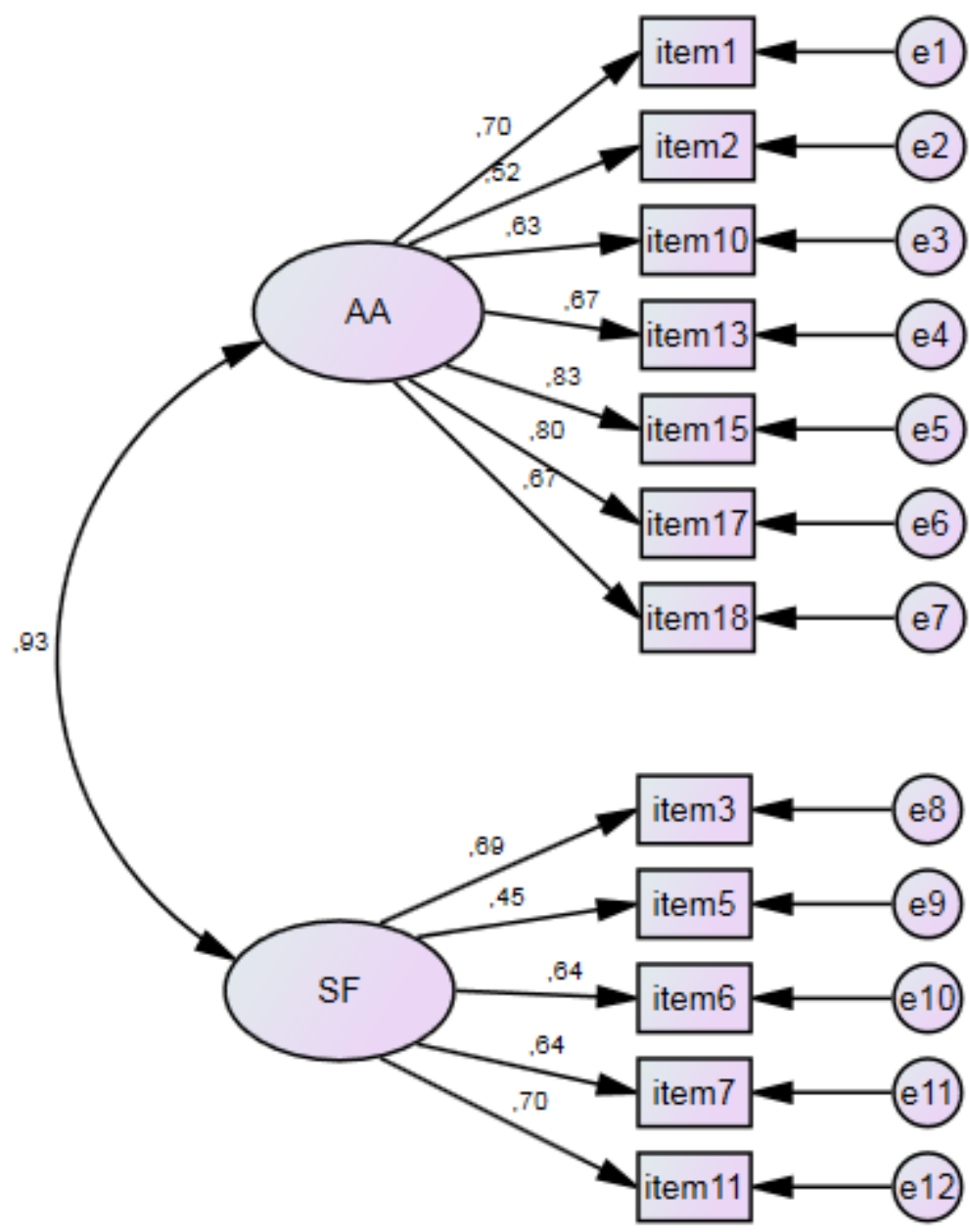

Figura 3. Análise Fatorial da TSK/TMD-Br

EM- Domínio Evitando Movimento; FS- Domínio Foco Somático

\subsection{Validade de Construto - Teste de Hipóteses}

Para verificação da Validade de Construto a pontuação total da TSK/TMD-Br e dos domínios foram correlacionados com as pontuações totais das seguintes ferramentas: Escala de Pensamento Catastrófico sobre a Dor (B-PCS), Questionário sobre a saúde do paciente (PHQ-8), Índice de Limitação Funcional Mandibular (MFIQ) e Pontuação do domínio intensidade, pontuação do domínio incapacidade e pontuação total da Escala Graduada de Dor Crônica (EGDC-Br) (Tabela 8). Foram definidas como hipóteses 
iniciais correlações positivas e moderadas entre o contruto cinesiofobia relacionada à DTM e os demais construtos (catastrofização, depressão, incapacidade relacionada à dor, incapacidade relacionda a DTM). Uma vez que não há na literatura outra opção de instrumento que avalie o construto cinesiofobia relacionada à DTM.

Confirmando nossa hipótese inicial foram observadas correlações positivas e moderadas entre o escore total da TSK-TMD-Br e escore do domínio FS e escore de catastrofização (BPCS), escore de depressão (PHQ-8) e de incapcaidade relacionada à DTM (MFIQ) (Tabela 8). Também foram observadas moderadas positivas entre o escore do domínio Evitando Movimento e os escores das escalas de catastrofização (BPCS) e de incapcaidade relacionada à DTM (MFIQ), entrentao foi observada correlação fraca entre o domínio Evitando Movimento e escore de depressão (PHQ-8) (Tabela 8). Para todas as correlações dos escores total e domínios da TSK-TMD-Br e o escore de incapacidade relacionada à dor (EGDC) foram observadas correlações positivas, significativas, porém fracas (Tabela 8).

A correlação do construto cinesiofobia apresentou-se postivo para todos os construtos, quando observou os valores da pontuação dos domínios da TSK/TMD-Br vs. domínios da B-PCS a correlação foi positiva e moderada para todos os itens (Tabela 9). 
Tabela 8. Valores de Correlação entre as pontuações totais e domínios da TSK/TMD-Br e os instrumentos Escala de Pensamento Catastrófico sobre a Dor (B-PCS), Questionário sobre a saúde do paciente (PHQ-8), Índice de Limitação Funcional Mandibular (MFIQ) e Pontuação do domínio intensidade, pontuação do domínio incapacidade e pontuação total da Escala Graduada de Dor Crônica (EGDC-Br) para n= 100 .

\begin{tabular}{lccc}
\hline Escalas & $\begin{array}{c}\text { TSK/TMD-Br } \\
\text { Activity Avoidance }\end{array}$ & $\begin{array}{c}\text { TSK/TMD-Br } \\
\text { Somatic Focus }\end{array}$ & $\begin{array}{c}\text { TSK/TMD-Br } \\
\text { Pontuação Total }\end{array}$ \\
\hline BPCS & $0,41^{* *}$ & $0,45^{* *}$ & $0,46^{* *}$ \\
PHQ-8 & $0,25^{* *}$ & $0,40^{* *}$ & $0,33^{* *}$ \\
MFIQ & $0,31^{* *}$ & $0,31^{* *}$ & $0,33^{* *}$ \\
EGDC- Intensidade & $0,18^{*}$ & $0,25^{*}$ & $0,22^{*}$ \\
EGDC- Incapacidade & $0,22^{*}$ & $0,23^{*}$ & $0,24^{*}$ \\
EGDC- Total & $0,22^{*}$ & $0,25^{*}$ & $0,25^{*}$ \\
& & & \\
\hline
\end{tabular}

* p $<0,05$, Correlação de Pearson

**p $<0,01$, Correlação de Pearson

n- números de indivíduos da amostra; BPCS- Escala de pensamento catastrófico sobre a dor; PHQ-

Questionário sobre a saúde do paciente; MFIQ- Índice funcional mandibular; EGDC- Escala graduada de dor crônica.

Tabela 9. Tabela de valores de correlação entre as pontuações totais e os domínios da TSK/TMD-Br e os domínios da ferramenta B-PCS para n=100.

$\begin{array}{lll}\text { TSK/TMD-Br } & \text { TSK/TMD-Br } & \text { TSK/TMD-Br }\end{array}$

EM FS Pontuação Total

\begin{tabular}{cccc}
\hline B-PCS & & & \\
\hline Magnificação & $0,47^{* *}$ & $0,45^{* *}$ & $0,49 * *$ \\
Ruminação & $0,37^{* *}$ & $0,39^{* *}$ & $0,40^{* *}$ \\
Desesperança & $0,34^{* *}$ & $0,41^{* *}$ & $0,39 * *$
\end{tabular}

\footnotetext{
**p $<0,01$, Correlação de Pearson

n-números de indivíduos da amostra; BPCS- Escala de pensamento catastrófico sobre a dor; EM-Evitando Movimento; FS-Foco Somático
} 


\subsection{Erro padrão da medida e Mínima Diferença Detectável}

Também foram analisados os valores de Erro Padrão da Medida (EPM) e Mínima Diferença Detectável (MDD) para os domínios e pontuação total da TSK/TMD-Br. O EPM/MDD foi de 0,94/2,60 para o domínio EM, para o domínio FS foi de 0,46/1,28 e para a pontuação total da escala foi de 1,17/3,24.

\subsection{Disfunção Temporomandibular e os subtipos de DTM}

Foi observado escore médio significativamente maior no grupo DTM mista em relação ao grupo DTM miogênica para a pontuação do domínio Evitando Movimento, pontuação total da TSK/TMD e MFIQ (Tabela 10). 
Tabela 10. Valores das diferenças nas pontuações das escalas entre os subgrupos DTM.

Subgrupos de DTM (n=100) IC95\%

\begin{tabular}{lcccc}
\hline Escalas & 1. Miogênico & 2. Artrogênico $(\mathbf{n}=12)$ & 3. Misto $(\mathbf{n = 4 4})$ & DTM $(\mathbf{n = 1 0 0})$ \\
& $(\mathbf{n = 4 4})$ & & & \\
\hline TSK/TMD-Br (AA) & $17,52(16,31-18,73)$ & $17,50(15,44-19,56)$ & $19,43(18,47-20,39)^{*}$ & $18,36(17,62-19,10)$ \\
TSK/TMD-Br (SF) & $12,40(11,68-13,12)$ & $11,66(10,66-12,66)$ & $13,45(12,72-14,18)$ & $12,78(12,30-13,26)$ \\
TSK/TMD-Br Pontuação total & $29,93(28,08-31,78)$ & $29,16(26,22-32,10)$ & $32,88(31,33-34,43)^{*}$ & $31,14(29,99-32,29)$ \\
BPCS & $30,63(26,68-34,58)$ & $25,50(19,94-31,06)$ & $32,59(29,12-36,06)$ & $30,88(28,46-33,30)$ \\
PHQ-8 & $10,84(8,84-12,84)$ & $8,25(4,58-11,92)$ & $11,79(9,76-13,82)$ & $10,95(9,62-12,28)$ \\
MFIQ & $13,81(10,39-17,23)$ & $14,08(11,05-17,11)$ & $21,43(17,86-25,0 * *$ & $17,20(14,89-19,51)$ \\
EGDC-Intensidade & $61,59(55,67-67,51)$ & $54,44(40,19-68,69)$ & $66,81(61,22-72,40)$ & $63,03(59,03-67,03)$ \\
EGDC-Incapacidade & $36,43(27,07-45,79)$ & $36,39(21,11-51,67)$ & $39,39(29,83-48,95)$ & $37,73(31,62-43,84)$ \\
EGDC- Classificação final & $1,13(0,77-1,49)$ & $0,91(0,30-1,52)$ & $1,22(0,84-1,60)$ & $1,15(0,91-1,39)$ \\
Intensidade da dor “agora” & $4,13(3,31-4,95)$ & $3,08(1,27-4,89)$ & $4,90(4,07-5,73)$ & $4,35(3,79-4,91)$ \\
Intensidade da dor na maioria & $6,38(5,72-7,04)$ & $5,25(3,98-6,52)$ & $6,52(5,85-7,19)$ & $6,31(5,87-6,75)$ \\
dos dias & & & & \\
\hline
\end{tabular}

* MANOVA, diferença em relação ao grupo DTM miogênica $(\mathrm{p}<0,05)$

n-número de indivíduos da amostra; DTM- Disfunção Temporomandibular; TSK/TMD- Escala Tampa de

Cinesiofobia para Disfunção Temporomandibular; AA- Domínio Activity Avoidance; SF- Domínio

Somatic Focus; BPCS- Escala de pensamento catastrófico sobre dor; PHQ- Questionário sobre a saúde do paciente; MFIQ- Índice de limitação funcional mandibular; EGDC- Escala graduada de dor crônica; IC95\%- Intervalo de Confiança 

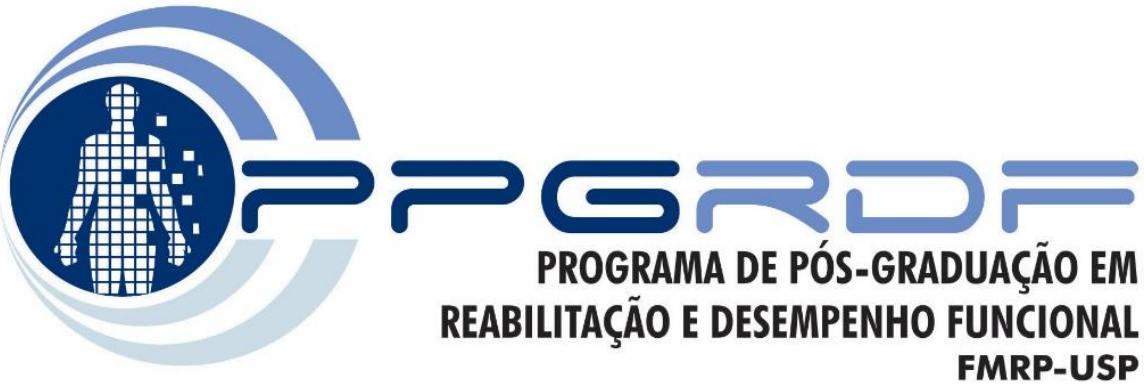

\section{DISCUSSÃ̃}

"Escrever é prolongar o tempo,

é dividi-lo em partículas de segundo,

dando a cada uma delas uma vida insubstituível."

Clarice Lispector 


\section{DISCUSSÃO}

O objetivo inicial deste trabalho foi realizar a adaptação transcultural para o português brasileiro da Tampa Scale for Kinesiophobia for Temporomandibular Disorders (TSK/TMD), originalmente elaborado em holandês. A adaptação seguiu as recomendações internacionais do COSMIN e Beaton et al. (2000), como já descrito anteriormente, e foi realizada concomitantemente a partir do questionário em inglês e holandês com o objetivo de tornar o processo o mais fidedigno possível.

A justificativa para realização deste estudo de adaptação e validação da TSK/TMD-Br para o português brasileiro está atrelada à importância de se avaliar cinesiofobia em pacientes com dores crônicas (SLADE et al., 2016), especialmente considerando-se que no Brasil não existem ferramentas disponíveis específicas para avaliação de cinesiofobia em pacientes com DTM. A disponibilização de uma ferramenta como a TSK/TMD-Br poderá auxiliar no entendimento dos aspectos psicossociais que acometem estes pacientes.

\subsection{Amostras do estudo e Diferenças entre os subgrupos de DTM}

Em nosso estudo consideramos participantes com diferentes perfis de escolaridade e pelo menos $20 \%$ da amostral total apresentou até 8 anos de escolaridade. O último senso do Instituto de Pesquisa Econômica Aplicada (IPEA) demonstrou que 20\% da população brasileira tem menos de 4 anos de escolaridade e a taxa de analfabetismo funcional de 10,7\% (IPEA, 2010). Dessa maneira, nossa amostra, contemplou a porcentagem de nível de escolaridade relatada pela pesquisa do IPEA na população brasileira na faixa etária economicamente ativa. Assim, como não foram relatadas dúvidas durante a aplicação da TSK/TMD-Br no pré-teste, exceto a dúvida sobre a localização da queixa de dor orofacial, 
é possível afimar que a ferramenta é de fácil entendimento para públicos de diferentes níveis de escolaridade.

No presente estudo incluímos participantes com diagnóstico de DTM crônica, considerando a amostra recrutada por Visscher et al. (2010). Não verificamos diferença significativa entre os subgrupos de DTM para catastrofização, depressão e nível de dor crônica, entretanto observamos diferenças no grupo de DTM mista para a TSK (pontuação total e domínio Evitando Movimento) e incapacidade mandibular (MFIQ). Esses resultados sugerem quadros de DTM mais complexos (miogênico e artrogênico) podem estar mais associados a fatores psicossociais, de acordo com o estudo OPPERA, um estudo prospectivo que envolve a avaliação de fatores de risco para o desenvolvimento da DTM que teve início em 2005 e os objetivos iniciais deste estudo foram determinar se características sócio-demográficas, resposta a estímulo nocivo, perfil psicossocial e variações genéticas estariam associados ao risco elevado de desenvolvimento de DTM e aumento da chance da pessoa apresentar DTM crônica. (SLADE et al., 2016), tornando reconhecido na literatura que os aspectos psicossociais podem influenciar no desenvolvimento de dor crônica, podendo influenciar no desenvolvimento inicial ou na transição da fase aguda para crônica, na manutenção da dor cônica e na pobre capacidade de resposta ao tratamento (SLADE et al., 2016). O modelo medo-evitação identifica a função da percepção negativa com a depressão e catastrofização no desenvolvimento da cinesiofobia (VLAEYEN et al., 1995), especificamente em pacientes com DTM, há um estudo que demonstra que os fatores psicossociais, como a depressão pode predizer a cronificação da DTM (FILLINGIM et al., 2013).

Por outro lado, não foram encontrados na literatuta consultada estudos que tenham verificado diferenças entre os subgrupos de indivíduos com DTM para aspectos 
psicossociais. Assim, futuros estudos precisam ser conduzidos para confirmação de nossos achados.

\subsection{Adaptação Transcultural da TSK/TMD versão português-Brasil}

As recomendações sugeridas pelo manual COSMIN (MOKKINK et al., 2010; TERWEE et al., 2012) foram seguidas para adequação transcultural. O COSMIN (MOKKINK et al., 2010) recomenda que a confiabilidade, consistência interna e validade estrutural (dentro da validade de construto) de ferramentas de avaliação em saúde sejam testadas.

Neste processo, foram necessárias poucas adaptações culturais para a língua portuguesa e apenas a inclusão da imagem da face na versão pré-final, sugerindo que o processo de tradução foi realizado de maneira adequada e que a ferramenta é de fácil entendimento. É possível que a expertise dos profissionais $(n=14)$ envolvidos no processo de tradução, retrotradução e reuniões do comitê de especialistas sobre o construto cinesiofobia relacionada à DTM possa ter contribuído para que o conteúdo original traduzido para o idioma Português-Brasil mantivesse os itens que representavam o construto na versão no idioma holandês. Esses ascpectos enfatizam a importância de seguir os critérios e recomendações descritos na literatura para realização de processos de adaptação transcultural (MOKKINK et al., 2010; BEATON et al., 2000).

No total 8 voluntárias relataram dificuldade de entender a localização da dor na mandíbula, o que resultou em $26 \%$ de dúvidas sobre o item considerando-se a amostra total de 30 indivíduos no pré-teste. Segundo Orfale et al. (2005), um índice de incompreensão de até $20 \%$ é aceitável, minimizando à necessidade de reaplicação do instrumento reformulado em nova amostra. Por isso, a sugestão foi acatada, levando a reformulação da ferramenta e os 8 voluntárias foram excluídos do estudo. 
Além disso, todo o processo de elaboração e construção da ferramenta foi realizado com a ativa participação do público-alvo da ferramenta (VISSCHER et al., 2010) o que pode ter contribuído para a disponibilização de uma ferramenta final adequada ao entendimento para avaliar cinesiofobia em pacientes com DTM. Assim, é possível considerar que a TSK/TMD-Br apresente níveis adequados de validade de conteúdo devido à contribuição da perspectiva dos pacientes no desenvolvimento do questionário. Não há versões em outras línguas da TSK/TMD e, dessa forma, não foi possível comparar se em outras línguas houve necessidade de grandes adaptações linguísticas na escala.

\subsection{Confiabilidade da TSK/TMD versão português-Brasil}

Quanto à confiabilidade da ferramenta, segundo o protocolo COSMIN (MOKKINK et al., 2010), o tamanho amostral para análise da confiabilidade da TSK/TMD-Br pode ser considerado adequado, tendo em vista que o n de 30 individuos é considerado como "bom" segundo essa recomendação. Os valores de confiabilidade dos domínios e da pontuação total do questionário demonstraram nível de concordância excelente (TERWEE et al., 2007; MAHER et al., 2007), atestando, portanto, a confiabilidade da TSK/TMD-Br. Na versão da TSK/TMD original (VISSCHER et al., 2010) a confiabilidade demontrada através do teste-reteste da ferramenta apresentou confiabilidade satisfatória para avaliação do modelo de 12 itens $(\mathrm{CCI}=0,73)$ e para os domínios da escala EM $(\mathrm{CCI}=0,67)$ e FS $(\mathrm{CCI}=0,71)$, o período de teste-reteste foi quatro semanas no estudo da ferramenta original, assim, os níveis mais elevados de confiabilidade observados em nosso estudo podem estar relacionados ao período de apenas uma semana entre as avaliações conduzidas no teste-reteste e, dessa maneira contribuindo para uma maior estabilidade do quadro clínico nos pacientes com DTM. 
Esse período de tempo do reteste foi determinado considerando-se que pacientes com dores crônicas podem apresentar alta variabilidade no sintoma ao longo do mesmo dia e entre dias diferentes (YAKUT et al., 2007).

Alguns estudos consideram intervalos de até cinco semanas para verificação da confiabilidade teste-reteste (MACDERMID et al., 2009), embora seja importante para compreender a estabilidade da medida em longo prazo, é necessário considerar que outros fatores podem contribuir aumentado o nível de viés dos resultados obtidos no testereteste. Os aspectos psicossociais e referencias múltiplas externas e internas podem influenciar na severidade da dor de um paciente ou dificuldade ao realizar uma tarefa que permaneça consistente ao longo de várias semanas. Assim, as mudanças nos fatores enfrentamento, auto-eficácia, ou suporte social podem contribuir para alterações na incapacidade e funcionalidade percebida ao longo de um período de cinco semanas. Entretanto, cabe destacar a importância de teste-reteste com períodos longos e curtos: estudos de confiabilidade com intervalos de teste-reteste mais longos são necessários para a determinação de intervalos de tempo adequados no delineamente experimental de ensaios clínicos, por outro lado, estudos realizados em intervalos mais curtos são mais apropriados para adequada estimativa de erro real da medida (MACDERMID et al., 2009).

\subsection{Consitência Interna, Validade Estrutural e Erro Padrão da Medida da}

\section{TSK/TMD-Br}

De acordo com COSMIN (MOKKINK et al., 2010), recomenda-se a análise da consistência interna de questionários que meçam construtos subjetivos em saúde. A consistência interna corresponde ao grau de correlação entre os itens de uma escala aplicada a um determinado grupo, supondo que seja proporcional a força de expressão da variável latente, desta forma, se os itens de uma escala estão fortemente relacionados com 
a variável latente, deverão também apresentar correlações consistentes entre si (DEVELLIS, 2003).

O coefiecinte alpha para a TSK/TMD-Br foi 0,78 para todos os dois domínios da escala. Estes valores indicam que a escala atingiu os valores de alpha recomendados por Terwee et al. (2007) ( $\alpha$ cronbach $>0,70)$. Os valores do alpha de Cronbach obtidos na versão original da ferramenta foi de 0,82 para o domínio EM e 0,66 para o domínio FS, indicando que nossos resultados estão em concordância com os achados de Visscher et al. (2010).

Os valores de alpha de Cronbach se o item for excluido variaram entre 0,74 e 0,86. Para os valores observados do alpha de Cronbach da Correlação Total do Item Corrigido (CTI) variou entre 0,54 e 0,75, com exceção do item 18 apresentou valor 1,0. O CTI mensura a correlação entre um item de uma escala e a pontuação total desta, excluindose os itens inferiores a 0,2 . Valores elevados (acima de 0,80 ) podem sugerir a necessidade de exclusão do item do questionário, por redundância. Assim, segundo os valores decritos na literatura a questão 18- "Tenho medo de abrir muito minha boca, porque é possível que eu não consiga fechá-la novamente”, poderia ser excluída do instrumento. Por outro lado, essa questão contempla aspecto importante em pacientes com DTM, especialmente para aqueles com tendências à subluxação da mandíbula e trata-se de um aspecto importante do contruto mensurado (medo de abrir a boca amplamente). Além disso, neste estudo realizou-se uma adaptação transcultural e, dessa forma, não é recomedada a exclusão de itens do instrumento testado. Os autores da ferramenta original não verificaram os valores de alpha de Cronbach se o item for excluido e o CTI, o que impossibilita comparações entre os estudos.

De acordo com o COSMIN, a validade estrutural é parte da validade de construto (MOKKINK et al., 2010), sendo que a análise fatorial exploratória ou confirmatória é o 
método geral de decomposição da variância de uma medida em um ou mais fatores comuns, e refletem aquilo que as variáveis compartilham, além de fatores únicos que normalmente descrevem a variância de uma medida que não é compartilhada por outras variáveis (NUNALLY e BERSTEIN, 1994).

Neste estudo foram verificados três fatores estruturais diferentes: Visscher et al. (2010), Vlaeyen et al. (1995) e Woby et al. (2005). A validade estrutural indica o grau em que as pontuações das ferramentas são um reflexo adequado da dimensionalidade do construto a ser medido (MOKKINK et al, 2012). No presente estudo foi utilizado a análise CFA, e o modelo conceitual pré-especificado de 12 itens e com dois domínios (EM e FS) foi confirmado. Além disso, no presente estudo todos os itens apresentaram uma carga fatorial superior a 0,4. De acordo com Mainly (1994) cargas fatoriais de 0,4 ou mais são aceitáveis e são consideradas representativos do construto a ser medido em cada domínio.

Em divergência com achados deste estudo, as cargas fatoriais dos itens 13 (Meus sintomas mandíbulares me avisam quando devo parar de mexer minha mandíbula para evitar que eи me machuque) e 17 (Ninguém que tenha problemas mandibulares, como o meu, deveria mexer sua mandíbula) da TSK/TMD versão original (Visscher et al., 2010) apresentaram valores inaceitáveis, os autores enfatizam a importância para esclarecer se esta é uma observação consistente e se esses itens podem ser omitidos para melhorar a TSK/TMD. Por outro lado, as cargas fatoriais da versão TSK/TMD-Br demosntrou valores aceitáveis para ambas as perguntas $(0,67$ e 0,80$)$. Pelo menos dois fatores poderiam explicar a diferença: em primeiro lugar, o uso de uma imagem que ilustra a região orofacial pode contribuir para uma melhor compreensão do significado, e em segunda, o procedimento de pré-teste em que os voluntários optaram na formulação mais adequada da questão 17, supõe-se que uma melhor compreensão dos conceitos subjacentes pode levar a um melhor ajuste da escala. 
Ainda dentro dos aspectos recomendados pelo consenso COSMIM (MOKKINK et al., 2010) faz-se necessária a avaliação do erro padrão da medida (EPM) e mínima diferença detectável (MDD). O EPM/MDD foi de 0,94/2,60 para o domínio Evitando o Movimento, para o domínio Foco Somático foi de 0,46/1,28 e para a pontuação total da escala foi de 1,17/3,24. Assim, para a TSK/TMD-Br as alterações minimamente relevantes a ser consideradas na pontuação do escore bruto total da escala total devem ser de 3,24, para o domínio EM 2,60 e para o domínio FS de 1,28. Nossos dados estão em concordância com relatos prévios sobre os valores de EPM da TSK. Woby et al. (2005) relataram valores de EPM de 3,16 para pontuação total da TSK-17 e para a versão reduzida (TSK-11) 2,54 em pacientes com dor lombar. Já a MDD foi descrita em pacientes com dor lombar como 9,2 para a pontuação total da TSK com 17 itens. Os valores mais elevados obtidos no estudo de Ostelo et al. (2007) podem ser atribuídos ao fato de que uma amostra de dor lombar aguda foi considerada

\subsection{Validade de Construto - teste de hipóteses da TSK/TMD-Br}

A validade de construto - teste de hipóteses é o grau com que escores de um instrumento se mostram consistentes com hipóteses prévias (exemplos: inter-relações internas da ferramenta, relações com escores de outros instrumentos ou diferenças entre grupos relevantes), baseando-se na suposição de que o instrumento em questão realmente mensura o construto específico (MOKKINK et al., 2010). Neste estudo adotamos a análise de validade de construto baseada na verificação de relação entre os escores da TSK/TMD-Br e os escores das seguintes ferramentas: BPCS- Escala de pensamento catastrófico sobre a dor; PHQ- Questionário sobre a saúde do paciente; MFIQ- Índice funcional mandibular; EGDC- Escala graduada de dor crônica. Assim foram 
estabelecidas hipóteses previas de correlação positivas e moderadas entre os instrumentos.

Para a TSK/TMD-Br vs. B-PCS, nossos achados comfirmam a hipótese inicial, já que foram verificadas correlações positivas e moderadas entre os construtos Cinesiofobia e Catastrofização de acordo com os valores da pontuação total da B-PCS e a pontuação total da TSK/TMD-Br $(\mathrm{R}=0,46)$, também apresentou correlação positiva e moderada com os domínios Evitando Movimento $(\mathrm{R}=0,41)$ e Somatic Focus $(\mathrm{R}=0,45)$. A Escala de Pensamento catastrófico sobre dor apresenta três subdomínios (Magnificação, Ruminação e Desesperança), que foram verificadas correlações positivas e moderadas quando comparados com os domínios da TSK/TMD-Br. No artigo da versão original da TSK/TMD, Visscher et al. (2010), relataram valores de correlação entre Catastrofização vs. pontuação total da TSK/TMD e do domínio Evitando Movimento positiva e fraca $(\mathrm{R}=$ $0,23, \mathrm{R}=0,12$, respectivamente). No entanto, quando correlacionado com o domínio Foco Somático o valor foi similar aos nossos achados $(R=0,33)$.

O fato da catastrofização melhor se correlacionar com o domínio Foco Somático segundo estes autores, é que este domínio representa a crença do paciente de que suas queixas estão relacionadas a problemas de saúde sérios, intimamente associados aos pensamentos catastróficos. Por outro lado, a evitação de movimento é uma reação frequentemente observada em pacientes com DTM, especialmente aqueles indivíduos que tentam evitar movimentos mandibulares por medo dos ruídos articulares ou medo da subluxação. Sugere-se que futuros estudos confirmem o nível de correlação esperado entre evitação de movimento e catastrofização. Assim nossos achados demontram haver uma correlação positiva e moderada entre B-PCS e os domínios da TSK/TMD, atigindo características psicométricas mais adequadas do que a versão original. Isso sugere que a 
a TSK/TMD-Br parece contemplar o construto cinesiofobia, já que foram confirmadas as hipóteses inicialmente pré-definidas.

Para a correlação entre os construtos depressão (PHQ-8, limitação funcional mandibular (MFIQ) vs. TSK/TMD-Br a hipótese estipulada inicialmente também foi de correlação positiva e moderada. No no geral foram confirmadas as hipóteses inicialmente estipuladas, exceto para pontuação do domínio Evitando Movimento e PHQ-8 (R=0,25) considerada uma correlação fraca. Também para a pontuação potal da TSK/TMD-Br e os seus domínios vs. Escala Graduada de Dor Crônica (EGDC), os nossos achados demontram haver uma correlação positiva e fraca entre os itens.

A correlação entre o construto cinesiofobia e os construtos observados neste estudo (depressão, limitação funcional mandibular e intensidade/incapacidade relacionada à dor crônica), não foram relatados no artigo original. Assim, não é possível comparar nossos resultados com achados prévios disponíveis na literatura.

No entanto, futuros estudos precisam ser conduzidos para se verificar a influência da cinesiofobia no curso da DTM e sua associação com outros fatores psicossociais. De acordo com o modelo de medo-evitação, é possível que percepções negativas tais como ansiedade e catastrofização levem ao medo-evitação que por sua vez pode levar a comportamentos deletérios e prejuízo da performance física, estes aspectos podem contribuir para prejuízos na realização das atividades de vida diárias ou para adoção de estratégias adaptativas de enfrentamento (VLAEYEN et al., 1995).

Esse estudo tem algumas limitações: 1)Responsividade da TSK/TMD-Br não foi valiada; 2)A Mínima Diferença Importante precisa ser conduzindo em análises baseadas em âncoras; 3)Este estudo foi realizado apenas com mulheres, tornando assim os resultados para pacientes do sexo masculino inviáveis. 


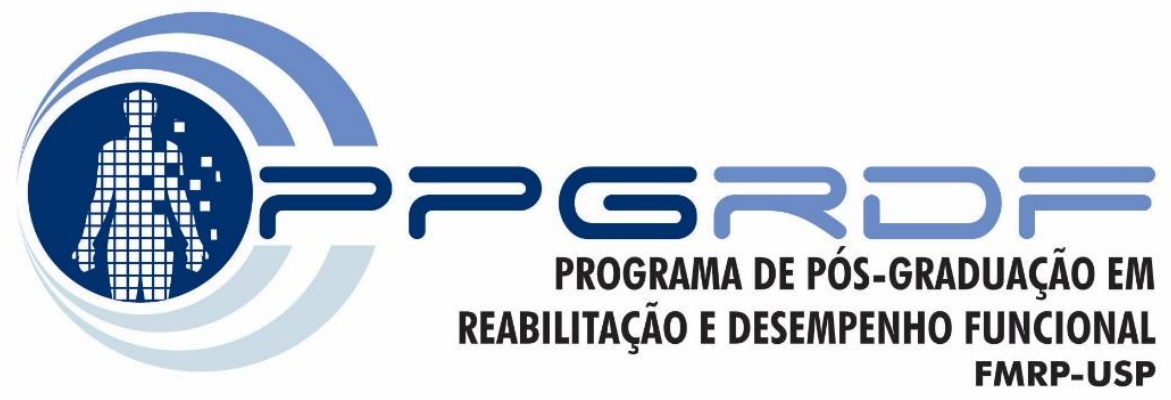

“A tarefa não é tanto ver aquilo que ninguém viu,

mas pensar o que ninguém ainda pensou

sobre aquilo que todo mundo vê."

Arthur Schopenhauer 


\section{CONCLUSÃO}

Em conclusão, os resultados deste estudo mostraram que a Tampa Scale for Kinesiophobia for Temporomandibular Disorders foi devidamente adaptada transculturalmente para o português-brasileiro segundo as recomendações internacionais do COSMIN e Beaton et al. (2000), e é um instrumento válido e confiável para avaliação de cinesiofobia entre pacientes com DTM.

As propriedades de medida (confiabilidade, consistência interna e análise estrutural) apresentaram resultados aceitáveis e, dessa forma, sugere-se que a TSK/TMDBr pode ser comparável a versão original. E desta forma, recomenda-se seu uso na prática clínica e pesquisa em pacientes com Disfunção Temporomandibular. 


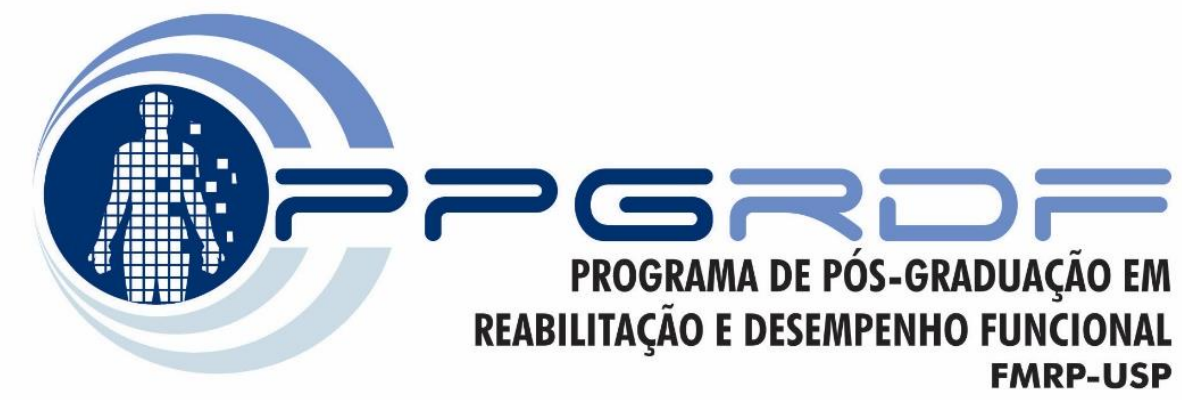

"Amanhecer é uma lição do universo,

que nos ensina que é preciso renascer"

Renato Teixeira 
Referências $\mid 82$

\section{REFERÊNCIAS}

1. ALEXANDRE NMC, COLUCI MZO. Validade de conteúdo nos processos de construção e adaptação de instrumentos de medidas. Ciênc Saúde Colet. 16(7):30613068, 2011.

2. BEATON, D. E. et al. Guidelines for the process of cross-cultural adaptation of selfreport measures. Spine. Hagerstown. v. 25, n. 24, p. 3186-3191, Dec. 2000.

3. BEATON, D. et al. Recommendations for the Cross-Cultural Adaptation of Health Status Measures. American Academy of Orthopaedic Surgeons Institute for Work \& Health. Rosemont. p. 1-36, 2002.

4. BEVILAQUA-GROSSI D, CHAVES TC, OLIVEIRA AS. Cervical spine signs and symptoms: perpetuating rather than predisposing factors for temporomandibular disorders in women. J. Appl. Oral Sci. vol.15, n.4, pp. 259-264, 2007.

5. BULLINGER M, ALONSO J, APOLONE G, LEPLÈGE A, SULLIVAN M, WOODDAUPHINEE S, GANDEK B, WAGNER A, AARONSON N, BECH P, et al. Translating health status questionnaires and evaluating their quality: The IQOLA project approach. J Clin Epidemiol. 51:913-923, 1998.

6. CAMPOS JA, CARRACOSA AC, MAROCO J. Validity and reliability of the Portuguese version of Mandibular Function Impairment Questionnaire. J Oral Rehabil. 39(5):377-83, 2012.

7. CLARK ME, KORI SH, BROECKEL J. Kinesiophobia and chronic pain: psychometric characteristics and factor analysis of the Tampa scale. In: 15th Annual Scientific Meeting of the American Pain Society. Washington: American Pain Societ. p.16-27,1996. 


\section{Referências $\mid$}

8. CLARK, L. A.; WATSON, D. Constructing validity: basic issues in objective scale development. In: KAZDIN, A. E. (Org.). Methodological Issues and Strategies in Clinical Research. Washington (DC): 2nd ed. American Psychological Association, p. 215-239, 1998.

9. CHAVES TC, OLIVEIRA AS, BEVILAQUA-GROSSI D. Principais instrumentos para avaliação da disfunção temporomandibular, parte II: critérios diagnósticos, uma contribuição para a prática clínica e de pesquisa. Fisioterapia e Pesquisa. v.15, n.1, p.101-6, 2008.

10. CROMBEZ G, VLAEYEN JW, HEUTS PH, LYSENS R. Pain-related fear is more disabling than pain itself: evidence on the role of pain-related fear in chronic back pain disability. Pain. 80:329-39, 1999.

11. DANCEY, C.P.; REIDY, J. Statistics without maths for psychology: Using SPSS for Windows. New York: Prentice Hall, 2004.

12. DE LEEUW R. Dor orofacial: guia de avaliação, diagnostico e tratamento. $4^{\circ}$ ed. São Paulo: Quintessence, 2010.

13. DEVELLIS RF. Scale development: Theory and applications. $2^{\text {nd }}$ ed. Thousand Oaks: Sage Publications, 2003.

14. DE VET , H. C. et al. Measurement in Medicine: a practical guide. Cambridge University Press, 2011.

15. DURHAM J, STEELE JG, WASSELL RW, EXLEY C. Living With Uncertainty: Temporomandibular Disorders. J Dent Res. 89(8):827-30, 2010.

16. DWORKIN SF, LERESCHE L. Research Diagnostic Criteria for temporomandibular disorders: review, criteria, examinations and specifications, critique. Journal Temporomandibular disorders: Facial and Oral pain. v.6, n.4, p.300-55, 1992.

17. DWORKIN SF. The Oppera study act one. J. Pain. v.12, n.11, nov.,2011. 
Referências $\mid 84$

18. EGERMARK I, CARLSSON GE, MAGNUSSON T. A 20-Year Longitudinal Study

Of Subjective Symptoms Of Temporomandibular Disorders From Childhood To Adulthood. Acta Odontol Scand. 59:40-8, 2001.

19. EREMENCO SL, CELLA D, ARNOLD BJ. A comprehensive method for the translation and cross-cultural validation of health status questionnaires. Evaluation \& the Health Professions, 28(2), 212-232, 2005.

20. FERNÁNDEZ-DE-LAS-PEÑAS C, GALÁN-DEL-RÍO F, FERNÁNDEZCARNERO J, PESQUERA J, ARENDT-NIELSEN L, SVENSSON P. Bilateral widespread mechanical pain sensitivity in women with myofascial temporomandibular disorder: evidence of impairment in central nociceptive processing. J Pain. v. 10, n.11, p.1170-8, 2009.

21. FERNÁNDEZ-DE-LAS-PEÑAS C, GALÁN-DEL-RÍO F, ORTEGA-SANTIAGO R, JIMÉNEZ-GARCÍA R, ARENDT- NIELSEN L, SVENSSON P. Bilateral Thermal Hyperalgesiain Trigeminal And Extra-Trigeminal Regions In Patients With Myofascial Temporomandibular Disorders. Exp Brain Res. 202(1):171-9, 2010.

22. FILLINGIM RB, SLADE GD, DIATCHENKO L, DUBNER R, GREENSPAN JD, KNOTT C et al. Summary of findings from the OPPERA baseline case-control study: implications and future direc-tions. J Pain. 12:102-107, 2011.

23. FLEISS J.L., LEVIN B., PAIK M.C. Statistical Methods for Rates and Proportions. Hoboken, New Jersey: John Wiley \& Sons, Inc., 2003.

24. FRICTON JR, SCHIFFMAN EL. Epidemiologia das desordens temporomandibulares. In: FRICTON JR, DUBNER R. Dor Orofacial e Desordens Temporomandibulares. São Paulo: Santos. p.1-15, 2003. 
Referências

25. GLIEM, J. A.; GLIEM, R. R. Calculating, interpreting, and reporting Cronbach's alpha reliability coefficient for Likert-type scales. Midwest Research-to-Practice Conference in Adult, Continuing, and Community Education, 2003.

26. GONÇALVES DA, SPECIALI JG, JALES LC, CAMPARES CM, BIGAL ME. Temporomandibular symptoms, migraine and chronic daily headaches in the population. Neurology. 73(8): 645-6, 2009.

27. GUILLEMIN, F.; BOMBARDIER, C.; BEATON, D. Cross-Cultural Adaptation of Health-Related Quality of Life Measures: Literature Review and Proposed Guidelines. J Clin Epidemiol. Oxford. v. 6, n. 12, p. 1417-1432, 1993.

28. HAYNES, S. N.; RICHARD, D. C. S.; KUBANY, E. S. Content Validity in Psychological Assessment: A Functional Approach to Concepts and Methods. Psychological Assessment. Washington. v. 7, n. 3, p. 238-247, 1995.

29. HAUGEN AJ, GROVLE L, KELLER A, \& GROTLE M. Cross-cultural adaptation and validation of the Norwegian version of the Tampa scale for kinesiophobia. Spine. 33(17), E595-601, 2008.

30. HEUTS PH, VLAEYEN JW, ROELOFS J, DE BIE RA, ARETZ K, van WEEL C, van SCHAYCK OC. Pain-related fear and daily functioning in patients with osteoarthritis. Pain. 110:228-35, 2004.

31. HILGENBERG PB, CUNALI RS, BONOTTO D, FARIAS AC, CUNALI PA. Temporomandibular disorders and pregnancy. Ver Dor. 13(4):371-373, 2012.

32. INGAWALE S, GOSWAMI T. Temporomandibular joint: disorders, treatments, and biomechanics. Ann. Biomed Eng. v.37, p.976-996, 2009.

33. IPEA. Instituto de Pesquisa Econômica. Secretaria de Assuntos Estratégicos da Presidência da República. Evolução do analfabetismo e do analfabetismo funcional no Brasil Período 2004-2009. Comunicados IPEA. Brasília, 2010. 
Referências 86

http://www.ipea.gov.br/portal/images/stories/PDFs/comunicado/101209_comunicadoip ea70.pdf. Acesso em 10/04/2016

34. JOHN MT, REISSMAN DR, SCHIERZ O, WASSELL RW. Oral healthrelated quality of life in patients with temporomandibular disorders. J Orofac Pain. v.21,n.1, p.46-54, 2007.

35. LIMA OF, VILELA MA, CRIPPA JA, LOUREIRO SR. Study of the discriminative validity of the PHQ-9 and PHQ-2 in a sample of Brazilian women in the context of primary health care. Perspect Psychiatr Care. 45:216-27, 2009.

36. LUNDBERG MKE, STYF J, CARLSSON SG. A psychometric evaluation of the Tampa Scale for Kinesiophobia-from a physiotherapeutic perspective. Physiotherapy Theory and Practice. 20, 121-133, 2004.

37. MACDERMID, J.C.; et al. Measurement properties of the neck disability index: a systematic review. Journal of Orthopedics \& Sports Physical Therapy. Washington. v. 39, n.5, p.400-17, 2009.

38. MACFARLANE TV, GLENNY AM, WORTHINGTON HV. Systematic review of population-based epidemiological studies of oro-facial pain. J Dent. 29(7):451-467, 2001.

39. MAHER, C.G.; LATIMER, J. COSTA, L.O.P. The relevance of cross-cultural adaptation and clinimetrics for physical therapy instruments. Revista Brasileira de Fisioterapia. São Carlos. v.11, p.245-52, 2007.

40. MANFREDINI D, GUARDA-NARDINI L, WINOCUR E, et al. Research Diagnostic Criteria For Temporomandibular Disorders: A Systematic Review Of Axis I Epidemiologic Findings. Oral Surg Oral Med Oral Pathol Oral Radiol Endod. 112: 453-462, 2011. 
Referências

41. MANLY, B.F.J. Factor analysis. In: MANLY B.F.J, editor. Multivariate statistical methods. A primer. London, United Kingdom: Chapman \& Hall. p. 93-106, 1994.

42. MCNEELY ML, ARMIJO Olivo S, MAGEE DJ. A systematic review of the effectiveness of physical therapy interventions for temporomandibular disorders. Phys Ther. 86(5): 710-25,2006.

43. MILLER RP, KORI S, TODD D. The Tampa Scale: a measure of kinesiophobia. Clin J Pain. 7:51-52, 1991.

44. MOKKINK, L. B. et al. The COSMIN checklist for evaluating the methodological quality of studies on measurement properties: a clarification of its content. BMC Med Res Methodol. London. v. 18, p. 10-22, Mar. 2010.

45. MOKKINK, L. B. et al. COSMIN checklist manual. Amsterdam. VU University Medical Center. 2012.

46. NEVO B. Face validity revisited. Journal of Educational Measurement. Malden. v. 22, p. 287-293, 1985.

47. NUNALLY JC, BERTEIN IH. Psychometric theory. $3^{\text {rd }}$ ed. New York: McGrawHill; 1994.

48. OSTELO RW, SWINKELS-MEEWISSE IJ, KNOL DL, VLAEYEN JW, DE VET HC. Assessing pain and pain-related fear in acute low back pain: what is the smallest detectable change? Int J Behav Med. 2007;14(4):242-8.

49. ORFALE, A. G. et al. Translation into Brazilian Portuguese, cultural adaptation and evaluation of the reliability of the Disabilities of the Arm, Shoulder and Hand Questionnaire. Braz J Med Biol Res. São Paulo. v. 38, n. 2, p. 293-302, 2005.

50. OKESON JP. Dor orofacial: Guia De Avaliação, Diagnóstico e tratamento. São Paulo: Quintessence; 2003 
Referências $\mid 88$

51. PICAVET HS, VLAEYEN JW, SCHOUTEN JS. Pain catastrophizing and kinesiophobia: predictors of chronic low back pain. Am J Epidemiol. 156:1028-34, 2002.

52. PICON, P. et al. The Portuguese language version of social phobia and Anxiety Inventory: analysis of items and internal consistency in a Brazilian sample of 1,014 undergraduate students. Jornal Brasileiro de Psiquiatria. Rio de Janeiro. v. 55, n. 2, p. 114-119, 2006.

53. PINCUS T, VOGEL S, BURTON AK, SANTOS R, FIELD AP. Fear avoidance and prognosis in back pain: a systematic review and synthesis of current evidence. Arthritis Rheum. 54:3999-4010, 2006.

54. REICHENHEIM ME, MORAES CL. Operacionalização de adaptação transcultural de instrumentos de aferição usados em epidemiologia. Revista de Saúde Pública. 41(4): 665-73, 2007.

55. ROELOFS J, SLUITER JK, FRINGS-DRESEN MH, GOOSSENS M, THIBAULT P, BOERSMA K, VLAEYEN JW. Fear of movement and (re)injury in chronic musculoskeletal pain: evidence for an invariant two-factor model of the Tampa Scale for Kinesiophobia across pain diagnoses and Dutch, Swedish, and Canadian samples. Pain. 131:181-90, 2007.

56. SCHERMELLEH-ENGEL K, MOOSBRUGGER H, MÜLLER H. Evaluating the fit of structural equation models: test of significance and descriptive goodness-of-fit measures. MPR-Online. 8:23-74,2003.

57. SCHIFFMAN E. et al. Diagnostic Criteria For Temporomandibular Disorders (Dc/Tmd) For Clinical And Research Applications: Recommendations Of The International Rdc/Tmd Consortium Network* And Orofacial Pain Special Interest Group †. Journal Of Oral \& Facial Pain And Headache. 28(1): 6-27, 2014. 
Referências

58. SEHN F, CHACHAMOVICH E, VIDOR LP, DALL-AGNOL L, De SOUZA IC, Torres IL, Fregni F, Caumo W. Cross-cultural adaptation and validation of the Brazilian Portuguese version of the pain catastrophizing scale. Pain Med. 13:1425-35, 2012.

59. SIQUEIRA FB, TEIXEIRA-SALMELA LF, MAGALHÃES LC. Análise das propriedades psicométricas da versão brasileira da escala tampa de cinesiofobia. ACTA Ortop Bras. 15(1) 19-24, 2007.

60. SLADE GD, OHRBACH R, GREENSPAN JD, FILLINGIM RB, BAIR E, SANDERS AE, DUBNER R, DIATCHENKO L, MELOTO CB, SMITH S, MAIXNER W. Painful Temporomandibular Disorder: Decade of Discovery from OPPERA Studies. J Dent Res. 95:1084-1092, 2016.

61. STUDART L, ACIOLI MD. A Comunicação Da Dor: Um Estudo Sobre As Narrativas Dos Impactos Da Disfunção Temporomandibular. Interface. 15(37): 487-503, 2011.

62. SULLIVAN MJL, BISHOP SR. The Pain Catastrophizing Scale: Development and validation. Psychological Assessment. 7: 524-532, 1995.

63. SWINKELS-MEEWISSE EJ, SWINKELS RA, VERBEEK AL, VLAEYEN JW, OOSTENDORP RA. Psychometric properties of the Tampa Scale for kinesiophobia and the fear-avoidance beliefs questionnaire in acute low back pain. Man Ther. 8:2936,2003 .

64. TERWEE, C. B. et al. Rating the methodological quality in systematic reviews of studies on measurement properties: a scoring system for the COSMIN checklist. Qual Life Res. Oxford. v. 21, n. 4, p. 651-657, 2012.

65. TERWEE, C. B. et al. Quality criteria were proposed for measurement properties of health status questionnaires. Journal of Clinical Epidemiology. Oxforf. v. 60, p. 34-42, 2007. 
Referências $\mid 90$

66. VISSCHER CM, OHRBACH R, van WIJK AJ, WILKOSZ M, NAEIJE M. The Tampa Scale for Kinesiophobia for Temporomandibular Disorders (TSK-TMD). Pain. 492-500, 2010.

67. VLAEYEN JW, CROMBEZ G. Fear of movement/(re)injury, avoidance and pain disability in chronic low back pain patients. Man Ther. 4:187-95,1999.

68. VLAEYEN JW, KOLE-SNIJDERS AM, BOEREN RG, VAN EH. Fear of movement/(re)injury in chronic low back pain and its relation to behavioral performance. Pain. 62:363-72,1995.

69. VON KORFF M. Epidemiological and survey methods assessment of chronic pain. In: Turk DC, Melzack R. Handbook of pain assessment. New York: The Guildford Press. 603-618, 2001.

70. WADHWA S, KAPILA S. TMJ Disorders: Future Innovations In Diagnostics And Therapeutics. J Dent Educ. 72(8): 930-47, 2008.

71. WARE JE, JR.; SHERBOURNE, C.D. The MOS 36-item short-form health survey (SF-36). I. Conceptual framework and item selection. Medical Care. Philadelphia. v.30, n.6, p.473-83, 1992.

72. WEIR JP. Quantifying test-retest reliability using the intraclass correlation coefficient and the SEM. Journal of Strength Conditioning Research. 2005; 19(1):231-40.

73. WOBY SR, ROACH NK, URMSTON M, WATSON PJ. Psychometric properties of the TSK-11: a shortened version of the Tampa Scale for Kinesiophobia. Pain. $2005 ; 117: 137-44$.

74. YAKUT, Y.; et al. Reliability and validity of the Turkish version short-form McGill pain questionnaire in patients with rheumatoid arthritis. Clinical Rheumatology. Heidelberg. v.26, n.7, p. 1083-7, 2007. 
Referências $\mid 91$

75. YAP AU, CHUA EK, TAN KB, CHAN YH. Relationships between depression/somatization and self-reports of pain and disability. J Orofac Pain, v.18, n.3, p.220-5, 2004. 


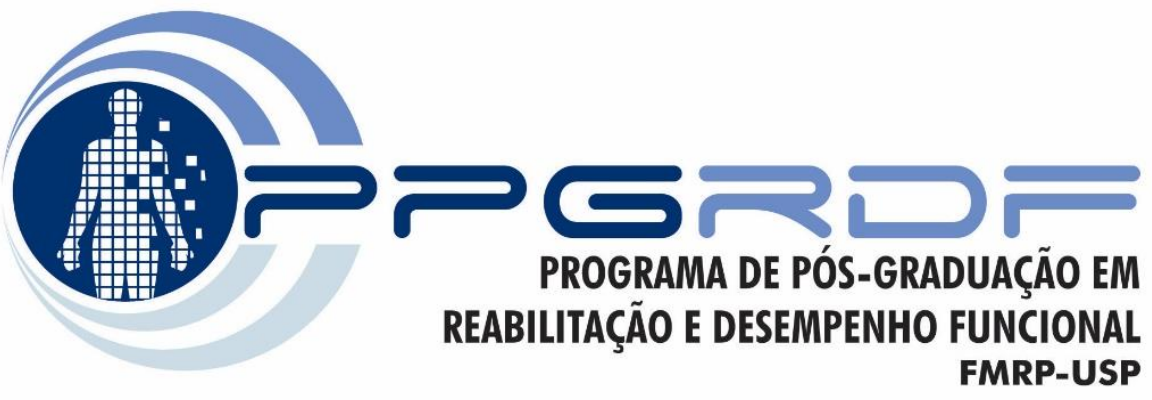

ANEXOS e APÊNDICES

“Todas as vitórias ocultam uma abdicação."

Simone de Beauvoir 


\section{ANEXO A - Autorização para realização da tradução e adaptação transcultural}

\section{da TSK/TMD.}

Re: Permission to perform a transcultural of the tampa kinesiophobia scale for TMD

De : Thais Cristina Chaves

<chavestc@fmrp.usp.br>

Assunto : Re: Permission to perform a transcultural of

the tampa kinesiophobia scale for TMD

Para : C.M. Visscher <c.visscher@acta.nl>

Dear Prof. Corine Visscher

Thanks for attention and permission. We have been following your work (and

appreciate it) and we will appreciate your collaboration during this work.

As Beaton et al (2000) recommended, we will send to you reports about the stages of transcultural adaptation and possible doubts that can arise during the process.

Feel free to make suggestions.

Sincerely yours,

-..-- Mensagem original -....

De: "C.M. Visscher" <c.visscher@acta.nl>

Para: "Thais Cristina Chaves" <chavestc@fmrp.usp.br>

Enviadas: Terça-feira, 20 de Novembro de 2012 7:30:26

Assunto: RE: Permission to perform a transcultural of the tampa kinesiophobia scale for

TMD

Dear prof. Thais Chaves,

I give permission for the transcultural adaptation of the TSK TMD. I don't think you need permission from the authors of the original one (you could give reference to them in your publication), but if you want to be sure, you need to contact them.

Sincerely,

Dr. Corine Visscher

Department of Oral Kinesiology

Academic Centre for Dentistry Amsterdam (ACTA)

University of Amsterdam and VU University,

MOVE Research Institute Amsterdam,

Gustav Mahlerlaan 3004

1081 LA Amsterdam

The Netherlands

Tel: +31205980412 


\section{ANEXO B-Aprovação do Comitê de Ética}

\section{HOSPITAL DAS CLINICAS DA FACULDADE DE MEDICINA DE RIBEIRÃO PRETO DA UNIVERSIDADE DE SẢO PAULO}

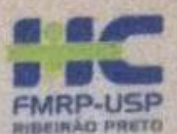

Ribeirão Preto, 03 de setembro de 2014

Oficio $\mathrm{n}^{\circ} 3186 / 2014$

CEP/MGV

\section{PROCESSO HCRP $\mathrm{n}^{\circ} 2721 / 2014$}

Prezados Pesquisadores,

O trabalho intitulado "ADAPTAÇÃo TRANSCULTURAL PARA O PORTUGUESS DA TAMPA SCALE FOR KINESIOPHOBIA FOR TEMPOROMANDIBULAR DISORDERS (TSK-TMD)", foi analisado pelo Comitê de Ética em Pesquisa, em sua 393" Reuniào Ordinaria realizada em 01/09/2014, e enquadrado na categoria: APROVADO, bem como o Termo de Consentimento Livre e Esclarecido 4 de 06 de agosto de 2014.

Bste Comite segue integralmente a Conferencia Internacional de Harmonizaçao de Boas Praticas Clínicas (IGH-GCP), bem como a Resoluçao $n^{\circ}$ 196/96 CNS/MS.

Lembramos que devem ser apresentados a este CEP, o Relatório Pancial e Relatorio Final da pesquisa. De acordo com Carta Circular $n^{\circ}$ $003 / 2011 / C O N B P / C N S$, datada de 21/03/2011, o sujeito de pesquisa ou seu representante, quando for o caso, deverá rubricar todas as folhas do Termo de Consentimento Liure e Esclarecido - TCLE - apondo sua assinatura na última do referido Termo; o pesquisador responsável devera da mesma forma, rubricar todas as folhas do Termo de Consentimento Livre e Esclarecido - TCLE - apondo sua assinatura na última pagina do referido Termo.

Atenciosamente.

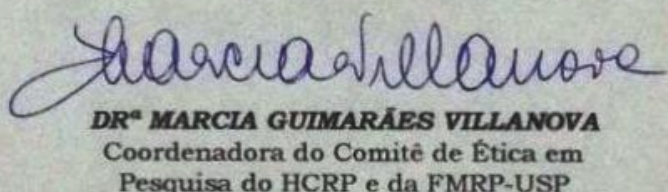

Ilustrissimos Senhores

PROF* DR. THAIS CRISTINA CHAVES

AROLDO DOS SANTOS AGULAR (Aluno)

Depto. de Neurociências e Ciências do Comportamento Campus Universitilio - Monte Avegre
$14048-900$ Ribeirlo Proto SP
Comite de Etica em Posquisa do HCRP o FMRP.USP FWA-00002733, IRB-00002 186 e Registro PBICONEP n' 5440 (016) $3602-2228$ 


\section{Anexo C- Versão Inglês da Tampa Scale for Kinesiophobia for}

\section{Temporomandibular Disorders (TSK/TMD).}

\section{Tampa Scale for Kinesiophobia: Temporomandibular Disorders}

Jaw problems can cause many difficulties in different ways. From the list below, please indicate which.

Jaw problems are giving you trouble (circle yes or no; multiple "yes" responses are possible.

- jaw pain

Yes No

- noises in my jaw when I move my mouth (e.g., clicking or crunching) Yes No

- lower jaw is stuck or locked such that it cannot be opened or closed any further

Yes No

other jaw problem - please describe:

For each of the statements below, please indicate how much you agree or disagree.

Please use the following scale:

1. Strongly disagree

2. Disagree

3. Agree

4. Strongly agree

\begin{tabular}{|c|c|c|c|c|c|}
\hline 1 & I am afraid that I might injure myself if I move my jaw. & 1 & 2 & 3 & 4 \\
\hline 2 & If I ignored my jaw symptoms, they would get worse. & 1 & 2 & 3 & 4 \\
\hline 3 & My jaw is telling me that something is seriously wrong with it. & 1 & 2 & 3 & 4 \\
\hline 4 & $\begin{array}{l}\text { My jaw symptoms would probably be better if I moved my jaw } \\
\text { more. }\end{array}$ & 1 & 2 & 3 & 4 \\
\hline 5 & Other people do not take my jaw symptoms seriously enough. & 1 & 2 & 3 & 4 \\
\hline 6 & $\begin{array}{l}\text { My jaw symptoms have put my health at risk for the rest of my } \\
\text { life. }\end{array}$ & 1 & 2 & 3 & 4 \\
\hline 7 & My jaw symptoms mean that I have injured my jaw. & 1 & 2 & 3 & 4 \\
\hline 8 & $\begin{array}{l}\text { Just because something aggravates my jaw symptoms does not } \\
\text { mean that it is harmful. }\end{array}$ & 1 & 2 & 3 & 4 \\
\hline 9 & I am afraid that I might accidentally injure my jaw. & 1 & 2 & 3 & 4 \\
\hline 10 & $\begin{array}{l}\text { The safest way to prevent my symptoms from getting worse is to } \\
\text { be careful and not to move my jaw any more than necessary. }\end{array}$ & 1 & 2 & 3 & 4 \\
\hline
\end{tabular}


Apêndices 96

\begin{tabular}{|c|c|c|c|c|c|}
\hline 11 & $\begin{array}{l}\text { I would not have this many jaw symptoms if there was not } \\
\text { something potentially harmful going on. }\end{array}$ & 1 & 2 & 3 & 4 \\
\hline 12 & $\begin{array}{l}\text { Although I have jaw symptoms I would be better off if I kept } \\
\text { using my mouth normally. }\end{array}$ & 1 & 2 & 3 & 4 \\
\hline 13 & $\begin{array}{l}\text { My jaw symptoms let me know when to stop moving my jaw so } \\
\text { that I do not injure myself. }\end{array}$ & 1 & 2 & 3 & 4 \\
\hline 14 & $\begin{array}{l}\text { It is really not safe for someone with a jaw condition like mine to } \\
\text { use the mouth a lot. }\end{array}$ & 1 & 2 & 3 & 4 \\
\hline 15 & $\begin{array}{l}\text { I cannot do everything other people can do, because it is too } \\
\text { easy for me to injure my jaw. }\end{array}$ & 1 & 2 & 3 & 4 \\
\hline 16 & $\begin{array}{l}\text { Even if doing something aggravates my jaw symptoms, I do not } \\
\text { think that it is harmful. }\end{array}$ & 1 & 2 & 3 & 4 \\
\hline 17 & $\begin{array}{l}\text { No one should have to move the jaw when he/she has a jaw } \\
\text { problem. }\end{array}$ & 1 & 2 & 3 & 4 \\
\hline 18 & $\begin{array}{l}\text { I am afraid to open my mouth wide because then I may not be } \\
\text { able to close it again. }\end{array}$ & 1 & 2 & 3 & 4 \\
\hline
\end{tabular}




\section{ANEXO D - Versão Dutch da Tampa Scale for Kinesiophobia for Temporomandibular Disorders (TSK/TMD).}

Tampa schaal voor Kinesiofobie: Temporomandibulaire Dysfunctie:

TMD symptomen checklist:

Kaakklachten Kunnen zich op verschillende manieren uiten. Wilt u in onderstaand lijstje aangeven waar u last van heft (meerdere antwoorden mogelijk):

*pijn

*geluiden in mijn kaak tijdens bewegingen van de mond (bv. Knappen of kraken)

*vastzitten of blokkeren van de onderkaak, zodat hij niet meer vender open of dicht kan ja nee

*anders, namelijk:

Geef van onderstaande beweringen ann in welke mate $u$ het eens of oneens bent met deze bewering. De betekenis van de cijfers is als volgt:

1. In hoge mate mee oneens

2. Enigszins mee oneens

3. Enigszins mee eens

4. In hoge mate mee eens

\begin{tabular}{|l|l|l|l|l|l|}
\hline 1. & $\begin{array}{l}\text { Ik ben bang om bij het uitvoeren van kaakbewegingen letsel op te } \\
\text { lopen }\end{array}$ & 1 & 2 & 3 & 4 \\
\hline 2. & Als ik mijn kaakklachten zou negeren, dan zouden ze erger worden & 1 & 2 & 3 & 4 \\
\hline 3. & Mijn kaak zegt me date r iets gevaarlijk mis mee is & 1 & 2 & 3 & 4 \\
\hline 4. & $\begin{array}{l}\text { Mijn kaakklachten zouden waarschijnlijk minder worden als ik mijn } \\
\text { kaak meer zou bewegen }\end{array}$ & 1 & 2 & 3 & 4 \\
\hline 5. & Mijn kaakklachten worden door anderen niet serieus genoeg genomen & 1 & 2 & 3 & 4 \\
\hline 6. & $\begin{array}{l}\text { Door mijn kaakklachten loopt mijn gezondheid de rest van mijn leven } \\
\text { gevaar }\end{array}$ & 1 & 2 & 3 & 4 \\
\hline 7. & Mijn kaakklachten betekenen date r sprake is van letsel & 1 & 2 & 3 & 4 \\
\hline 8. & $\begin{array}{l}\text { Als iets mijn kaakklachten vererget, betekent dat nog niet dat het } \\
\text { gevaarlijk is }\end{array}$ & 1 & 2 & 3 & 4 \\
\hline 9. & Ik ben bang om per ongeluk letsel aan mijn kaak op te lopen & 1 & 2 & 3 & 4 \\
\hline 10. & $\begin{array}{l}\text { De veiligste manier om te voorkomen dat mijn klatchten erger worden } \\
\text { is genoon oppassen dat ik geen onnodige bewegingen met mijn mond } \\
\text { maak }\end{array}$ & 1 & 2 & 3 & 4 \\
\hline 11. & $\begin{array}{l}\text { lk zou niet zoveel kaakklachten hebben al ser niet iets gevaarlijks aan } \\
\text { de hand zou zijn }\end{array}$ & 1 & 2 & 3 & 4 \\
\hline 12. & $\begin{array}{l}\text { Hoewel ik kaakklachten heb, zou ik er beter aan toe zijn als ik mijn } \\
\text { mond normal blijf gebruiken }\end{array}$ & 1 & 2 & 3 & 4 \\
\hline 13. & $\begin{array}{l}\text { Mijn kaakklachten zeggen me wanneer ik moet stoppen met bewegen } \\
\text { van mijn kaak om geen letsel op te lopen }\end{array}$ & 1 & 2 & 3 & 4 \\
\hline 14. & $\begin{array}{l}\text { Voor iemand met kaakklachten zoals die van mij, is het echt af te } \\
\text { raden om de mond veel te gebruiken }\end{array}$ & 1 & 2 & 3 & 4 \\
\hline 15. & $\begin{array}{l}\text { Ik kan niet alles doen wat andere mensen doen, omdat ik te } \\
\text { gemakkelijk letsel aan mijn kaak oploop }\end{array}$ & 1 & 2 & 3 & 4 \\
\hline 16. & $\begin{array}{l}\text { Zelfs als ik ergens veel kaakklachten door krijg, geloof ik niet dat dat } \\
\text { gevaarlijk is }\end{array}$ & 1 & 2 & 3 & 4 \\
\hline 17. & $\begin{array}{l}\text { Je zou je kaak zo min mogelijk hoeven bewegen wanneer je } \\
\text { kaakklachten hebt }\end{array}$ & 1 & 2 & 3 & 4 \\
\hline 18. & $\begin{array}{l}\text { lk ben bang om mijn mond te ver te openen, omdat ik hem dan } \\
\text { misschien niet meer dicht kan doen }\end{array}$ & 1 & 2 & 3 & 4 \\
\hline
\end{tabular}




\section{APÊNDICE 1 - TERMO DE CONSENTIMENTO FORMAL E ESCLARECIDO PARA OS PARTICIPANTES DA PESQUISA}

Pesquisadores responsáveis: Profa. Dra. Thaís Cristina Chaves (chavestc@fmrp.usp.br) Fone:(016)36024694 e Aroldo dos Santos Aguiar (aroldone@hotmail.com) Fone:(016) 81606070

\section{“ADAPTAÇÃO TRANSCULTURAL PARA O PORTUGUÊS DA TAMPA SCALE FOR KINESIOPHOBIA (TSK) FOR TEMPOROMANDIBULAR DISORDERS"}

Esclarecimento Geral - Este estudo será realizado para disponibilizar uma versão em português de uma escala que avalia a cinesiofobia (medo do movimento), o qual é constituído por 17 itens que representam a percepção de cada individuo para a confiança de realizar movimento, abordando a dor e a intensidade dos sintomas.

Objetivo do Estudo - Tornar disponível no português uma escala (Tampa Scale for Kinesiophobia) para avaliar a intensidade de cinesiofobia em pacientes com disfunção temporomandibular.

Explicação dos Procedimentos da Pesquisa - Em uma primeira etapa, um pesquisador responsável aplicará a escala para avaliar e observar as dificuldades dos pacientes que apresentam DTM, com relação as questões. Tais dificuldades serão utilizadas como subsídio para possíveis alterações na versão da escala. Em alguns pacientes a mesma será aplicada novamente após uma semana, para avaliação da consistência das informações fornecidas.

Possíveis Benefícios - Não há benefícios diretamente destinados a mim durante a participação nesta pesquisa e que os dados obtidos pelos responsáveis pela pesquisa auxiliaram no maior conhecimento a respeito dos aspectos físico, mental e social que envolvem a saúde dos pacientes portadores de DTM.

Desconforto e risco - Existe um risco mínimo nessa pesquisa relacionado ao sigilo de identidade, entretanto todas as informações colhidas serão mantidas em sigilo assim como minha identidade através da adoção de senhas em arquivos e numeração dos dados nas planilhas.

Seguro de Saúde ou de Vida - Não existe nenhum tipo de seguro de saúde ou de vida que possa me beneficiar em função da minha participação neste estudo.

Liberdade de Participação - A minha participação neste estudo depende plenamente da minha autorização. É meu direito deixar de participar deste estudo em qualquer momento sem que isso incorra em qualquer penalidade ou prejuízo à minha pessoa. E fui informado de que não terei nenhum gasto adicional devido à participação nesse projeto.

Sigilo de Identidade - As informações obtidas nesta pesquisa não serão de maneira alguma associadas à identidade dos participantes e não poderão ser consultadas por pessoas leigas sem autorização oficial. Estas informações poderão ser utilizadas para fins científicos, desde que fiquem resguardadas a privacidade e anonimato dos participantes da pesquisa. 
Apêndices $\mid 99$

Eventuais dúvidas sobre os aspectos éticos relacionados a essa pesquisa devem ser elucidados junto ao Comitê de Ética em Pesquisa do Hospital das Clínicas da Faculdade de Medicina de Ribeirão Preto (F: 36022228).

Os responsáveis pelo estudo me explicaram todos os riscos envolvidos, a necessidade da pesquisa e se prontificaram a responder todas as minhas dúvidas sobre a pesquisa. Eu aceitei participar neste estudo de livre e espontânea vontade. Entendo que é meu direito manter uma cópia deste consentimento.

$\mathrm{Eu}$, portador do RG no: declaro que tenho anos de idade. de de 20 


\section{APÊNDICE 2- Versão Tradutor Leigo (T1) da TSK/TMD-Br}

\section{Escala Tampa de Cinesiofobia para Disfunção Temporomandibular}

Nome do paciente: Data:

Problemas mandibulares podem causar muitas dificuldades de maneiras diferentes. Dalista abaixo, por favor, indique quais problemas mandibualres estão lhe causando alguma dificuldade (circule sim ou não; várias respostas sim são possíveis).

- Dor mandibular

$$
\text { SIM NÃO }
$$

- Ruídos na minha mandíbula quando eu mexo minha boca (estalos ou crepitações) SIM NÃO

- A minha mandíbula trava ou bloqueia de tal modo que eu não consigo abri-la ou fechala totalmente<smiles>[Mg][Mg]</smiles>

- Outros incômodos mandibulares- por favor, descreva:

Para cada uma das afirmações abaixo, indique o quanto você concorda ou discorda.

Por favor, utilize aseguinte escala:

5. Discordo totalmente

6. Discordo

7. Concordo

8. Concordo totalmente

\begin{tabular}{|l|l|l|l|l|l|}
\hline 1 & $\begin{array}{l}\text { Tenho medo de me machucar se eu movimentar minha } \\
\text { mandíbula. }\end{array}$ & 1 & 3 & 4 \\
\hline 2 & $\begin{array}{l}\text { Se eu ignorasse meus sintomas mandibulares, eles } \\
\text { poderiam piorar. }\end{array}$ & 1 & 3 & 4 \\
\hline 3 & $\begin{array}{l}\text { Parece que há alguma coisa grave ocorrendo com minha } \\
\text { mandíbula. }\end{array}$ & 1 & 2 & 3 & 4 \\
\hline 4 & $\begin{array}{l}\text { Meus sintomas mandibulares provavelmente melhorariam } \\
\text { se eu mexesse mais minha mandíbula. }\end{array}$ & 1 & 3 & 4 \\
\hline 5 & $\begin{array}{l}\text { As pessoas não estão levando meus sintomas mandibulares } \\
\text { a sério. }\end{array}$ & 1 & 2 & 3 & 4 \\
\hline 6 & $\begin{array}{l}\text { Meus sintomas mandibulares podem colocar minha saúde } \\
\text { está risco para o resto da minha vida. }\end{array}$ & 1 & 2 & 3 & 4 \\
\hline 7 & $\begin{array}{l}\text { Meus sintomas mandibulares significam que eu tenho uma } \\
\text { lesão mandibular. }\end{array}$ & 1 & 2 & 3 & 4 \\
\hline sorque algo agrava meus sintomas mandibulares não & 1 & 2 & 3 & 4 \\
\hline
\end{tabular}




\begin{tabular}{|l|l|l|l|l|l|}
\hline 9 & $\begin{array}{l}\text { Tenho medo de que eu possa machucar minha mandíbula } \\
\text { sem querer. }\end{array}$ & 1 & 2 & 3 & 4 \\
\hline 10 & $\begin{array}{l}\text { A atitude para prevenir a piora dos meus sintomas, é ser } \\
\text { cuidadoso e não fazer nenhum movimento mandibular } \\
\text { desnecessário. }\end{array}$ & 1 & 2 & 3 & 4 \\
\hline 11 & $\begin{array}{l}\text { Eu não teria tantos sintomas mandibulares se algo } \\
\text { potencialmente perigoso não estivesse acontecendo. }\end{array}$ & 1 & 2 & 3 & 4 \\
\hline 12 & $\begin{array}{l}\text { Apesar de eu ter sintomas mandibulares, eu estaria melhor } \\
\text { se continuasse usando minha boca normalmente. }\end{array}$ & 1 & 2 & 3 & 4 \\
\hline 13 & $\begin{array}{l}\text { Meus sintomas mandibulares me avisam quando parar a } \\
\text { movimentação da minha mandíbula para não me machucar. }\end{array}$ & 1 & 2 & 3 & 4 \\
\hline 14 & $\begin{array}{l}\text { Não é realmente seguro para alguém com uma condição } \\
\text { mandibular como a minha movimentar muito a boca. }\end{array}$ & 1 & 2 & 3 & 4 \\
\hline 15 & $\begin{array}{l}\text { Eu não posso fazer todas as coisas que a maioria das } \\
\text { pessoas fazem, porque eu machuco minha mandíbula } \\
\text { facilmente. }\end{array}$ & 1 & 2 & 3 & 4 \\
\hline 16 & $\begin{array}{l}\text { Mesmo fazendo algo que piora meus sintomas } \\
\text { mandibulares, eu não acho que isto seja perigoso. }\end{array}$ & 1 & 2 & 3 & 4 \\
\hline 17 & $\begin{array}{l}\text { Ninguém que está com problemas mandibulares deveria } \\
\text { fazer movimentos mandibulares. }\end{array}$ & 1 & 2 & 3 & 4 \\
\hline 18 & $\begin{array}{l}\text { Tenho medo de abrir muito minha boca, porque é possível } \\
\text { que eu não consiga fechá-la novamente. }\end{array}$ & 1 & 2 & 3 & 4 \\
\hline
\end{tabular}




\section{APÊNDICE 3- Versão Tradutor expert (T2) da TSK/TMD-Br}

\section{Escala Tampa de Cinesiofobia para Disfunção Temporomandibular}

Nome do paciente: Data:

Problemas mandibulares podem causar muitas dificuldades de maneiras diferentes. A partir da lista abaixo, por favor indique quais problemas mandibulares tem te dado trabalho ( circule sim ou não; respostas vom mais de um sim são possíveis ).

- Dor mandibular

$$
\text { SIM NÃO }
$$
- Barulhos mandibulares quando eu mexo minha boca (estalos ou ruídos)
SIM

- Meu maxilar fica travado ou preso de maneira que eu não consigo mais abri-lo ou fechalo
SIM
NÃO

- Outros incômodos mandibulares- por favor, descreva:

Para cada uma das frases abaixo, por favor, indique o quanto você concorda ou discorda.

Por favor, utilize a escala abaixo:

\section{Discordo fortemente}

2.Discordo

3.Concordo

4.Concordo fortemente

\begin{tabular}{|l|l|l|l|l|l|}
\hline 1 & $\begin{array}{l}\text { Eu temo que eu possa me machucar caso eu mova minha } \\
\text { mandíbula. }\end{array}$ & 1 & 2 & 3 & 4 \\
\hline 2 & $\begin{array}{l}\text { Se eu ignorasse meus sintomas mandibulares, eles } \\
\text { piorariam. }\end{array}$ & 1 & 2 & 3 & 4 \\
\hline 3 & $\begin{array}{l}\text { Minha mandíbula está me dizendo que temalgo seriamente } \\
\text { errado com ela. }\end{array}$ & 1 & 2 & 3 & 4 \\
\hline 4 & $\begin{array}{l}\text { Meus sintomas mandibulares provavelmente melhorariam } \\
\text { se eu movesse mais a minha mandíbula. }\end{array}$ & 1 & 2 & 3 & 4 \\
\hline 5 & $\begin{array}{l}\text { As pessoas não levam meus sintomas mandibulares } \\
\text { suficientemente a sério. }\end{array}$ & 1 & 2 & 3 & 4 \\
\hline 6 & $\begin{array}{l}\text { Meus sintomas mandibulares colocaram minha saúde em } \\
\text { risco pelo resto da minha vida. }\end{array}$ & 1 & 2 & 3 & 4 \\
\hline 7 & $\begin{array}{l}\text { Meus sintomas mandibulares significam que eu machuquei } \\
\text { minha mandíbula. }\end{array}$ & 1 & 2 & 3 & 4 \\
\hline 8 & $\begin{array}{l}\text { Só porque algo agrava meus sintomas mandibulares não } \\
\text { quer dizer que seja prejudicial. }\end{array}$ & 1 & 2 & 3 & 4 \\
\hline
\end{tabular}




\begin{tabular}{|l|l|l|l|l|l|}
\hline 9 & $\begin{array}{l}\text { Eu temo que eu possa acidentalmente machucar minha } \\
\text { mandíbula. }\end{array}$ & 1 & 2 & 3 & 4 \\
\hline 10 & $\begin{array}{l}\text { A maneira mais segura de evitar que os meus sintomas } \\
\text { piorem é ter cuidado e não mover minha mandíbula mais do } \\
\text { que o necessário. }\end{array}$ & 1 & 2 & 3 & 4 \\
\hline 11 & $\begin{array}{l}\text { Eu não teria tantos sintomas mandibulares se não estivesse } \\
\text { acontecendo algo potencialmente prejudicial. }\end{array}$ & 1 & 2 & 3 & 4 \\
\hline 12 & $\begin{array}{l}\text { Embora eu tenha sintomas mandibulares, o melhor para mim } \\
\text { é continuar usando minha boca normalmente. }\end{array}$ & 1 & 2 & 3 & 4 \\
\hline 13 & $\begin{array}{l}\text { Meus sintomas mandibulares me avisam quando devo parar } \\
\text { de mover minha mandíbula para evitar que eu me machuque. }\end{array}$ & 1 & 2 & 3 & 4 \\
\hline 14 & $\begin{array}{l}\text { Usar muito a boca realmente não é seguro para alguém com } \\
\text { um problema mandibular como eu. }\end{array}$ & 1 & 2 & 3 & 4 \\
\hline 15 & $\begin{array}{l}\text { Eu não consigo fazer tudo que outras pessoas fazem, porque } \\
\text { eu machuco minha mandíbula muito facilmente. }\end{array}$ & 1 & 2 & 3 & 4 \\
\hline 16 & $\begin{array}{l}\text { Mesmo que algo que eu faça agrave meus sintomas } \\
\text { mandibulares, eu não acredito que seja prejudicial. }\end{array}$ & 1 & 2 & 3 & 4 \\
\hline 17 & $\begin{array}{l}\text { Nenhuma pessoa deveria ter que mover sua mandíbula } \\
\text { quando tem um problema mandibular. }\end{array}$ & 1 & 2 & 3 & 4 \\
\hline 18 & $\begin{array}{l}\text { Eu temo abrir muito a boca porque é possível que eu não } \\
\text { consiga mais fecha-la. }\end{array}$ & 1 & 2 & 3 & 4 \\
\hline
\end{tabular}




\section{APÊNDICE 4- Versão Dutch Tradutor Expert (T3) da TSK/TMD}

\section{Escala Tampa de Cinesiofobia para Disfunção Temporomandibular}

Nome do paciente: Data:

As queixas na mandíbula podem se manifestar de maneiras diferentes. Indique na lista abaixo, o que lhe incomoda (varias respostas são possíveis).

- Dor
SIM
$\mathrm{NÃO}$

- $\quad$ Sons na minha mandíbula ao movimentar a boca (estalidos) NÃO

- Travamento ou bloqueio da mandíbula, de modo que a boca não pode abrir ou fechar direito

SIM

$\mathrm{NÃO}$

- Outros a saber:

Indique nas afirmações abaixo até que ponto você concorda ou discorda com as mesmas.

Segue os significados dos números:

1.Discordo em grande parte

2.Discordo em parte

3.Concordo em parte

4.Concordo em grande parte

\begin{tabular}{|c|c|c|c|c|c|}
\hline 1 & $\begin{array}{l}\text { Eu tenho medo de sofrer lesão ao realizar movimentos } \\
\text { mandibulares. }\end{array}$ & 1 & 2 & 3 & 4 \\
\hline 2 & $\begin{array}{l}\text { Se eu ignorasse minhas queixas mandibulares, elas } \\
\text { piorariam. }\end{array}$ & 1 & 2 & 3 & 4 \\
\hline 3 & Minha mandíbula me diz que há algo sério de errado comigo. & 1 & 2 & 3 & 4 \\
\hline 4 & $\begin{array}{l}\text { Provavelmente minhas queixas mandibulares melhorariam } \\
\text { se eu mexesse a minha mandíbula com mais frequência. }\end{array}$ & 1 & 2 & 3 & 4 \\
\hline 5 & $\begin{array}{l}\text { Outras pessoas não levam a serio as minhas queixas } \\
\text { mandibulares. }\end{array}$ & 1 & 2 & 3 & 4 \\
\hline 6 & $\begin{array}{l}\text { Por causa das minhas queixas mandibulares, a minha saúde } \\
\text { corre risco pelo resto da minha vida. }\end{array}$ & 1 & 2 & 3 & 4 \\
\hline 7 & Minhas queixas mandibulares significam que há lesão. & 1 & 2 & 3 & 4 \\
\hline 8 & $\begin{array}{l}\text { Se alguma coisa piora as minhas queixas mandibulares, isso } \\
\text { não significa que as minhas queixas mandibulares são } \\
\text { perigosas. }\end{array}$ & 1 & 2 & 3 & 4 \\
\hline 9 & $\begin{array}{l}\text { Eu tenho medo de sofrer lesão na minha mandíbula por } \\
\text { acidente. }\end{array}$ & 1 & 2 & 3 & 4 \\
\hline
\end{tabular}




\begin{tabular}{|l|l|l|l|l|l|}
\hline 10 & $\begin{array}{l}\text { A maneira mais segura de prevenir que as minhas queixas } \\
\text { piorem, é simplesmente ser cuidadoso em não fazer } \\
\text { movimentos desnecessários com a minha boca. }\end{array}$ & 1 & 3 & 4 \\
\hline 11 & $\begin{array}{l}\text { Eu não teria tantas queixas mandibulares senão fosse } \\
\text { alguma coisa perigosa. }\end{array}$ & 1 & 2 & 3 & 4 \\
\hline 12 & $\begin{array}{l}\text { Embora eu tenha queixas mandibulares, seria melhor se eu } \\
\text { continuasse a usar a minha boca normalmente. }\end{array}$ & 1 & 2 & 3 & 4 \\
\hline 13 & $\begin{array}{l}\text { Minhas queixas mandibulares me dizem quando eu devo } \\
\text { parar de mover minha mandíbula para não sofrer nenhuma } \\
\text { lesão. }\end{array}$ & 1 & 2 & 3 & 4 \\
\hline 14 & $\begin{array}{l}\text { Para alguém com queixas mandibulares como eu, não é } \\
\text { realmente aconselhável utilizar muito a boca. }\end{array}$ & 1 & 2 & 3 & 4 \\
\hline 15 & $\begin{array}{l}\text { Eu não posso fazer tudo o que outras pessoas fazem, porque } \\
\text { eu posso sofrer lesão na minha mandíbula facilmente. }\end{array}$ & 1 & 2 & 3 & 4 \\
\hline 16 & $\begin{array}{l}\text { Mesmo se algo me causa queixas mandibulares eu não } \\
\text { acredito que seja perigoso. }\end{array}$ & 1 & 2 & 3 & 4 \\
\hline 17 & $\begin{array}{l}\text { Você mexe a sua mandíbula o mesnos possível, quando } \\
\text { você tem queixas mandibulares. }\end{array}$ & 1 & 2 & 3 & 4 \\
\hline 18 & $\begin{array}{l}\text { Eu tenho medo de abrir muito a boca, porque talvez depois } \\
\text { que abrir eu não consiga fechá-la. }\end{array}$ & 1 & 2 & 3 & 4 \\
\hline
\end{tabular}


APÊNDICE 5- Versão sintetizada T123 da TSK/TMD

\section{Escala Tampa de Cinesiofobia para Disfunção Temporomandibular}

Nome do paciente: Data:

Problemas mandibulares podem causar muitas dificuldades de maneiras diferentes. Por favor, indique na lista abaixo, o que the incomoda (circule sim ou não; em todas as questões).

- Dor mandibular
SIM
NÃO

- Ruídos na minha mandíbula quando eu mexo minha boca (estalos ou outros ruídos) SIM NÃO

- Minha mandíbula fica travada ou presa de maneira que minha boca não abre ou fecha direito
SIM
NÃO

- Outros incômodos mandibulares- por favor, descreva

Para cada uma das frases abaixo, por favor, indique o quanto você concorda ou discorda.

Por favor, utilize a escala abaixo:

9. Discordo fortemente

10. Discordo

11. Concordo

12. Concordo fortemente

\begin{tabular}{|l|l|l|l|l|l|}
\hline 1 & $\begin{array}{l}\text { T: Eu tenho medo de me machucar seriamente, se eu } \\
\text { movimentar minha mandíbula. }\end{array}$ & 1 & 3 & 4 \\
\hline 2 & $\begin{array}{l}\text { Se eu ignorasse meus sintomas mandibulares, eles } \\
\text { poderiam piorar. }\end{array}$ & 1 & 2 & 3 & 4 \\
\hline 3 & $\begin{array}{l}\text { Parece que há alguma coisa errada com minha mandíbula } \\
\text { que pode ficar séria. }\end{array}$ & 1 & 2 & 3 & 4 \\
\hline 4 & $\begin{array}{l}\text { Meus sintomas mandibulares provavelmente melhorariam } \\
\text { se eu mexesse mais minha mandíbula. }\end{array}$ & 1 & 2 & 3 & 4 \\
\hline 5 & $\begin{array}{l}\text { As pessoas não estão levando minhas queixas } \\
\text { mandibulares realmente a sério. }\end{array}$ & 1 & 2 & 3 & 4 \\
\hline 6 & $\begin{array}{l}\text { Por causa dos meus sintomas mandibulares minha saúde } \\
\text { está risco pelo resto da minha vida. }\end{array}$ & 1 & 2 & 3 & 4 \\
\hline 7 & $\begin{array}{l}\text { Meus sintomas mandibulares significam que eu machuquei } \\
\text { minha mandíbula seriamente. }\end{array}$ & 1 & 2 & 3 & 4 \\
\hline
\end{tabular}




\begin{tabular}{|l|l|l|l|l|l|}
\hline 8 & $\begin{array}{l}\text { Se alguma coisa piora meus sintomas mandibulares, isso } \\
\text { não quer dizer que seja perigoso. }\end{array}$ & 1 & 3 & 4 \\
\hline 9 & $\begin{array}{l}\text { Tenho medo de que eu possa machucar minha mandíbula } \\
\text { sem querer. }\end{array}$ & 1 & 2 & 3 & 4 \\
\hline 10 & $\begin{array}{l}\text { A maneira mais segura de evitar que os meus sintomas } \\
\text { piorem é simplesmente ter cuidado em não mexer minha } \\
\text { mandíbula mais do que o necessário. }\end{array}$ & 1 & 2 & 3 & 4 \\
\hline 11 & $\begin{array}{l}\text { Eu não teria tantos sintomas mandibulares se algo } \\
\text { realmente perigoso não estivesse acontecendo. }\end{array}$ & 1 & 2 & 3 & 4 \\
\hline 12 & $\begin{array}{l}\text { Embora eu tenha sintomas mandibulares, o melhor para } \\
\text { mim seria continuar usando minha boca normalmente. }\end{array}$ & 1 & 2 & 3 & 4 \\
\hline 13 & $\begin{array}{l}\text { Meus sintomas mandibulares me avisam quando devo } \\
\text { parar de mexer minha mandíbula para evitar que eu me } \\
\text { machuque seriamente. }\end{array}$ & 1 & 2 & 3 & 4 \\
\hline 14 & $\begin{array}{l}\text { Para alguém com problemas mandibulares, como o meu, } \\
\text { não é realmente seguro utilizar muito a boca. }\end{array}$ & 1 & 2 & 3 & 4 \\
\hline 15 & $\begin{array}{l}\text { Eu não consigo fazer tudo o que outras pessoas fazem, } \\
\text { porque eu machuco minha mandíbula muito facilmente. }\end{array}$ & 1 & 2 & 3 & 4 \\
\hline 16 & $\begin{array}{l}\text { Mesmo que algo piore meus sintomas mandibulares eu não } \\
\text { acho que isto seja perigoso. }\end{array}$ & 1 & 2 & 3 & 4 \\
\hline 17 & $\begin{array}{l}\text { Alguém que tenha problemas mandibulares, como o meu, } \\
\text { não deveria ter que mexer sua mandíbula. }\end{array}$ & 1 & 2 & 3 & 4 \\
\hline 18 & $\begin{array}{l}\text { Tenho medo de abrir muito minha boca, porque é possível } \\
\text { que eu não consiga fechá-la novamente. }\end{array}$ & 1 & 2 & 3 & 4 \\
\hline
\end{tabular}




\section{APÊNDICE 6- Versão pré- final da TSK/TMD-Br}

\section{Escala Tampa de Cinesiofobia para Disfunção Temporomandibular}

Nome do paciente: Data:

Problemas mandibulares podem causar muitas dificuldades de maneiras diferentes. Por favor, indique na lista abaixo, o que lhe incomoda (circule sim ou não; em todas as questões).

- Dor mandibular

$$
\text { SIM NÃO }
$$

- Ruídos na minha mandíbula quando eu mexo minha boca (estalos ou outros ruídos) SIM NÃO

- Minha mandíbula fica travada ou presa de maneira que minha boca não abre ou fecha direito

$$
\text { SIM NÃO }
$$

- Outros incômodos mandibulares- por favor, descreva:

Para cada uma das frases abaixo, por favor, indique o quanto você concorda ou discorda.

Por favor, utilize a escala abaixo:

1.Discordo fortemente

2.Discordo

3.Concordo

4.Concordo fortemente

\begin{tabular}{|l|l|l|l|l|l|}
\hline 1 & $\begin{array}{l}\text { Eu tenho medo de me machucar seriamente, se eu } \\
\text { movimentar minha mandíbula. }\end{array}$ & 2 & 3 & 4 \\
\hline 2 & $\begin{array}{l}\text { Se eu ignorasse meus sintomas mandibulares, eles } \\
\text { poderiam piorar. }\end{array}$ & 1 & 2 & 3 & 4 \\
\hline 3 & $\begin{array}{l}\text { Parece que há alguma coisa errada com minha mandíbula } \\
\text { que pode ficar séria. }\end{array}$ & 1 & 2 & 3 & 4 \\
\hline 4 & $\begin{array}{l}\text { Meus sintomas mandibulares provavelmente melhorariam } \\
\text { se eu mexesse mais minha mandíbula. }\end{array}$ & 1 & 2 & 3 & 4 \\
\hline 5 & $\begin{array}{l}\text { As pessoas não estão levando minhas queixas } \\
\text { mandibulares realmente a sério. }\end{array}$ & 1 & 2 & 3 & 4 \\
\hline 6 & $\begin{array}{l}\text { Por causa dos meus sintomas mandibulares minha saúde } \\
\text { está risco pelo resto da minha vida. }\end{array}$ & 1 & 2 & 3 & 4 \\
\hline 7 & $\begin{array}{l}\text { Meus sintomas mandibulares significam que eu machuquei } \\
\text { minha mandíbula seriamente. }\end{array}$ & 1 & 2 & 3 & 4 \\
\hline 8 & $\begin{array}{l}\text { Se alguma coisa piora meus sintomas mandibulares, isso } \\
\text { não quer dizer que seja perigoso. }\end{array}$ & 1 & 2 & 3 & 4 \\
\hline 9 & $\begin{array}{l}\text { Tenho medo de que eu possa machucar minha mandíbula } \\
\text { sem querer. }\end{array}$ & 1 & 2 & 3 & 4 \\
\hline
\end{tabular}




\begin{tabular}{|l|l|l|l|l|l|}
\hline 10 & $\begin{array}{l}\text { A maneira mais segura de evitar que os meus sintomas } \\
\text { piorem é simplesmente ter cuidado em não mexer minha } \\
\text { mandíbula mais do que o necessário. }\end{array}$ & 1 & 2 & 3 & 4 \\
\hline 11 & $\begin{array}{l}\text { Eu não teria tantos sintomas mandibulares se algo realmente } \\
\text { perigoso não estivesse acontecendo. }\end{array}$ & 1 & 2 & 3 & 4 \\
\hline 12 & $\begin{array}{l}\text { Embora eu tenha sintomas mandibulares, o melhor para mim } \\
\text { seria continuar usando minha boca normalmente. }\end{array}$ & 1 & 2 & 3 & 4 \\
\hline 13 & $\begin{array}{l}\text { Meus sintomas mandibulares me avisam quando devo parar } \\
\text { de mexer minha mandíbula para evitar que eu me machuque } \\
\text { seriamente. }\end{array}$ & 1 & 2 & 3 & 4 \\
\hline 14 & $\begin{array}{l}\text { Para alguém com problemas mandibulares, como o meu, } \\
\text { não é realmente seguro utilizar muito a boca. }\end{array}$ & 1 & 2 & 3 & 4 \\
\hline 15 & $\begin{array}{l}\text { Eu não consigo fazer tudo o que outras pessoas fazem, } \\
\text { porque eu machuco minha mandíbula muito facilmente. }\end{array}$ & 1 & 2 & 3 & 4 \\
\hline 16 & $\begin{array}{l}\text { Mesmo que algo piore meus sintomas mandibulares eu não } \\
\text { acho que isto seja perigoso. }\end{array}$ & 1 & 2 & 3 & 4 \\
\hline $17 a$ & $\begin{array}{l}\text { Alguém que tenha problemas mandibulares, como o meu, } \\
\text { não deveria ter que mexer sua mandíbula. }\end{array}$ & 1 & 2 & 3 & 4 \\
\hline $17 b$ & $\begin{array}{l}\text { Você não deveria mexer a sua mandíbula se você tem } \\
\text { problemas mandibulares como o meu }\end{array}$ & 1 & 2 & 3 & 4 \\
\hline 18 & $\begin{array}{l}\text { Tenho medo de abrir muito minha boca, porque é possível } \\
\text { que eu não consiga fechá-la novamente. }\end{array}$ & 1 & 2 & 3 & 4 \\
\hline
\end{tabular}




\section{APÊNDICE 7- Formulário de sugestões para aprimorar a Escala Tampa de Cinesiofobia para a DTM}

Nome do paciente: Data:

Tempo de aplicação da ferramenta:

1. Você conseguiu entender aos enunciados de todos os itens do questionário? Se não, por favor, marque com um X o quadrado correspondente à questão (ou questões) não compreendida(s).

\begin{tabular}{|c|l|}
\hline 01 & \\
\hline 02 & \\
\hline 03 & \\
\hline 04 & \\
\hline 05 & \\
\hline 06 & \\
\hline 07 & \\
\hline 08 & \\
\hline 09 & \\
\hline 10 & \\
\hline 11 & \\
\hline 12 & \\
\hline 13 & \\
\hline 14 & \\
\hline 15 & \\
\hline 16 & \\
\hline $17 \mathrm{a}$ & \\
\hline $17 \mathrm{~b}$ & \\
\hline 18 & \\
\hline
\end{tabular}

Agora, por favor, responda qual foi a sua dificuldade referente ao item assinalado (Se houver mais de um item, não se esqueça de mencionar quais são).

2. As opções de resposta foram claras para responder ao item solicitado? Em caso de resposta negativa, por favor, sugira opções.

3. Você tem alguma sugestão para a mudança do lay-out (estrutura/organização) desse questionário?

4. Você tem alguma sugestão para tornar as questões do questionário mais fáceis de serem entendidas?

5. Sobre a questão 17 - por favor, marque um $X$ na questão que ficou mais clara para você:

\begin{tabular}{|l|l|}
\hline $17 \mathrm{a}$ & \\
\hline $17 \mathrm{~b}$ & \\
\hline
\end{tabular}




\section{APENDICE 8- Versão final da TSK/TMD-Br}

Escala Tampa de Cinesiofobia para Disfunção Temporomandibular - Versão Português-

\section{Brasil}

Nome do paciente: Data:

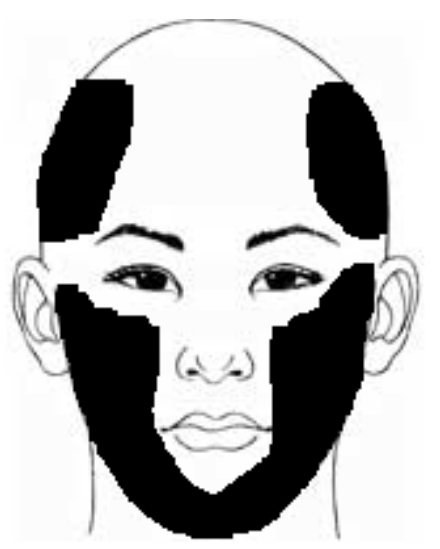

Problemas na região mandibular (por favor, considere a região mandibular toda a área marcada em preto na imagem acima) podem causar muitas dificuldades de maneiras diferentes. Por favor, indique na lista abaixo, o que lhe incomoda (marque sim ou não nos quadrados abaixo).

- Dor mandibular

\begin{tabular}{|l|l|}
\hline SIM & NÃO \\
\hline
\end{tabular}

- Ruídos em frente ao ouvido quando eu mexo minha boca (estalos ou outros ruídos)

$$
\begin{array}{l|l}
\text { SIM } & \text { NÃO }
\end{array}
$$

- Minha mandíbula fica travada ou presa de maneira que minha boca não abre ou fecha direito

\begin{tabular}{|l|l|}
\hline SIM & NÃO \\
\hline
\end{tabular}

- Outros incômodos na região mandibular, por favor, descreva:

Para cada uma das frases abaixo, por favor, indique o quanto você concorda ou discorda com as frases abaixo considerando sua dor ou desconforto na região mandibular.

Por favor, utilize a escala abaixo:

\begin{tabular}{|l|l|c|l|l|c|}
\hline 1 & $\begin{array}{l}\text { Eu tenho medo de me machucar, se eu movimentar } \\
\text { minha mandíbula. }\end{array}$ & $\begin{array}{c}\text { Discordo } \\
\text { fortemente }\end{array}$ & Discordo & Concordo & $\begin{array}{c}\text { Concordo } \\
\text { fortemente }\end{array}$ \\
\hline 2 & $\begin{array}{l}\text { Se eu ignorasse meus sintomas na região } \\
\text { mandibular, eles poderiam piorar. }\end{array}$ & $\begin{array}{c}\text { Discordo } \\
\text { fortemente }\end{array}$ & Discordo & Concordo & $\begin{array}{c}\text { Concordo } \\
\text { fortemente }\end{array}$ \\
\hline 3 & $\begin{array}{l}\text { Parece que há alguma coisa errada na minha região } \\
\text { mandibular que pode ficar séria. }\end{array}$ & $\begin{array}{c}\text { Discordo } \\
\text { fortemente }\end{array}$ & Discordo & Concordo & $\begin{array}{c}\text { Concordo } \\
\text { fortemente }\end{array}$ \\
\hline
\end{tabular}


Apêndices 112

\begin{tabular}{|c|c|c|c|c|c|}
\hline 4 & $\begin{array}{l}\text { Meus sintomas mandibulares provavelmente } \\
\text { melhorariam se eu mexesse mais minha mandíbula. }\end{array}$ & $\begin{array}{l}\text { Discordo } \\
\text { fortemente }\end{array}$ & Discordo & Concordo & $\begin{array}{l}\text { Concordo } \\
\text { fortemente }\end{array}$ \\
\hline 5 & $\begin{array}{l}\text { As pessoas não levam minhas queixas na } \\
\text { mandíbula a sério. }\end{array}$ & $\begin{array}{l}\text { Discordo } \\
\text { fortemente }\end{array}$ & Discordo & Concordo & $\begin{array}{l}\text { Concordo } \\
\text { fortemente }\end{array}$ \\
\hline 6 & $\begin{array}{l}\text { Por causa dos meus sintomas mandibulares minha } \\
\text { saúde está risco pelo resto da minha vida. }\end{array}$ & $\begin{array}{l}\text { Discordo } \\
\text { fortemente }\end{array}$ & Discordo & Concordo & $\begin{array}{l}\text { Concordo } \\
\text { fortemente }\end{array}$ \\
\hline 7 & $\begin{array}{l}\text { Meus sintomas mandibulares significam que eu } \\
\text { machuquei minha mandíbula. }\end{array}$ & $\begin{array}{l}\text { Discordo } \\
\text { fortemente }\end{array}$ & Discordo & Concordo & $\begin{array}{l}\text { Concordo } \\
\text { fortemente }\end{array}$ \\
\hline 8 & $\begin{array}{l}\text { Se alguma coisa piora meus sintomas mandibulares, } \\
\text { isso não quer dizer que seja perigoso. }\end{array}$ & $\begin{array}{l}\text { Discordo } \\
\text { fortemente }\end{array}$ & Discordo & Concordo & $\begin{array}{l}\text { Concordo } \\
\text { fortemente }\end{array}$ \\
\hline 9 & $\begin{array}{l}\text { Tenho medo de que eu possa machucar minha } \\
\text { região mandibular sem querer. }\end{array}$ & $\begin{array}{l}\text { Discordo } \\
\text { fortemente }\end{array}$ & Discordo & Concordo & $\begin{array}{l}\text { Concordo } \\
\text { fortemente }\end{array}$ \\
\hline 10 & $\begin{array}{l}\text { A maneira mais segura de evitar que os meus } \\
\text { sintomas piorem é simplesmente ter cuidado e não } \\
\text { mexer minha mandíbula mais do que o necessário. }\end{array}$ & $\begin{array}{l}\text { Discordo } \\
\text { fortemente }\end{array}$ & Discordo & Concordo & $\begin{array}{l}\text { Concordo } \\
\text { fortemente }\end{array}$ \\
\hline 11 & $\begin{array}{l}\text { Eu não teria tantos sintomas mandibulares se } \\
\text { alguma coisa potencialmente prejudicial não } \\
\text { estivesse acontecendo. }\end{array}$ & $\begin{array}{l}\text { Discordo } \\
\text { fortemente }\end{array}$ & Discordo & Concordo & $\begin{array}{l}\text { Concordo } \\
\text { fortemente }\end{array}$ \\
\hline 12 & $\begin{array}{l}\text { Embora eu tenha sintomas mandibulares, o melhor } \\
\text { para mim seria continuar usando minha boca } \\
\text { normalmente. }\end{array}$ & $\begin{array}{l}\text { Discordo } \\
\text { fortemente }\end{array}$ & Discordo & Concordo & $\begin{array}{l}\text { Concordo } \\
\text { fortemente }\end{array}$ \\
\hline 13 & $\begin{array}{l}\text { Meus sintomas mandibulares me avisam quando } \\
\text { devo parar de mexer minha mandíbula para evitar } \\
\text { que eu me machuque. }\end{array}$ & $\begin{array}{l}\text { Discordo } \\
\text { fortemente }\end{array}$ & Discordo & Concordo & $\begin{array}{l}\text { Concordo } \\
\text { fortemente }\end{array}$ \\
\hline 14 & $\begin{array}{l}\text { Para alguém com problemas mandibulares, como o } \\
\text { meu, não é realmente seguro utilizar muito a boca. }\end{array}$ & $\begin{array}{l}\text { Discordo } \\
\text { fortemente }\end{array}$ & Discordo & Concordo & $\begin{array}{l}\text { Concordo } \\
\text { fortemente }\end{array}$ \\
\hline 15 & $\begin{array}{l}\text { Eu não consigo fazer tudo o que outras pessoas } \\
\text { fazem, porque eu machuco minha mandíbula muito } \\
\text { facilmente. }\end{array}$ & $\begin{array}{l}\text { Discordo } \\
\text { fortemente }\end{array}$ & Discordo & Concordo & $\begin{array}{l}\text { Concordo } \\
\text { fortemente }\end{array}$ \\
\hline 16 & $\begin{array}{l}\text { Mesmo que algo piore meus sintomas mandibulares } \\
\text { eu não acho que isto seja perigoso. }\end{array}$ & $\begin{array}{l}\text { Discordo } \\
\text { fortemente }\end{array}$ & Discordo & Concordo & $\begin{array}{l}\text { Concordo } \\
\text { fortemente }\end{array}$ \\
\hline 17 & $\begin{array}{l}\text { Alguém que tenha problemas mandibulares, como o } \\
\text { meu, não deveria ter que mexer sua mandíbula. }\end{array}$ & $\begin{array}{l}\text { Discordo } \\
\text { fortemente }\end{array}$ & Discordo & Concordo & $\begin{array}{l}\text { Concordo } \\
\text { fortemente }\end{array}$ \\
\hline 18 & $\begin{array}{l}\text { Tenho medo de abrir muito minha boca, porque é } \\
\text { possível que eu não consiga fechá-la novamente. }\end{array}$ & $\begin{array}{l}\text { Discordo } \\
\text { fortemente }\end{array}$ & Discordo & Concordo & $\begin{array}{l}\text { Concordo } \\
\text { fortemente }\end{array}$ \\
\hline
\end{tabular}




\section{APÊNDICE 9- Relatório da $1^{\text {aa }}$ Reunião do comitê de especialistas}

\section{RELATÓRIO DA $1^{\mathrm{a}}$ REUNIÃO- TSK/TMD-Br (05/02/2014)}

- Na introdução da escala foi sugerido que no trecho inicial acrescentasse a palavra, por favor, e o restante do trecho foi substituído por o que lhe incomoda, no final optou-se por substituir a resposta "sim, são possíveis em todas as questões", por marque sim ou não no quadro abaixo, a frase ficou da seguinte forma: Por favor, indique na lista abaixo, o que lhe incomoda (marque sim ou não nos quadrados abaixo).

- Nos itens de opção da introdução da escala foram feitas as seguintes substituições: eu movimento minha boca para eu mexo minha boca, estalidos por estalos, crepitações por outros ruídos e a substituição de outros problemas mandibulares para outros incômodos da região mandibular.

- Sugeriu que na frase " a mandíbula trava ou bloqueia que eu não posso abri-la", fosse substituída por" Minha mandíbula fica travada ou presa de maneira que minha boca não abre ou fecha direito".

- Os itens de respostas da escala foram substituídos de concordo/discordo totalmente para eu concordo/discordo fortemente.

- Item 1: Acrescentou artigo "Eu"

- Item 2: Substituição de ignorasse/ ignorar, poderiam/podem

- Item 3: Substituição da palavra grave por muito errada

- Item 4: Substituição de Movimentasse para mexesse

- Item 5: Substituição de Meus sintomas para minhas queixas

- Item 6: Optou-se pela versão T2

- Item 7: Substituição da palavra lesão por machuquei

- Item 8: Optou-se pela versão T3

- Item 9: Substituição de acidentalmente por sem querer

- Item 10: Optou-se pela versão T2, e a palavra mover foi substituído por mexer

- Item 11: Substituição de potencialmente por realmente

- Item 12: Optou-se pela versão T2

- Item 13: Optou-se pela versão T2, e a palavra mover foi substituído por mexer

- Item 14: Optou-se pela versão T3, com substituição das palavras queixas por problemas e aconselhável por seguro

- Item 15: Optou-se pela versão T2

- Item 16: Optou-se pela versão T1

- Item 17: Substituição de movimentos mandibulares por ter que mexer sua mandíbula.

- Item 18: Optou-se pela versão T1 


\section{APÊNDICE 10- Versão Retrotraduzida para o inglês (RT1)}

\section{Tampa Scale for kinesiophobia for Temporomandibular Disorders}

Jaw problems can cause many different types of discomfort. Please indicate on the list below what applies to you. (circle yes or no for each question).

- Jaw Pain $\quad$ YES NO

- Noise in my jaw when I move my mouth (clicking or other sounds)

YES NO

- My jaw locks or gets stuck in such a way that I am not able to open or close

my mouth.

YES NO

- For other types of jaw discomfort, please describe here:

Please indicate if you agree or disagree with the following statements.

Please use the scale below:

1. Strongly disagree

2. Disagree

3.Agree

4.Strongly agree

\begin{tabular}{|c|c|c|c|c|c|}
\hline 1 & I am afraid that moving my jaw may cause injury. & 1 & 2 & 3 & 4 \\
\hline 2 & If I ignore my jaw problems, they could get worse. & 1 & 2 & 3 & 4 \\
\hline 3 & It feels like there is something really wrong with my jaw. & 1 & 2 & 3 & 4 \\
\hline 4 & $\begin{array}{l}\text { My jaw symptoms would probably improve if I moved my jaw } \\
\text { more. }\end{array}$ & 1 & 2 & 3 & 4 \\
\hline 5 & Nobody is taking my jaw complaints seriously. & 1 & 2 & 3 & 4 \\
\hline 6 & My jaw problems put my health at risk for the rest of my life. & 1 & 2 & 3 & 4 \\
\hline 7 & My jaw symptoms are the result of a jaw injury. & 1 & 2 & 3 & 4 \\
\hline
\end{tabular}




\begin{tabular}{|l|l|l|l|l|l|}
\hline 8 & $\begin{array}{l}\text { If I do something that worsens my jaw symptoms, it is not } \\
\text { necessarily serious. }\end{array}$ & 1 & 2 & 3 & 4 \\
\hline 9 & I am afraid that I might accidentally injure my jaw. & 1 & 2 & 3 & 4 \\
\hline 10 & $\begin{array}{l}\text { The best way to avoid my symptoms getting worse, is by being } \\
\text { careful not to move my jaw. }\end{array}$ & 1 & 2 & 3 & 4 \\
\hline 11 & $\begin{array}{l}\text { I would not have so many jaw symptoms if something really } \\
\text { serious was not happening. }\end{array}$ & 1 & 2 & 3 & 4 \\
\hline 12 & $\begin{array}{l}\text { Even though I have jaw discomfort, it is better to simply continue } \\
\text { using my mouth normally. }\end{array}$ & 1 & 2 & 3 & 4 \\
\hline 13 & $\begin{array}{l}\text { I am aware of when to stop moving my jaw in order to avoid } \\
\text { hurting myself. }\end{array}$ & 1 & 2 & 3 & 4 \\
\hline 14 & $\begin{array}{l}\text { For someone with jaw problems like me, it is not very safe to use } \\
\text { the mouth too much. }\end{array}$ & 1 & 2 & 3 & 4 \\
\hline 15 & $\begin{array}{l}\text { I am not able to do what other people do because my jaw is more } \\
\text { prone to injury. }\end{array}$ & 1 & 2 & 3 & 4 \\
\hline 16 & $\begin{array}{l}\text { Even doing something that could make my jaw symptoms worse, } \\
\text { is not necessarily serious. }\end{array}$ & 1 & 2 & 3 & 4 \\
\hline 17 & $\begin{array}{l}\text { It is better, for people with jaw problems to keep the jaw still. } \\
\text { I'm afraid to open my mouth too much because I worry that I won't } \\
\text { be able to shut it again. }\end{array}$ & 1 & 2 & 3 & 4 \\
\hline
\end{tabular}




\section{APÊNDICE 11- Versão Retrotraduzida para o inglês (RT2)}

\section{Tampa Scale for Kinesiophobia: Temporomandibular Disorders}

Mandibular problems can cause many difficulties in different ways. Please indicate on the list below what bothers you (circle yes or no; for all questions).

- Mandibular pain

YES

NO

- Noises in my mandible when I move my mouth (popping or other noises) YES NO

- My mandible gets locked in or stuck in a way that my mouth does not open or close properly

YES NO

- Other madibular troublesome - please describe:

For each statement below, please indicate how much you agree or disagree.

Please use the following scale:

1.Strongly disagree

2.Disagree

3.Agree

4.Strongly agree

\begin{tabular}{|c|c|c|c|c|c|}
\hline 1 & I am afraid of hurting myself if I move my mandible. & 1 & 2 & 3 & 4 \\
\hline 2 & If I ignore my mandibular symptoms they way get worse. & 1 & 2 & 3 & 4 \\
\hline 3 & $\begin{array}{l}\text { It seems that there is something very wrong going on with my } \\
\text { mandible. }\end{array}$ & 1 & 2 & 3 & 4 \\
\hline 4 & $\begin{array}{l}\text { My mandibular symptoms would probably improve if I move my } \\
\text { mandible more frequently. }\end{array}$ & 1 & 2 & 3 & 4 \\
\hline 5 & People are not taking my mandibular complaints seriously. & 1 & 2 & 3 & 4 \\
\hline 6 & $\begin{array}{l}\text { My mandibular symptoms have putted my health at risk for the } \\
\text { rest of my life. }\end{array}$ & 1 & 2 & 3 & 4 \\
\hline 7 & My mandibular symptoms mean that I hurt my mandible. & 1 & 2 & 3 & 4 \\
\hline 8 & $\begin{array}{l}\text { If anything worsens my mandibular symptoms it does not mean } \\
\text { that it is dangerous. }\end{array}$ & 1 & 2 & 3 & 4 \\
\hline
\end{tabular}




\begin{tabular}{|l|l|l|l|l|l|}
\hline 9 & I am afraid that I can hurt my mandible without meaning to. & 1 & 2 & 3 & 4 \\
\hline 10 & $\begin{array}{l}\text { The safest way to avoid the worsening of my symptoms is to be } \\
\text { careful and not move my mandible more than necessary. }\end{array}$ & 1 & 2 & 3 & 4 \\
\hline 11 & $\begin{array}{l}\text { I would not have so many mandibular symptoms if something } \\
\text { really dangerous was not happening. }\end{array}$ & 1 & 2 & 3 & 4 \\
\hline 12 & $\begin{array}{l}\text { Although I have mandibular symptoms the best for me is to keep } \\
\text { using my mouth normally. }\end{array}$ & 1 & 2 & 3 & 4 \\
\hline 13 & $\begin{array}{l}\text { My mandibular symptoms warn me when I should stop movng my } \\
\text { mandible in order to prevent me from getting hurt. }\end{array}$ & 1 & 2 & 3 & 4 \\
\hline 14 & $\begin{array}{l}\text { For someone with mandibular problems like me, is not really safe } \\
\text { to use the mouth a lot. }\end{array}$ & 1 & 2 & 3 & 4 \\
\hline 15 & $\begin{array}{l}\text { I am not capable of doing everything other people do because I } \\
\text { hurt my mandiblevery easily. }\end{array}$ & 1 & 2 & 3 & 4 \\
\hline 16 & $\begin{array}{l}\text { Even doing something that worsens my mandibular symptoms, I } \\
\text { do not think that my action is dangerous. }\end{array}$ & 1 & 2 & 3 & 4 \\
\hline 17 & $\begin{array}{l}\text { No one who has mandibular problems should have to move their } \\
\text { mandible. }\end{array}$ & 1 & 2 & 3 & 4 \\
\hline 18 & $\begin{array}{l}\text { I'm afraid to open my mouth too much, because it is possible that } \\
\text { I won't be able to close it back. }\end{array}$ & 1 & 2 & 3 & 4 \\
\hline
\end{tabular}




\section{APÊNDICE 12- Versão Retrotraduzida para o Dutch (RT3)}

\section{Tampa schaal voor Kinesiofobie: Temporomandibulaire Dysfunctie}

Kaakklachten kunnen op verschillende manieren veel problemen veroorzaken. Wilt $u$ in de onderstaande lijst aangeven waar u last van heeft (omkring ja of nee bij alle vragen).

- Kaakpijn JA NEE

- Geluiden in mijn kaak wanneer ik mijn mond beweeg (kraken of andere geluiden) JA NEE

- Mijn kaak komt vast te zitten op zo een manier dat mijn mond niet meer open of dicht kan JA NEE

- Andere kaakklachten - graag omschrijven:

Gelieve van de onderstaand beweringen aan te geven in welke mate $u$ het een of oneens bent.

Graag de volgende schaal gebruiken:

13. In hoge mate mee oneens

14. Oneens

15. Eens

16. In hoge mate mee eens

\begin{tabular}{|l|l|l|l|l|l|}
\hline 1 & Ik ben bang letsel op te lopen bij het bewegen van mijn kaak. & 1 & 2 & 3 & 4 \\
\hline 2 & $\begin{array}{l}\text { Als ik de symptomen van mijn kaakklachten zou negeren, } \\
\text { kunnen ze verergeren. }\end{array}$ & 1 & 2 & 3 & 4 \\
\hline 3 & Het schijnt dat er iets heel ergs aan de hand is met mijn kaak. & 1 & 2 & 3 & 4 \\
\hline 4 & $\begin{array}{l}\text { De symptomen van mijn kaakklachten zullen waarschijnlijk } \\
\text { verbeteren als ik mijn kaak meer zou bewegen. }\end{array}$ & 1 & 2 & 3 & 4 \\
\hline 5 & $\begin{array}{l}\text { Anderen nemen mijn kaakklachten niet serieus. } \\
\text { Mijn kaakklachten brengen mijn gezondheid voor de rest van } \\
\text { mijn leven in gevaar. }\end{array}$ & 1 & 2 & 3 & 4 \\
\hline 7 & \begin{tabular}{l} 
Mijn kaakklachten betekenen dat ik letsel heb opgelopen. \\
\hline 8
\end{tabular} & 1 & 2 & 3 & 4 \\
\hline $\begin{array}{l}\text { Als iets mijn kaakklachten verergert, betekent dat nog niet dat } \\
\text { het gevaarlijk is. }\end{array}$ & 1 & 2 & 3 & 4 \\
\hline 9 & $\begin{array}{l}\text { Ik ben bang dat ik per ongeluk letsel aan mijn kaak kan } \\
\text { oplopen. }\end{array}$ & 1 & 2 & 3 & 4 \\
\hline
\end{tabular}




\begin{tabular}{|c|c|c|c|c|c|}
\hline 10 & $\begin{array}{l}\text { De veiligste manier om te voorkomen dat mijn kaakklachten } \\
\text { verergeren is om ervoor te zorgen dat ik mijn kaak niet meer } \\
\text { dan dat nodig is beweeg. }\end{array}$ & 1 & 2 & 3 & 4 \\
\hline 11 & $\begin{array}{l}\text { Ik zou niet zoveel kaakklachten hebben als er niet echt iets } \\
\text { gevaarlijk aan de hand was. }\end{array}$ & 1 & 2 & 3 & 4 \\
\hline 12 & $\begin{array}{l}\text { Alhoewel ik kaakklachten heb, zou ik er beter aan toe zijn als } \\
\text { ik mijn mond normaal blijf gebruiken. }\end{array}$ & 1 & 2 & 3 & 4 \\
\hline 13 & $\begin{array}{l}\text { Mijn kaakklachten laat me weten wanneer ik moet stoppen } \\
\text { met het bewegen van mijn kaak om letsel te voorkomen. }\end{array}$ & 1 & 2 & 3 & 4 \\
\hline 14 & $\begin{array}{l}\text { Voor iemand met kaakklachten zoals die van mij, is het echt } \\
\text { niet veilig de mond veel te gebruiken. }\end{array}$ & 1 & 2 & 3 & 4 \\
\hline 15 & $\begin{array}{l}\text { Ik kan niet alles doen wat andere mensen kunnen, omdat ik } \\
\text { gemakkelijk letsel aan mijn kaak oploop. }\end{array}$ & 1 & 2 & 3 & 4 \\
\hline 16 & $\begin{array}{l}\text { Zelfs als iets mijn kaakklachten verergert, denk ik niet dat dat } \\
\text { gevaarlijk is. }\end{array}$ & 1 & 2 & 3 & 4 \\
\hline 17 & $\begin{array}{l}\text { Niemand die kaakklachten heeft zou zijn of haar kaak moeten } \\
\text { bewegen. }\end{array}$ & 1 & 2 & 3 & 4 \\
\hline 18 & $\begin{array}{l}\text { Ik ben bang mijn mond ver open te doen, omdat ik hem dan } \\
\text { mogelijk niet meer dicht kan doen. }\end{array}$ & 1 & 2 & 3 & 4 \\
\hline
\end{tabular}




\section{APÊNDICE 13- Relatório da $2^{\mathrm{a}}$ Reunião do comitê de especialistas}

RELATÓRIO DA $2^{\text {a }}$ REUNIÃO- Escala Tampa de Cinesiofobia para

Disfunção Temporomandibular versão português-Brasil- ETC/DTM

$(24 / 02 / 2015)$

- $\mathrm{Na}$ introdução da escala foi incluso uma figura para especificar o local da região orofacial, com legenda.

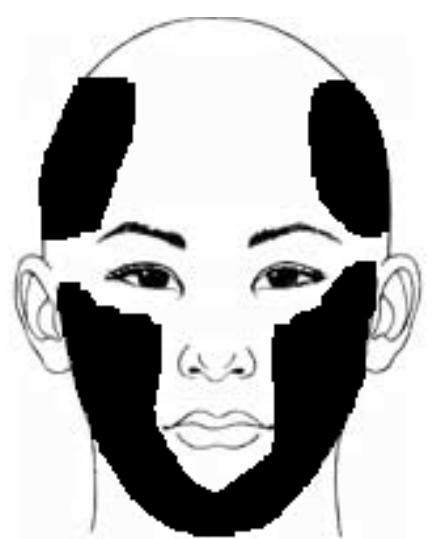

Problemas na região mandibular (por favor, considere a região mandibular toda a área marcada em preto na imagem acima) podem causar muitas dificuldades de maneiras diferentes.

- O item 17 não apresentou um consenso, optou-se por dividi-la em item 17a e 17b, e durante a fase de aplicação da versão pré-final em teste de campo, os voluntários responderiam á um questionário escolhendo qual das duas opções era mais clara de entendimento.

- Os demais itens da escala foram mantidos por apresentarem consenso pelo grupo que compôs a $2^{\text {a }}$ Reunião do comitê de especialistas. 